\title{
Breeding biology and post-fledging dispersal of red-crowned parakeets (Cyanoramphus novaezelandiae) translocated to a fenced mainland sanctuary
}

\author{
Ellen T. Irwin
}

A thesis submitted to Victoria University of Wellington

in fulfilment of the requirement for the degree of

Master of Science in Ecology and Biodiversity

Victoria University of Wellington

Te Whare Wānanga o te Ūpoko o te Ika a Māui

January 2017 


\section{Abstract}

With human impacts like habitat destruction and climate change contributing to range contractions in species, translocations stand out as an important tool for conserving species suffering from these effects. However, an understanding of the life history of many threatened species prior to translocation is often lacking, but critical for translocation success. For example, dispersal away from the release site-particularly when a protected release site is surrounded by unmanaged habitat — can result in translocation failure, and therefore successful translocation practice must include an understanding of a species' dispersal patterns. I conducted a study examining the breeding biology and post-fledging dispersal of a population of red-crowned parakeets (Cyanoramphus novaezelandiae), or kakariki, recently translocated to a mainland sanctuary in Wellington, New Zealand. The sanctuary, ZEALANDIA, is fenced to exclude invasive mammalian predators; however, birds can and do leave. Approximately one-third of juveniles that dispersed outside the sanctuary were killed by predators. Kakariki post-fledging dispersal was male-biased, possibly driven by inbreeding avoidance, and distance dispersed decreased with increasing body condition. Parental age may have also influenced offspring dispersal. In addition, I found that kakariki reproductive success may be affected by age, and estimated lifetime reproductive success was $>30$ fledglings by age five. Conservation initiatives could work on controlling predators in currently unprotected reserves and around food sources that kakariki targeted, particularly in summer and autumn when many plants are fruiting and recently fledged juveniles are more active. Future translocations should consider selecting younger birds to translocate to take advantage of their high lifetime reproductive success and therefore improve viability of populations. 


\section{Acknowledgements}

Firstly, I would like to thank my supervisors Nicola Nelson and Heidy Kikillus for their constant support and guidance throughout this whole process. I could not have asked for better advisers. I am very grateful to Richard Gray, who taught me everything I know about kakariki, and whose help and guidance made this project possible. My thanks also to Myfanwy Emeny, Raewyn Empson, and Matu Booth for their advice and support over the last two years. I was lucky enough to have the help of many wonderful volunteers, without whom much of the fieldwork would not have been possible. Special thanks go to Hannah Studdard, Angie Diana, Chris Gee, Johannes Fischer, Jake McGregor, Jo Hawthorne, Raewyn Empson, Chris Woolley, Latu Clark, Linton Miller, Brony Shepherd, Melissa Coton, as well as to my parents for acting as my tracking-chauffeurs during their visit to Wellington. I would also like to thank Rachael Shaw for her help with statistics as well as fieldwork. I am grateful for all the useful feedback provided by the Fixit lab group (Anna Carter, Kelly Hare, Sarah Herbert, Sue Keall, Heidy Kikillus, Zoe Lennon, Nicola Nelson, Stephanie Price, Patty Ramirez, Vaughn Stenhouse, Chris Woolley), Molly Zegans, and Doug Irwin, as well as the support and encouragement from everyone in Bird Nerds. Thanks also to all the staff at ZEALANDIA, as well as the staff at Rata Café and Milk and Honey Café for kindly putting up with me commandeering their tables whilst writing. Without the support of the New Zealand Department of Conservation and iwi, this project would not have been possible, and I would like to thank both the Department of Conservation and the Port Nicholson Block Settlement Trust. This research was generously supported by the FH Muter Trust and EM Pharazyn Trust together with Karori Sanctuary Trust, the Wellington City Council, the Ornithological Society of New Zealand (OSNZ) through the Birds NZ Research Fund 2015, the New Zealand Department of Conservation, the Jim and Margaret Collins Grant, and the Pukaha Mount Bruce/Elwin Welch Memorial Scholarship. I would also like to express my gratitude to the Victoria University of Wellington Scholarships Office for the Masters by Thesis Scholarship, as well as to Dartmouth College for the James B. Reynolds Scholarship, which allowed me to conduct the original kakariki pilot study. This research was conducted with approval from the Victoria University of 
Wellington Animal Ethics Committee (Permit No. 22384) and the New Zealand Department of Conservation (Permit No. 47965-FAU).

My final thanks go to my family and friends, particularly the friends I have made here who made me feel welcome and helped make Wellington a homeespecially Lynley McLay, without whom I could not have survived the last two years (literally). Their support and encouragement have meant the world to me, and I could not have done this without them. 


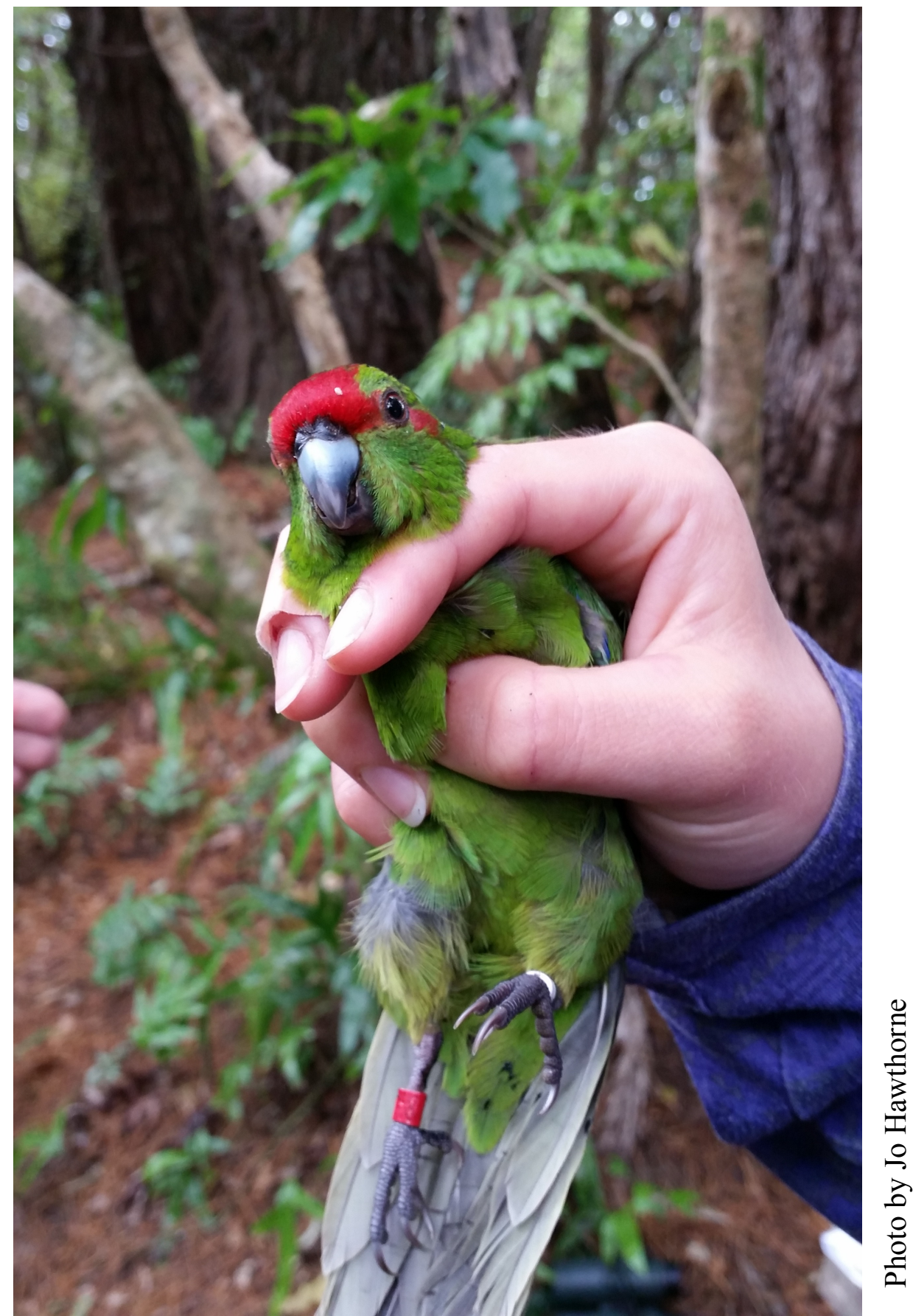




\section{Table of Contents}

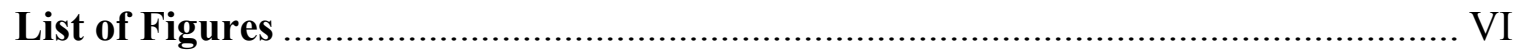

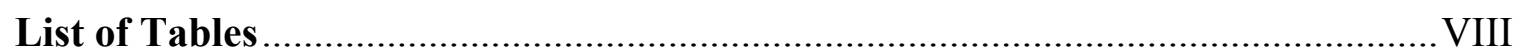

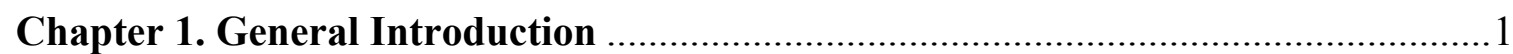

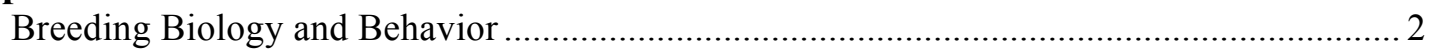

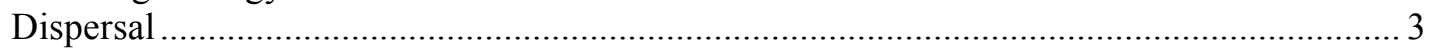

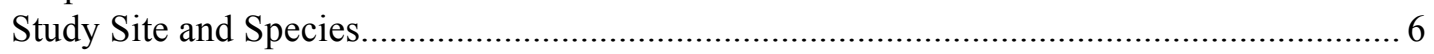

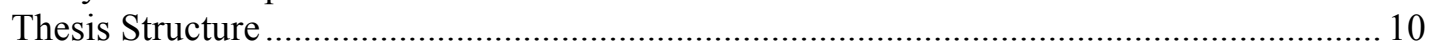

Chapter 2. Ecology and breeding biology of red-crowned parakeets

(Cyanoramphus novaezelandiae) after translocation to a mainland sanctuary..........11

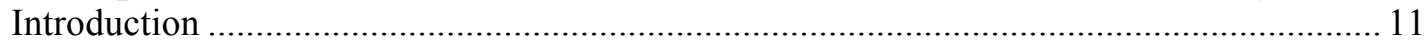

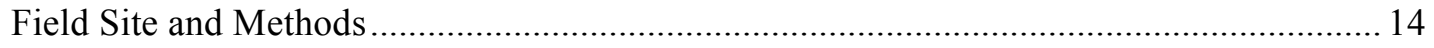

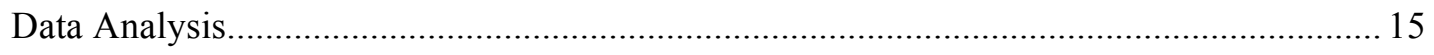

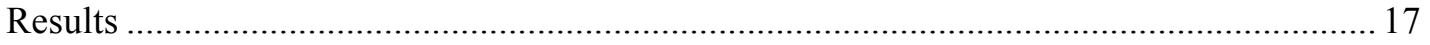

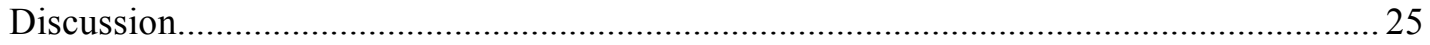

Chapter 3. Post-fledging dispersal of red-crowned parakeets (Cyanoramphus

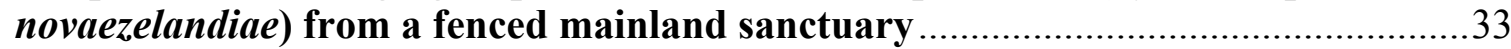

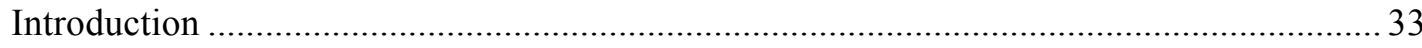

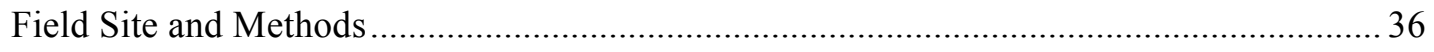

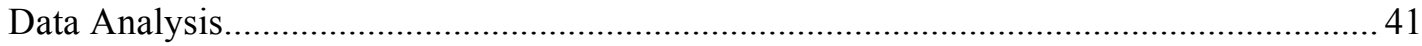

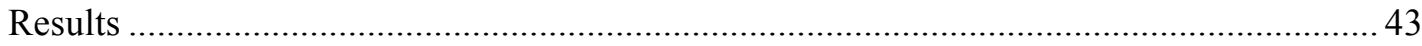

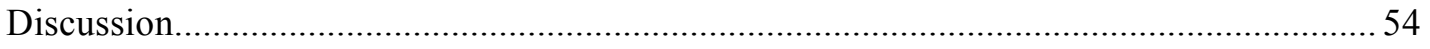

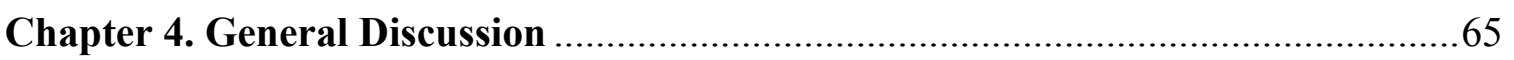

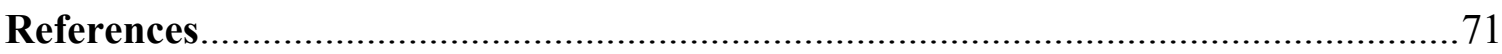

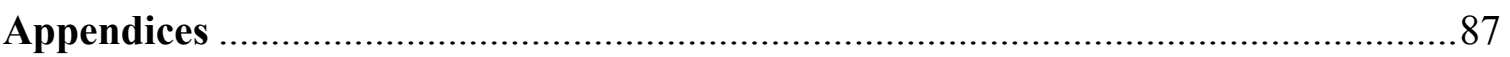




\section{List of Figures}

Figure 2.1. Nesting success increased with parent age, peaking around four to five years and then dropping off......

Figure 2.2. The number and proportion of chicks successfully fledged per clutch did not appear to change with female age

Figure 2.3. Proportion of kakariki chicks fledged did not vary substantially by the laying month of the nest

Figure 2.4. Older females had a slightly lower proportion of male fledglings

Figure 2.5. The average mass of male kakariki chicks increased with the age of their male parent

Figure 3.1. A catch cage and clap trap used to capture kakariki .38

Figure 3.2. A radio transmitter mounted on the tail of a juvenile kakariki....

Figure 3.3. Spot records of juvenile kakariki in 2016, with ZEALANDIA fence line outlined in yellow, and each bird represented by a different symbol.....

Figure 3.4. Example movements of male birds that remained close to their natal area and those that dispersed farther away.... 46

Figure 3.5. Some birds ( $n=2$, both male) never appeared to settle in a particular area, traveling outside the sanctuary each day to forage and returning at night.....

Figure 3.6. Male juvenile kakariki tended to move farther distances than females .48

Figure 3.7. Distance dispersed decreased with body condition, particularly for male birds

Figure 3.8. Distance dispersed increased with the proportion of the opposite sex in the tracked bird's brood.

Figure 3.9. Dispersal distance of juvenile males increased and then dropped off with male parent age. 
Figure 3.10. Activity area decreased with hatch date for juvenile kakariki, with the pattern primarily driven by males

Figure 3.11. Key kakariki food sources like Muehlenbeckia, five-finger, and totara were available in late summer through autumn, with the exception of mapou, which was available in late winter and spring.

Figure 3.12. Four kakariki targeted totara trees in early April while the trees were producing fruit 


\section{List of Tables}

Table 2.1. Summary of kakariki breeding dynamics since the first translocation in 2010, with average clutch size, brood size, and number fledged observed for each breeding season.

Table 2.2. Estimated kakariki lifetime reproductive success (LRS) for pairs of the same age, as well as males and females separately over time

Table 2.3. Results of analysis (LMM) examining factors influencing average mass of male kakariki nestlings

Table 2.4. Breeding dispersal distances (movement between clutches) differed within and between years, as well as between birds that remained with their partners between clutches (monogamous) versus those that changed partners between clutches (divorced).

Table 3.1. Results of analysis (LMM) examining factors influencing kakariki postfledging dispersal distance. .48

Table 3.2. Results of analysis (LMM) on factors influencing kakariki activity area .51 


\section{Chapter 1}

\section{General Introduction}

Many species today exist on the periphery of their historical ranges, and as a result face extinction (Towns and Daugherty 1994; Channell and Lomolino 2000). Most range contractions are due to human impact, through habitat destruction, the introduction of invasive species, and climate change (Towns and Daugherty 1994; Laliberte and Ripple 2004; reviewed by Parmesan 2006). One tool conservationists employ to help restore species back to their historical ranges or else to new areas where they can proliferate, is translocation: the deliberate, human-mediated movement and release of wildlife from one location to another (Griffith et al. 1989; Kleiman 1989; Mumme and Below 1999; Pierre 1999; Tweed et al. 2003; OrtizCatedral and Brunton 2010; IUCN/SSC 2013; Miskelly and Powlesland 2013). However, translocations can be expensive (Boyer and Brown 1988; Kleiman 1989; Phillips 1990; Fischer and Lindenmayer 2000), and historically have had a low success rate (Fischer and Lindenmayer 2000; Germano and Bishop 2009).

To improve the likelihood of translocation success, it is important to understand the life history of the species being moved (Powlesland and Lloyd 1994; reviewed by Sutherland 1998; Sigg et al. 2005; Oro et al. 2011). However, the basic ecology of many threatened species targeted for translocation is often little understood (Caughley 1994; Sarrazin and Barbault 1996). Conservationists could gain this information through long-term monitoring of reintroduced species, which allows appraisal of translocation methods and suggestions to improve those in the future (Sarrazin et al. 1994; Sarrazin and Barbault 1996; Sigg et al. 2005; Oro et al. 2011). Sometimes such research even results in the realization that translocation may not the best strategy for the management of a particular population, if, for example, the species in question regularly undertakes long-range movements (Van Houtan et al. 2010). Post-release monitoring is therefore critical both to evaluate long-term translocation success as well as to identify recommendations for future translocations. With this in mind, I conducted a study examining aspects of the life historybreeding biology and dispersal — of a population of red-crowned parakeets 
Chapter 1

(Cyanoramphus novaezelandiae) recently translocated to a sanctuary in Wellington, New Zealand.

\section{Breeding Biology and Behavior}

Successful translocations should result in not just the survival of the released individuals, but ultimately the establishment of a self-sustaining population (Griffith et al. 1989; Sigg et al. 2005; Germano and Bishop 2009; Miskelly and Powlesland 2013). To this end, an understanding of the species' breeding biology and behavior is key. For example, food availability and body condition are often related to reproductive success, and supplementary feeding after reintroduction has been used to increase productivity (Powlesland and Lloyd 1994; Castro et al. 2003). Powlesland and Lloyd (1994), using previous observations that kakapo (Strigops habroptilus) breeding coincided with protein-rich foods being available, were able to stimulate breeding by supplementing the birds' diet. However, in some species females in good body condition produce more male offspring (Clout et al. 2002; Whittingham et al. 2002; Alonso-Alvarez and Velando 2003). In this case, supplementary feeding can result in an excess of males, as was also discovered in kakapo, which is problematic for long-term population viability (Clout et al. 2002).

The age of the individuals translocated is another factor that could influence breeding. In translocations of many seabirds, which often exhibit high philopatry to their natal area, conservationists must translocate birds before they first emerge from their burrows lest they acquire a strong philopatry towards their natal area rather than their release site (e.g. Priddel et al. 2006). Many studies have also found that older individuals may be more successful, sometimes due to previous breeding experience (e.g. Sydeman et al. 1991; Lunn et al. 1994; Woodburn 2001; Castro et al. 2003). For example, Woodburn (2001) found that adult pheasants (Phasianus colchicus) were more successful in establishing territories and in protecting their nests from predation than juveniles. However, breeding success and survival will also generally decline as an individual nears senescence (Møller and Lope 1999; Bouwhuis et al. 2012). Knowing how a species' breeding success changes over time is therefore important for selecting the individuals that will likely have the highest reproductive output when translocated. 
Even a basic understanding of the species' breeding system can be helpful in translocations. For example, Sigg et al. (2005) monitored a population of bridled nailtail wallaby (Onychogalea fraenata) for four years post-translocation, and found that larger males $(>5800 \mathrm{~g})$ were much more likely to reproduce than smaller ones. Accordingly, translocations of this species should release a smaller proportion of males, and only larger ones that therefore have high reproductive potential (Sigg et al. 2005). In addition, Rowe and Bell (2007) observed assortative mating in the North Island kokako (Callaeas cinerea wilsoni) following a translocation, in which birds tended to pair with those whose song-dialect originated from the area they experienced before translocation. While in this case the assortative mating was a temporary phenomenon that disappeared over time, behaviors like that could cause inbreeding in small populations (Rowe and Bell 2007), something that many translocations, particularly in New Zealand, have struggled to address (Haig et al. 1993; Jamieson and Ryan 2000; Jamieson 2011). For example, Jamieson and Ryan (2000) observed increased egg infertility in translocated, inbred takahe (Porphyrio hochstetteri). Inbreeding can result in a loss of genetic diversity, potentially reducing both current fitness through inbreeding depression and limiting a population's ability to adapt in the future (Keller and Waller 2002). The possible negative impacts of inbreeding are extensive and of special concern when the founder population is small (Keller and Waller 2002).

\section{Dispersal}

Dispersal is another aspect of life history particularly relevant to translocation efforts, as dispersal from the target conservation area can result in a loss of animals to unsuitable habitat or predation, and decreases the chances of successful establishment (Clarke and Schedvin 1997; Armstrong et al. 2013; Tweed et al. 2003; Stamps and Swaisgood 2007; Van Houtan et al. 2010; Bradley et al. 2011). This source-sink effect is particularly evident when animals are released into a protected site surrounded by unmanaged habitat (van Heezik et al. 2009; Rickett 2010; Müller et al. 2014). For example, after one translocation, a third of critically endangered black stilts (Himantopus novaezelandiae) dispersed away from the populations they were meant to supplement, with many moving into unmanaged areas where the birds could not be monitored or protected from invasive predators (van Heezik et al. 2009). 
Conservation applications aside, dispersal is a fundamental ecological process, influencing individual survival and reproduction as well as the spatial structure, dynamics, and persistence of populations (Benton and Bowler 2012). Furthermore, dispersal has implications for evolution: for example, it can increase gene flow and therefore genetic variance, allowing populations to adapt (Bohonak 1999; Benton and Bowler 2012; Lenormand 2002; Garant et al. 2007). Dispersal may also help maintain isolated, low-density populations (or sinks), and rescue them from the negative effects of inbreeding (Ebert et al. 2002; Lenormand 2002; Garant et al. 2007).

It is postulated that individuals disperse for a variety of reasons, from inbreeding avoidance to locating areas with better quality habitat, reduced competition, and/or improved mating opportunities (Forero et al. 2002; Moksnes 2004; Doerr and Doerr 2005; reviewed by Liu et al. 2008; Rémy et al. 2011; Matthysen 2012; Nevoux et al. 2013). But while there are many potential benefits of dispersal, dispersers often face a lower probability of survival, due to an increased risk from predators, unsuitable habitat, and the energetic costs associated with dispersing (Yoder et al. 2004; Johnson et al. 2009; reviewed by Bonte et al. 2012). Furthermore, dispersal may result in deferred search costs, costs that are incurred during the search period but felt only after a disperser has settled in its new habitat (Stamps et al. 2005; Soulsbury et al. 2008).

A wide variety of factors, from social to environmental, may influence dispersal. These also include phenotypic attributes like sex (Greenwood 1980; Greenwood and Harvey 1982; Clarke and Heathcote 1990; Forero et al. 2002; Dingemanse et al. 2003; Serrano et al. 2003; Withey and Marzluff 2005; Støen et al. 2006; Bradley et al. 2011; Eldegard et al. 2014), body condition (Nilsson and Smith 1985; Pasinelli and Walters 2002; Barbraud et al. 2003; Zedrosser et al. 2007; McCauley 2010), and individual personality traits like boldness, aggressiveness or sociability (Fraser et al. 2001; Dingemanse et al. 2003; Cote and Clobert 2007; Duckworth and Badyaev 2007; reviewed by Cote et al. 2010). For example, many species exhibit sex-biased dispersal, in which one sex of a species is more likely to disperse greater distances: birds often exhibit female-biased dispersal, with females tending to move farther than males, while the opposite pattern has been found in mammals (Greenwood 1980; Greenwood and Harvey 1982; Clarke and Heathcote 1990; Dingemanse et al. 2003; Zedrosser et al. 2007; Gosselink et al. 2010). Some argue this could be due to a difference in avian versus mammalian mating systems 
("resource-competition hypothesis") (Greenwood 1980), while others hypothesize that sex-biased dispersal is primarily reflective of an inbreeding-avoidance strategy, as greater dispersal of one sex from its home ground will reduce the odds of mating with a close relative (Pusey 1987; Cockburn et al. 2003; Szulkin and Sheldon 2008).

Parents can also influence their offspring's behavior, through aggression (Wilkinson 1985; Tarwater and Brawn 2010), encouraging delayed dispersal (reviewed by Ekmann et al. 2001), or parental effects (typically maternal effects), or the "causal influence of the parental genotype or phenotype on the offspring's phenotype" (Ronce et al. 1998; Sinervo et al. 2006; Tschirren et al. 2007; Zedrosser et al. 2007; Wolf and Wade 2009). For example, several studies have observed decreased offspring dispersal with parent age, suggesting that as a parent nears senescence fewer of its offspring will disperse, as they have a greater chance of taking over their parent's territory (Ronce et al. 1998; Zedrosser et al. 2007).

In addition, ecological factors such as population density can also impact dispersal, with a range of results. Greater population density can increase dispersal, as individuals seek to avoid competition (Fonseca and Hart 1996; Moksnes 2004), but contrary to what one might expect, many researchers have also found decreased dispersal with increasing population density: this could be a reflection of greater competition (Boonstra 1989; Støen et al. 2006), lower disperser survival (Jones 1988), or favorable local conditions (Stamps 1988; Andreassen and Ims 2001; Martín et al. 2008), with individuals using the number of conspecifics as a signal of habitat quality, a phenomenon known as conspecific attraction (Stamps 1988; Forero et al. 2002; Serrano et al. 2003; Martín et al. 2008).

But while natural environmental conditions certainly play a role in affecting dispersal, human land use change can also have a large influence. One of the greatest human impacts on dispersal comes in the form of habitat fragmentation. Habitat fragmentation has been found to both increase dispersal distance- - species must travel farther to reach suitable habitat, thereby increasing their energetic costs and risk of mortality - and decrease the likelihood of dispersal, likely due to the aforementioned costs (Diffendorfer et al. 1995; Matthysen et al. 1995; Baguette et al. 2003; Willson 2004; Martín et al. 2008). Fragmentation can therefore have serious consequences for population persistence, as a reduction of dispersal (associated with lower gene flow) could lead to lower genetic diversity, and even local extinction (Bohonak 1999; 


\section{Chapter 1}

Benton and Bowler 2012; Lenormand 2002; Coulon et al. 2010). In Florida scrub-jays (Aphelocoma coerulescens), for example, levels of gene flow decreased as fragmentation increased due to the reduced breeding success of birds that dispersed farther distances (Coulon et al. 2010). Here, the lack of breeding success of dispersing individuals may have arisen through deferred search costs or threats related to breeding in unfamiliar habitat (Coulon et al. 2010). Fragmentation may also hinder pair formation (Cooper and Walters 2002; Willson 2004).

While related to habitat fragmentation, urbanization is nevertheless likely to produce different and more severe fragmentation effects than those due to agriculture, in part because it is often less similar to natural land cover (Marzluff and Ewing 2001). Furthermore, urbanization results in novel conditions, including the presence of buildings, cars, invasive species, and supplementary food and water, that may have varying effects on species inhabiting the area (Marzluff 2001; Marzluff and Ewing 2001; Lepczyk et al. 2003; Robb et al. 2008; van Heezik et al. 2010; Ausprey and Rodewald 2013; Machtans et al. 2013). For example, invasive predators like cats can have devastating impacts on native species (Lepczyk et al. 2003; van Heezik et al. 2010) while supplementary food sources, e.g. backyard bird feeders, can have both a positive impact on populations (increasing fecundity rates and overwinter survival) and negative (increased disease transmission) (reviewed by Robb et al. 2008). Finally, clearing of snags in addition to live trees in urban areas may impact species that rely on them for habitat or breeding. For example, Blewett and Marzluff (2005) observed lower densities of cavity-nesting birds in suburban areas compared to wildlands.

With the size and number of cities growing globally, resulting in dramatic land use change (Marzluff 2001), it is vital that we study how species interact with and move around an increasingly urbanizing landscape. This is particularly important in a place like New Zealand, where more and more species are being reintroduced to the mainland where they are likely to encounter these urban areas. Urban areas like Wellington also represent an opportunity to provide new habitat for threatened species, as we learn more about how these species operate within them.

\section{Study Site and Species}

New Zealand has pioneered translocation methods and practices (Bell and Merton 2002; Bell et al. 2005; Armstrong et al. 2007; Leech et al. 2007; reviewed by 
Miskelly and Powlesland 2013). As New Zealand has no native land mammals (with the exception of bats), the introduction of mammalian predators like rats and stoats decimated the country's native wildlife, in particular its birdlife (O’Donnell 1996; Clout 2001; Saunders and Norton 2001). The country has one of the highest proportions nationally of threatened avian species in the world (Clout 2001). Thus, since at least the $1890 \mathrm{~s}$, conservationists have used translocations as a tool to prevent the extinction of native birds. Historically, translocations within New Zealand have been to offshore, predator-free islands (reviewed by Miskelly and Powlesland 2013). Over the last decade, however, with the development of predator-resistant fencing, the majority of translocations have been to "mainland islands," which are areas that exclude mammalian pests through fencing, geographical features, and/or long-term intensive pest control regimes, but surrounded by areas in which predators are still present (Saunders and Norton 2001; Miskelly and Powlesland 2013). Many of these translocated populations are dispersing beyond the safety of the mainland islands, but little is known about their activities and survival outside of these preserves, particularly when they disperse into more urbanized areas.

Red-crowned parakeets (Cyanoramphus novaezelandiae), or kakariki, are considered good candidates for reintroduction to pest-free areas, as the species reproduces rapidly and is capable of nesting in a wide variety of sites (Pratt et al. 1987; Higgins 1999; Ortiz-Catedral and Brunton 2009). One of six species of parakeet endemic to mainland New Zealand, kakariki were once numerous throughout both islands (Pratt et al. 1987; Higgins 1999; Boon et al. 2000). However, their numbers have decreased dramatically due to habitat destruction, hunting, and predation by invasive mammals (Pratt et al. 1987; Higgins 1999). Kakariki are particularly vulnerable to mammalian predators, as they often feed on the ground and nest in single entry cavities where there is no escape from predators that enter the nest (Pratt et al. 1987; Greene 1998; Higgins 1999; Greene 2003; Ortiz-Catedral and Brunton 2009). As a result, they are now primarily confined to offshore islands (Pratt et al. 1987; O’Donnell 1996; Higgins 1999; Greene 2003).

Kakariki are gregarious birds, often found feeding in pairs or small groups, though historically, they could be found in flocks of hundreds (Pratt et al. 1987; Higgins 1999). So common were they that early European settlers even used their feathers to stuff mattresses (Pratt et al. 1987). Currently, they inhabit lowland native forests on the mainland, but on offshore islands, where they are more plentiful, they 


\section{Chapter 1}

also occur in scrubland and open grassy areas (Pratt et al. 1987; Higgins 1999). Kakariki are omnivorous, preferring seeds, berries, buds, flowers, and shoots of a variety of plants, as well as invertebrates (Pratt et al. 1987; Greene et al. 1998). During the breeding season, males lead females around to prospect potential nest sites (Greene 2003; Richard Gray pers. comm.). After the cavity is chosen, the female prepares the nest, incubates the eggs, and broods and feeds the nestlings (Pratt et al. 1987; Higgins 1999; Greene 2003). Male kakariki provision the female every two hours throughout the period when she is on the nest (Pratt et al. 1987). Kakariki are productive breeders and have been observed to produce 3-10 eggs per clutch and multiple clutches in a season (Greene 2003; Ortiz-Catedral and Brunton 2008; Gray 2014; Gray 2015; Gray 2016). Their reproductive success over time, however, has not been studied, and little is known about any patterns of reproductive senescence or even their average lifespan in the wild, although it is thought they are short-lived for parrots (Terry Greene pers. comm.).

While adult kakariki appear to move little before or after breeding, offshore they have been seen regularly moving between various islands (distances up to 2.5 $\mathrm{km})$ and may have colonized Solander Island from Stewart Island $(60 \mathrm{~km})$ or the mainland (40 km) (Higgins 1999). Ortiz-Catedral (2010) observed the homing of one adult female from its release site back to its original home, a minimum distance of 65 $\mathrm{km}$. There has also been possible dispersal to and recolonization of mainland sites from nearby islands in the Wellington region (Miskelly et al. 2005). Therefore, relatively long dispersal distances, even over expanses of sea, are possible (Higgins 1999; Ortiz-Catedral 2010). However, no studies have directly examined kakariki dispersal and movements on the mainland.

Furthermore, little is known about juvenile kakariki movement (Higgins 1999). Researchers have observed that recent fledglings usually remain within $100 \mathrm{~m}$ of their nest, fed by their parents, for the first two weeks (Pratt et al. 1987; Higgins 1999). Thereafter, fledglings forage over a larger area during the day, while returning to their natal area at night to roost (Pratt et al. 1987; Higgins 1999). The juveniles become independent at 4-5 weeks (Pratt et al. 1987; Higgins 1999). Movements of the juveniles post-independence are unknown as are the factors that may influence postfledging dispersal (e.g. sex, body condition). For birds in general, the post-fledging period is one of the least studied avian life cycle stages, even though juvenile survival 
rates play a critical role in overall population dynamics (Baker 1993; Vitz 2008; Kershner et al. 2004).

Kakariki have been translocated nearly a dozen times, with relatively high success (reviewed by Miskelly and Powlesland 2013). One of the most recent translocations was to ZEALANDIA (formerly the Karori Wildlife Sanctuary), a 225hectare sanctuary nestled within suburban Wellington and $2 \mathrm{~km}$ west of Wellington City (Campbell-Hunt 2002). This mainland island is surrounded by an $8 \mathrm{~km}$ predatorexclusion fence that excludes all mammalian pests, except the house mouse (Mus musculus), which is small enough to fit through flaws or damages in the fence (Campbell-Hunt 2002; Nelson et al. 2016). Therefore, sanctuary staff and volunteers undertake an annual baiting regime in an effort to control mouse numbers (Nelson et al. 2016). The sanctuary has been the recipient of many endemic bird species via translocation. By fostering native wildlife through the provision of food, protection, and nesting sites, the sanctuary has seen some great successes, with populations of birds such as saddleback (Philesturnus carunculatus) and kaka (Nestor meridionalis) flourishing (Campbell-Hunt 2002; Small 2004; Cote et al. 2013; Miskelly and Powlesland 2013).

Kakariki are another ZEALANDIA success story, translocated from Kapiti Island to ZEALANDIA in 2010 (Gray 2011; Gray 2012). Their reintroduction to ZEALANDIA represented the first time that these parakeets had been breeding in the mainland Wellington region in over one hundred years, and since then the birds have multiplied: in 2015, ZEALANDIA banded its $500^{\text {th }}$ kakariki chick (Richard Gray pers. comm.). While the birds are unquestionably thriving within the sanctuary, they can and do leave ZEALANDIA, and little is known about their activities once over the fence line, something I aim to address in this study. In addition, since their reintroduction in 2010, sanctuary staff have monitored the reproductive success of the birds. Although there have been several studies on kakariki breeding biology (e.g. Greene 2003; Ortiz-Catedral and Brunton 2008; Ortiz-Catedral and Brunton 2009; Ortiz-Catedral et al. 2013), these have been relatively short-term in scope.

ZEALANDIA therefore represents a good opportunity to assess long-term kakariki population trends, as well as to assess their breeding habits and potential factors related to individual reproductive success.

Given that kakariki are still only recently reintroduced to Wellington, their establishment on the mainland is not yet guaranteed. The viability of their population 


\section{Chapter 1}

in Wellington is contingent on understanding how both dispersal affects juvenile survival, and what factors influence dispersal and reproductive success.

\section{Thesis Structure}

I examined kakariki breeding biology and dispersal. This was accomplished through the investigation of the following topics:

1. Kakariki breeding trends with parent age, estimation of lifetime reproductive success, patterns of incest and divorce

2. Patterns of kakariki post-fledging dispersal, motivations for dispersal, and survival outside the sanctuary

This thesis consists of two research chapters formatted for submission to peer reviewed journals. Therefore, there is some repetition among chapters, particularly in the introduction sections. 


\section{Chapter 2}

Ecology and breeding biology of red-crowned parakeets (Cyanoramphus novaezelandiae) after translocation to a mainland sanctuary

\section{Introduction}

Humans have brought about the range contractions of numerous species, many of which now face extinction (Towns and Daugherty 1994; Channell and Lomolino 2000). For example, many species have suffered habitat reductions due to climate change, particularly polar species like penguins and polar bears and those living at higher elevations (reviewed by Parmesan 2006). Habitat destruction and the introduction of invasive species are other leading causes of range contraction as well as of extinction (Towns and Daugherty 1994; Vitousek et al. 1997a; Vitousek et al. 1997b; Laliberte and Ripple 2004; Clavero and García-Berthou 2005). Translocations, the deliberate, human-mediated movement and release of wildlife from one location to another, are a common conservation tool used to help restore species back to their historical ranges or to new areas where they can proliferate (Griffith et al. 1989; Kleiman 1989; Mumme and Below 1999; Pierre 1999; Tweed et al. 2003; OrtizCatedral and Brunton 2010; IUCN/SSC 2013; Miskelly and Powlesland 2013). However, translocations can be expensive (Boyer and Brown 1988; Kleiman 1989; Phillips 1990; Fischer and Lindenmayer 2000), and historically have had a low success rate (Fischer and Lindenmayer 2000; Germano and Bishop 2009); to maximize the likelihood of success, it is important to select the individuals that will likely have the highest reproductive output, as translocation success should be measured not only by the survival of the released individuals, but ultimately the establishment of a self-sustaining population (Griffith et al. 1989; Kleiman 1989; Sigg et al. 2005; Seddon et al. 2007; Germano and Bishop 2009; Miskelly and Powlesland 2013). Therefore, before a translocation should take place we need to understand the life history of the species in question (Powlesland and Lloyd 1994; Sarrazin and Barbault 1996; reviewed by Sutherland 1998; Sigg et al. 2005; Oro et al. 2011). 
However, the basic ecology of many of the threatened species likely to be targeted for translocation is little understood (Caughley 1994; Sarrazin and Barbault 1996; Bell 2016). Conservationists could gain this information through long-term monitoring of reintroduced species, which allows appraisal of translocation methods and proposals to improve them in the future (Sarrazin et al. 1994; Sarrazin and Barbault 1996; Sigg et al. 2005; Oro et al. 2011). For example, Sigg et al. (2005) monitored a translocated population of bridled nailtail wallaby (Onychogalea fraenata) for four years post-release and found that reproductive success in this polygynous species was highly influenced by individual male weight. This led to the recommendation that future translocation efforts should release a greater proportion of females and only males of high breeding potential (Sigg et al. 2005).

If the species in question is difficult to study, closely related species may be observed: Bell et al. (2005) studied methods for translocating the fluttering shearwater (Puffinus gavia), for example, to gain knowledge and experience to later translocate endangered seabird species. Aside from the conservation implications, translocations also represent an opportunity for ecologists to study the behavior and population ecology of rare species, as well as processes like colonization, in a population where the origin of all individuals may be known (Sarrazin and Barbault 1996). Burger and Both (2011), for example, used a translocation of the pied flycatcher (Ficedula hypoleuca) to study the influence of new habitat on reproductive performance. Translocations therefore provide opportunity for both basic ecological as well as conservation-oriented research.

New Zealand has pioneered translocation methods and practices (Bell and Merton 2002; Bell et al. 2005; Armstrong et al. 2007; Leech et al. 2007; reviewed by Miskelly and Powlesland 2013). Since at least the 1890s, conservationists have used translocations as a tool to prevent the extinction of native birds, which have been decimated by introduced mammalian predators (O’Donnell 1996; Clout 2001; Saunders and Norton 2001; reviewed by Miskelly and Powlesland 2013). Historically, translocations within New Zealand have been to offshore, predator-free islands (reviewed by Miskelly and Powlesland 2013). However, it may not be possible to preserve New Zealand's biodiversity on islands alone, as islands may be too small for some species and certain habitats are not available on islands (McLennan et al. 1987; Ryan and Jamieson 1998; Armstrong et al. 2002). There is therefore a need for additional conservation on the mainland. Consequently, in part due to the 
development of predator-resistant fencing, the majority of translocations over the last decade have been to "mainland islands" or sanctuaries, which are predator-free but are surrounded by areas in which predators are still present (Saunders and Norton 2001; Miskelly and Powlesland 2013).

Red-crowned parakeets (Cyanoramphus novaezelandiae), or kakariki, are considered good candidates for reintroduction to pest-free areas, as the species reproduces rapidly and is capable of nesting in a wide variety of sites (Pratt et al. 1987; Ortiz-Catedral and Brunton 2009). Once common on the mainland, kakariki numbers have decreased dramatically due to habitat destruction, hunting, and predation by invasive mammals (Pratt et al. 1987; Higgins 1999). They are particularly vulnerable to mammalian predators, as they often feed on the ground and nest in single entry cavities where there is no escape from predators that enter the nest (Pratt et al. 1987; O’Donnell 1996; Greene 1998; Higgins 1999; Greene 2003; OrtizCatedral and Brunton 2009). As a result, kakariki are now primarily confined to offshore islands (Pratt et al. 1987; Higgins 1999; Greene 2003).

Kakariki have been reintroduced to islands and mainland sanctuaries with relatively high success, one of the more recent being ZEALANDIA (formerly the Karori Wildlife Sanctuary), a mainland island in Wellington (Campbell-Hunt 2002; Miskelly and Powlesland 2013). Their reintroduction to ZEALANDIA represented the first time that these birds had been breeding in the mainland Wellington region in over one hundred years, and since then the birds have multiplied: in 2015, ZEALANDIA banded its $500^{\text {th }}$ kakariki chick (Richard Gray pers. comm.). Since their reintroduction in 2010, sanctuary staff have monitored the reproductive success of the birds. While there have been several studies on kakariki breeding biology (e.g. Greene 2003; Ortiz-Catedral and Brunton 2008; Ortiz-Catedral and Brunton 2009; Ortiz-Catedral et al. 2013), these have been relatively short-term in scope. ZEALANDIA therefore represents a good opportunity to assess long-term kakariki population trends, as well as to examine their breeding habits and potentially factors related to individual reproductive success. For example, the average lifespan of kakariki in the wild is unknown, although the birds are likely short-lived for parrots (Terry Greene pers. comm.). We therefore do not know how breeding success changes with age, a useful life history characteristic for assessing individuals for translocation. Furthermore, other Cyanoramphus parakeets in New Zealand can be difficult to study due to their remote locations and/or low numbers (West et al. 1995; 
Grant \& Kearvell 2001; Ortiz-Catedral et al. 2009; Ortiz-Catedral et al. 2013). Understanding the life history of a closely related species could help in species management of more endangered taxa (e.g. Butler \& Merton 1992; Bell et al. 2005).

\section{Field Site and Methods}

Research took place at ZEALANDIA ${ }^{\text {TM }}$ Eco-sanctuary, a 225 ha mainland island located within suburban Wellington and $2 \mathrm{~km}$ west of Wellington City (CampbellHunt 2002). The valley is surrounded by a predator-exclusion fence that excludes all mammalian pests, except the house mouse (Mus musculus), which can slip through warping in the fence (Campbell-Hunt 2002; Nelson et al. 2016). However, sanctuary staff regularly monitor mice populations and perform ongoing pest control within ZEALANDIA to keep mouse numbers low (Nelson et al. 2016).

Red-crowned parakeets (Cyanoramphus novaezelandiae), or kakariki, were translocated from Kapiti Island to ZEALANDIA in 2010/2011 (Gray 2011; Gray 2012). Kakariki are gregarious birds, often found feeding in pairs or small groups, though historically, they could be found in flocks of hundreds: early European settlers even used their feathers to stuff mattresses (Pratt et al. 1987; O’Donnell 1996; Higgins 1999). Currently, they inhabit lowland native forests on the mainland, but on offshore islands, where they are more plentiful, they also occur in scrubland and open grassy areas (Pratt et al. 1987; Higgins 1999). They are omnivorous, preferring seeds, berries, buds, flowers, and shoots of a variety of plants, as well as invertebrates (Pratt et al. 1987; Greene et al. 1998; Higgins 1999).

Kakariki are generally monogamous, although occasional divorces of pairs have been observed (Greene 2003). The birds nest in cavities, typically in native vegetation, but also in holes in cliffs, rocky crevices or burrows in the ground (Pratt et al. 1987; Higgins 1999; Greene 2003). Males escort their mates to a variety of sites (Greene 2003). After the nest site is chosen, the female prepares the nest, lays and incubates the eggs, broods and feeds the nestlings for the first 2-3 weeks while the male visits the nest at regular intervals to provide food to the female via regurgitation, who then feeds the nestlings (Pratt et al. 1987; Greene 2003). Chicks fledge after approximately 40 days (Males: $42.23 \pm 3.85$, Females: $40.2 \pm 4.62$ days; OrtizCatedral et al. 2013). Breeding season varies by location but at ZEALANDIA it is 
generally from August-March, and birds may produce several (1-3) clutches of 3-10 eggs over the course of one season (Gray 2014; Gray 2015; Gray 2016).

ZEALANDIA staff members have collected data on kakariki breeding each season from 2010-2016, by monitoring the nest boxes (wooden and plastic pipe boxes) set up around the sanctuary, as well as any observed natural nest sites. The sites also included some mamaku logs (Cyathea medullaris) positioned horizontally with a wooden plug at one end, allowing birds to come and go from the hollow log at the other end. All sites had their GPS coordinates recorded. Nests boxes were checked regularly, and any sites found to have a kakariki were monitored and the chicks banded, with the exception of a few inaccessible natural sites. All nest sites identified were monitored; there was no limit established for nest monitoring effort per year (Gray 2016).

For each active nest, staff noted the identity of the pair using each site, and the approximate lay date, hatch date, and fledge date of the chicks, recording the number of eggs and chicks in the process. When the chicks were approximately four weeks old, they were banded, weighed, and the length and width of their bills was measured to assign a tentative sex to each chick (Gray 2016).

\section{Data Analysis}

For each nest, I calculated fledging success, or the proportion of chicks successfully fledged based on the original number of eggs laid. To assess potential effects of seasonality and avoid the difficulty of using calendar dates in analyses, I also calculated a "Julian" lay date for each nest based on the earliest laid nest that breeding season. Twenty-two nests missing key information such as the clutch size or number fledged were removed from the analysis. I noted the age of the male and female parents based on their band cohort: for example, if a bird hatched in March 2012, it was part of the 11/12 cohort (breeding season 2011/12), and the following breeding season $(2012 / 13)$ it was listed as one year old. The only exception was for a few birds which attempted to breed in the same breeding season in which they hatched: these were listed as 0.5 years old at the time of their first breeding attempt. Birds translocated from Kapiti Island were either known or else assumed to be juveniles when caught and were therefore listed as one year old during their first breeding season at ZEALANDIA. 
Using these data, I examined factors influencing kakariki breeding success using generalized linear mixed models (GLMMs) and linear mixed models (LMMs). As the data included broods produced by the same pairs, both between breeding seasons and up to three within a season, pair identity nested within year was included as a random factor. The number and proportion of chicks fledged, as well as nesting success (proportion of nests that fledged at least one chick) were incorporated as response variables in separate GLMMs, using Poisson and binomial distributions respectively. Fixed effects included were male and female parent age and lay date. As male and female ages were highly correlated $\left(\mathrm{r}_{\mathrm{s}}=0.76, \mathrm{P}<0.001\right)$, they were not included together in the same model. In addition, because male age did not appear to have a linear relationship with number or proportion fledged, it was transformed using a quadratic term.

To assess factors influencing chick quality, I used LMMs to examine the influence of parental age and hatch date on log-transformed response variables of average male and female chick mass respectively, and a GLMM (binomial distribution) with the response variable of fledgling sex ratio, including all nests that fledged at least one chick. I used data only from the 2015/16 breeding season, as the chick sexing accuracy had been honed by the last year of monitoring. I separated the chicks by sex rather than calculate a total average chick mass, as male chicks often weighed more than females and the sex ratio of the nest could therefore skew the number. For all models, pair identity was included as a random factor, and male parent age, female parent age, and Julian lay date were included as fixed effects. Male and female age were again not included in the same models.

Models were compared with a forward stepwise procedure using second-order Akaike Information Criterion ( $\mathrm{AIC}$ ) value for small sample sizes (Burnham and Anderson 2003). Models were fitted with the lmer function in the lme 4 package in R, and AICc values and model weights were obtained using the R package AICcmodavg (Bates et al. 2015; Mazerolle 2016).

I estimated lifetime reproductive success for kakariki by calculating the average number fledged per clutch for a pair at each age (both members of the pair were the same age), and multiplying it by two, as birds typically had between one to three clutches in a season. Numbers fledged were summed over time to get an estimate of total number fledged by age 3 , age 4 and so on. Using the same method, I also calculated lifetime reproductive success for each sex, not controlling for the age 
of their partner. Finally, I included the observed reproductive success of two pairs followed over time from age one to facilitate comparison with the calculated values.

To determine the degree of nest philopatry, I calculated the breeding dispersal (distance moved between each nesting attempt) for pairs of kakariki for which there were at least two recorded attempts at breeding. Fifteen birds whose nest sites were unidentified were removed from the analysis. I calculated breeding dispersal distances for each individual for each clutch, noting whether the movement was within or between breeding seasons to examine if birds tended to move to farther nest sites between breeding seasons. I then removed repeat lines of birds that remained with the same partner (monogamous), so that there was only one record per movement of monogamous pairs, avoiding repeat measures in the analysis. However, if one or both birds changed partners, they each had their own record of movement for their original partner and their new partner. Each movement record was classified as either monogamous or divorced based on whether the pair was the same from one clutch to the next. I also noted whether the movement was between breeding seasons, or within a season. I then calculated the total within-season, and between-season average breeding dispersal for monogamous and divorced records. I also calculated breeding dispersal distance by sex using the divorced records. As there were repeated observations of both pairs and individual birds in both the monogamous and divorced groups, I did not perform any statistical tests on these data.

Analyses were performed in R v. 3.3.2 (R Core Team 2016), and reported values represent mean \pm standard error. All data were collected by Richard Gray from ZEALANDIA Sanctuary from 2010-2016.

\section{Results}

The breeding season in ZEALANDIA generally began in August or early-mid September (Table 2.1). With all seasons combined, approximately $74 \%$ of nests were successful (produced at least one fledgling), and on average birds fledged about half $(0.51 \pm 0.02)$ of the original number of eggs laid. No substantial differences were observed between seasons, although 2013/2014 was a particularly successful year for kakariki breeding, with the greatest average number of chicks fledged (Table 2.1). Per nest, kakariki produced an average of $5.55 \pm 0.1$ eggs, successfully hatched $3.57 \pm 0.1$ chicks, and fledged $2.85 \pm 0.15$ chicks over all seasons $(\mathrm{n}=209)$. 
The number of kakariki nests increased over time since the original 2010 translocation, peaking at 68 in 2014/2015. The majority of nests observed were in pipe boxes checked regularly by sanctuary staff $(n=160)$, followed by mamaku logs $(n=26)$, natural nests $(n=12)$ and wooden boxes $(n=11)$. The proportion of chicks fledged did not vary substantially among these nest types, except for in mamaku logs, which had a lower proportion fledged. There were 45 instances ( $26 \%$ of all records) in which pairs consecutively reused nest sites (32 within a season, 13 between one season and the next).

The number of chicks fledged increased dramatically after 2011/2012, doubling in 2012/2013 with only a slight increase in the number of breeding pairs, but with most pairs now producing more than one nest (Table 2.1). The number fledged nearly tripled in 2013/2014 with an increase in the number of breeding pairs, after which both the number of pairs and the number fledged remained relatively constant (Table 2.1).

Table 2.1. Summary of kakariki breeding dynamics since the first translocation in 2010, with average clutch size, brood size, and number fledged observed for each breeding season. Reported values represent mean numbers per nest \pm standard error.

\begin{tabular}{lcccclll}
\hline Year & $\begin{array}{c}\text { First } \\
\text { nest }\end{array}$ & $\begin{array}{l}\text { Number } \\
\text { of nests }\end{array}$ & $\begin{array}{l}\text { Number } \\
\text { of pairs }\end{array}$ & $\begin{array}{l}\text { Total } \\
\text { fledged }\end{array}$ & Clutch size & $\begin{array}{l}\text { Brood } \\
\text { size }\end{array}$ & Fledged \\
\hline $2010-11$ & 15-Sep & 8 & 5 & 25 & $3.9 \pm 0.8$ & $3.4 \pm 0.6$ & $3.1 \pm 0.4$ \\
$2011-12$ & 20 -Aug & 12 & 8 & 25 & $5.2 \pm 0.2$ & $3.6 \pm 0.5$ & $2.1 \pm 0.6$ \\
$2012-13$ & 7-Aug & 21 & 11 & 52 & $5.3 \pm 0.2$ & $3.0 \pm 0.5$ & $2.5 \pm 0.5$ \\
$2013-14$ & 27-Jul & 47 & 28 & 163 & $5.5 \pm 0.2$ & $4.1 \pm 0.3$ & $3.5 \pm 0.3$ \\
$2014-15$ & 7-Aug & 68 & 42 & 159 & $5.5 \pm 0.2$ & $3.1 \pm 0.3$ & $2.3 \pm 0.2$ \\
$2015-16$ & 7-Sep & 53 & 37 & 172 & $6.2 \pm 0.2$ & $3.9 \pm 0.4$ & $3.2 \pm 0.3$ \\
\hline
\end{tabular}

Estimated lifetime reproductive success of kakariki pairs living to five years was 38.7 fledglings, similar to the 47 and 40 observed in two pairs for which there were five years of records (Table 2.2). Separately, males and females had slightly lower lifetime reproductive success (approximately 34 and 32 fledglings respectively by age five) (Table 2.2). Both males and females tended to fledge fewer chicks when mating with an older/younger partner relative to a partner their age, with the exception of 1-2 year old males and 1-year-old females, which both fledged more chicks when paired with an older partner. 
Table 2.2. Estimated kakariki lifetime reproductive success (LRS) for pairs of the same age, as well as males and females separately over time. Two pairs for which there were records from age one to five are included as a comparison to the calculated values.

\begin{tabular}{cccccc}
\hline Age & Pair LRS & LRS Male & LRS Female & $\begin{array}{c}\text { LRS } \\
\text { Pair 1 }\end{array}$ & $\begin{array}{c}\text { LRS } \\
\text { Pair 2 }\end{array}$ \\
\hline$\leq 1$ & $4.9(\mathrm{n}=50)$ & $5.1(\mathrm{n}=71)$ & $4.8(\mathrm{n}=76)$ & 4 & 8 \\
2 & $10.9(\mathrm{n}=34)$ & $10.9(\mathrm{n}=65)$ & $10.2(\mathrm{n}=60)$ & 13 & 20 \\
3 & $20.2(\mathrm{n}=15)$ & $17.6(\mathrm{n}=33)$ & $18.5(\mathrm{n}=33)$ & 27 & 26 \\
4 & $28.2(\mathrm{n}=7)$ & $24.9(\mathrm{n}=18)$ & $25.9(\mathrm{n}=11)$ & 35 & 31 \\
5 & $38.7(\mathrm{n}=4)$ & $33.5(\mathrm{n}=7)$ & $32.2(\mathrm{n}=9)$ & 47 & 40 \\
6 & - & $36.5(\mathrm{n}=4)$ & - & - & - \\
\hline
\end{tabular}

GLMM analyses could not be adequately performed on nesting success, and number and proportion of chicks fledged because none of the models fit the data well and many had convergence issues, likely due to the high amount of variation in the response variables and the small sample size of birds at older ages. However, observed trends included nesting success (proportion of nests that fledged at least one chick) increasing with parent age until it dropped off at five years for females and six for males (Figure 2.1). The proportion and number of chicks fledged successfully did not change substantially with parent age, although both decreased at age six for males (Figure 2.2). Proportion of chicks fledged did not vary based on the laying date of the nest (Figure 2.3).

The total 2016 fledging sex ratio was 52.1\%: 47.9\% (males: females) $(n=35)$. Due to similar fit and convergence problems, GLMM analyses could not be performed on fledging sex ratio, average overall chick mass, or average female mass. There was a slight pattern of older females fledging a lower proportion of male offspring (Figure 2.4). However, given the small sample size this pattern should be interpreted cautiously. 
Chapter 2

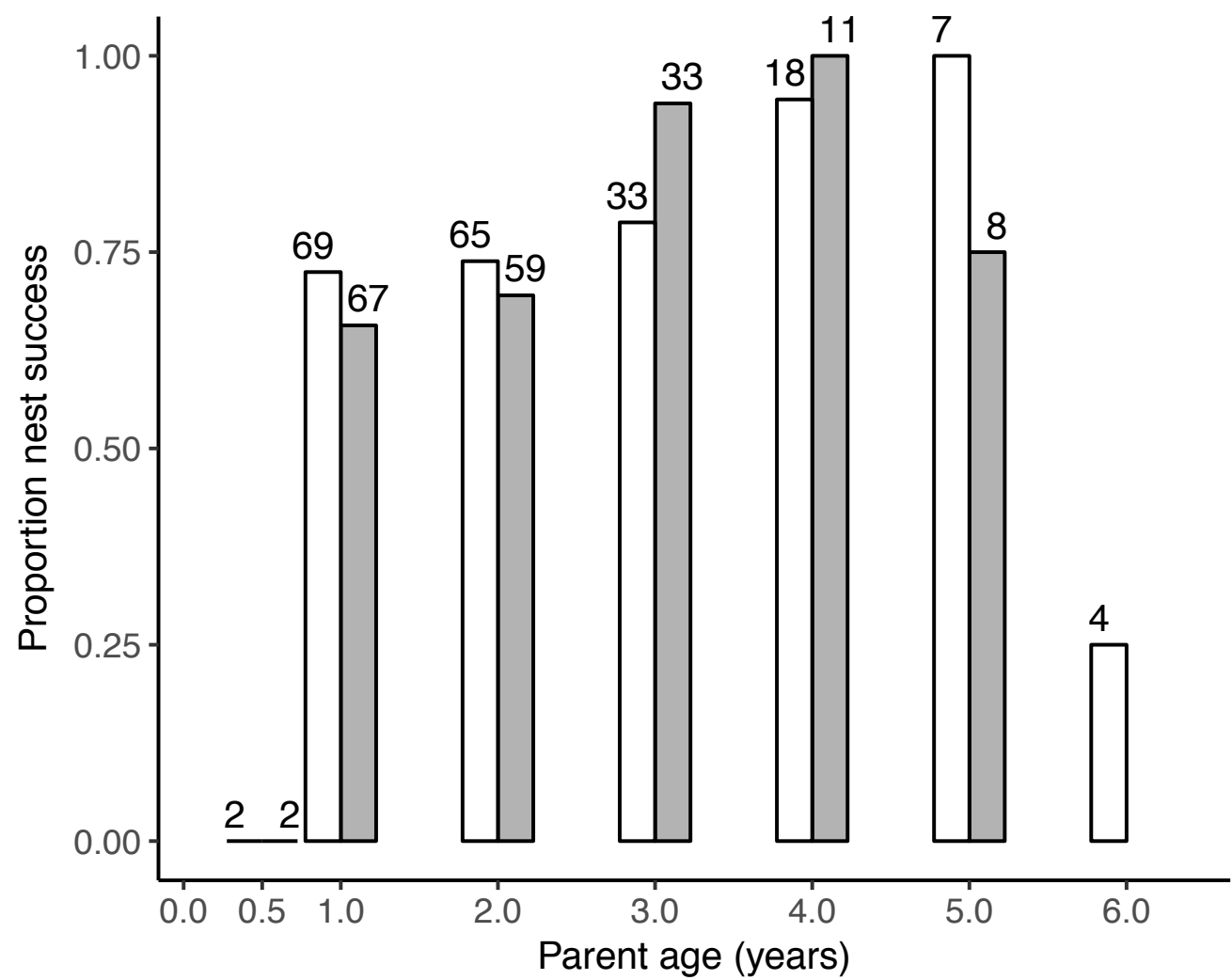

Figure 2.1. Nesting success increased with parent age, peaking around four to five years and then dropping off (male: white, female: gray). As there was only one nest produced by a female of age six, this was not included on the figure. 

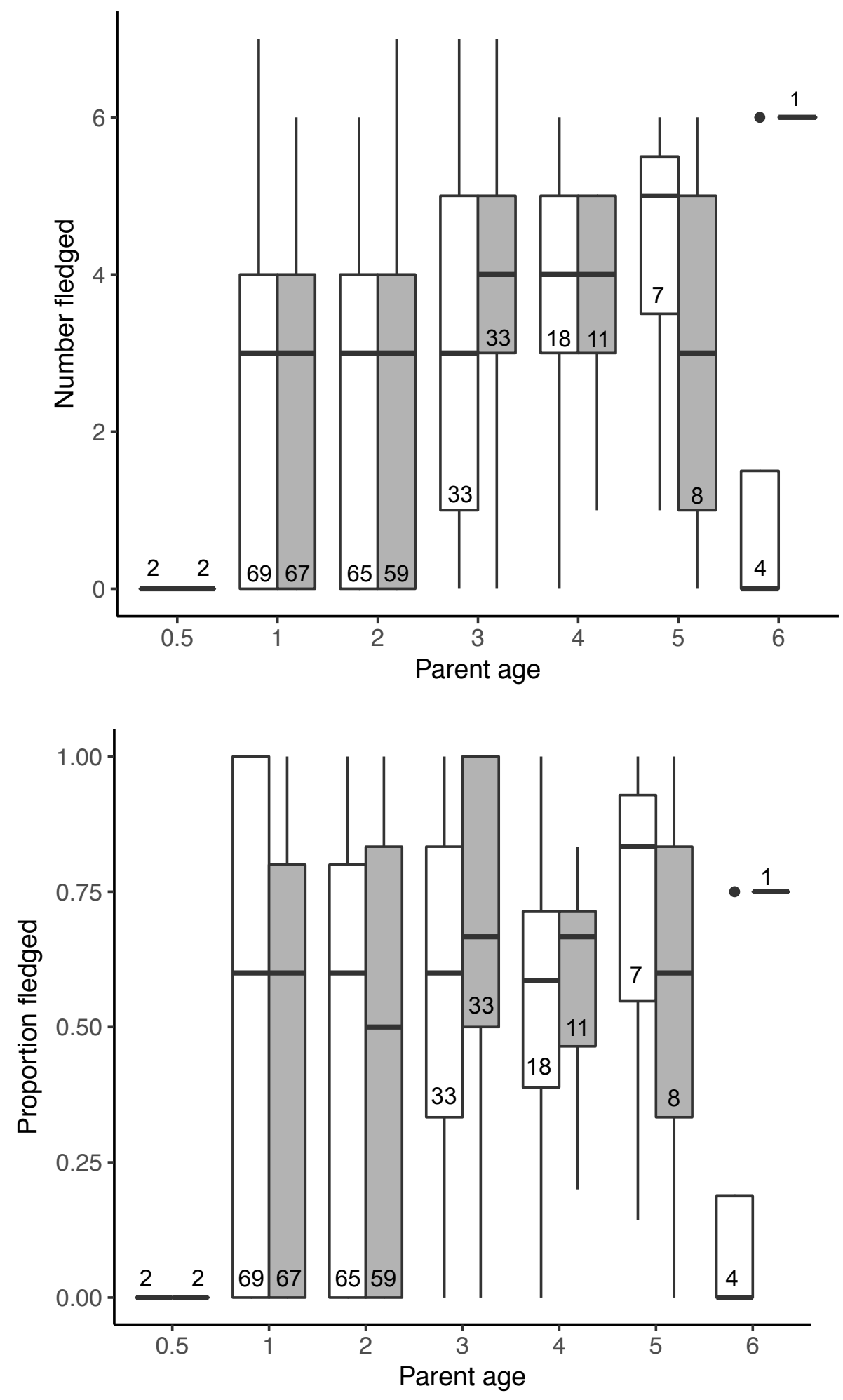

Figure 2.2. The number and proportion of chicks successfully fledged per clutch did not appear to change with female age. However, both decreased with male age (male: white, female: gray). Numbers inside boxes represent sample size. 
Chapter 2

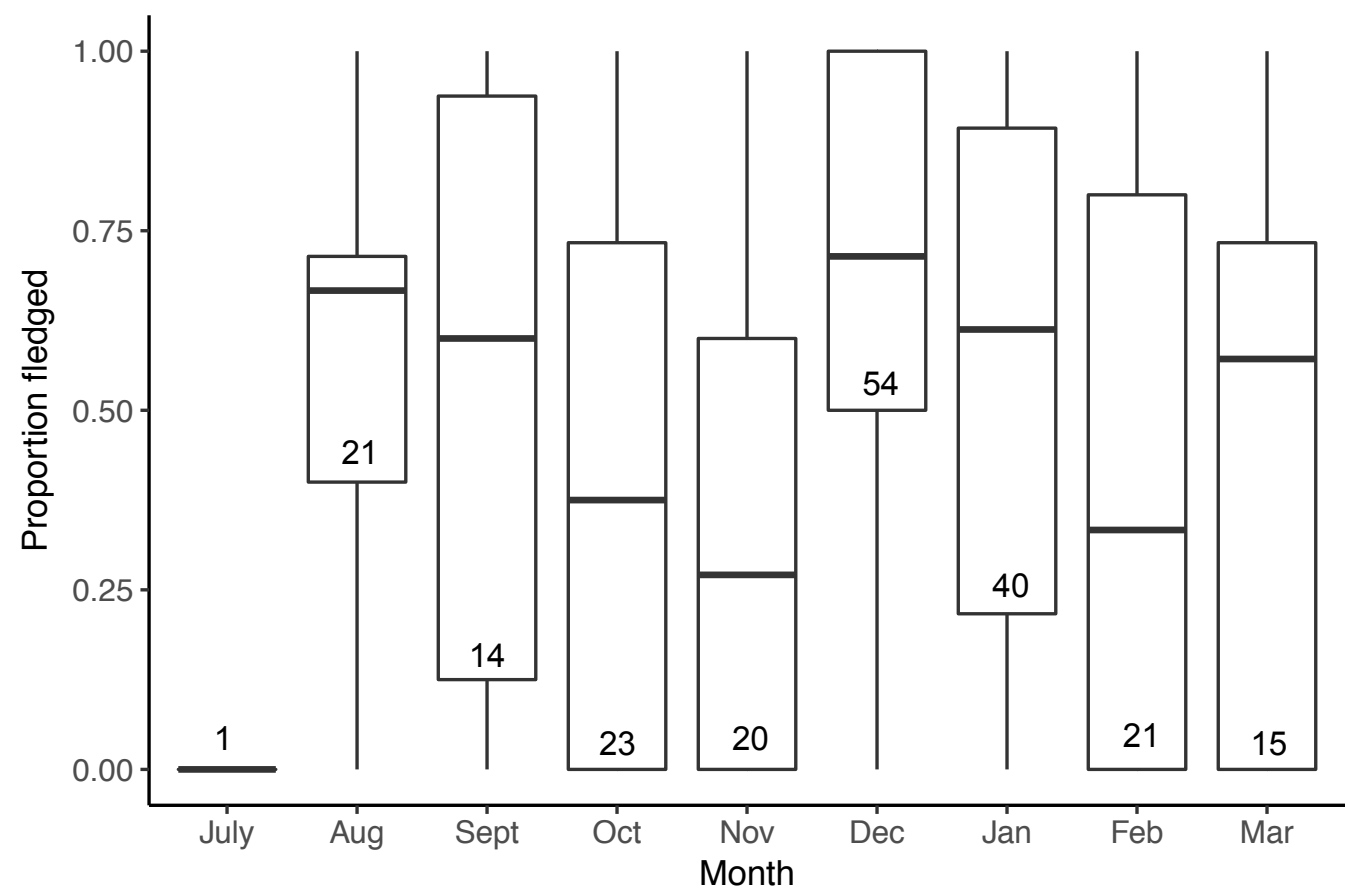

Figure 2.3. Proportion of kakariki chicks fledged did not vary substantially by the laying month of the nest. Peak reproductive success in December may have been due to a greater sample size available of nests laid in that month. Data were compiled across 2010-2016, and no effect of year was found. Numbers inside boxes represent sample size.

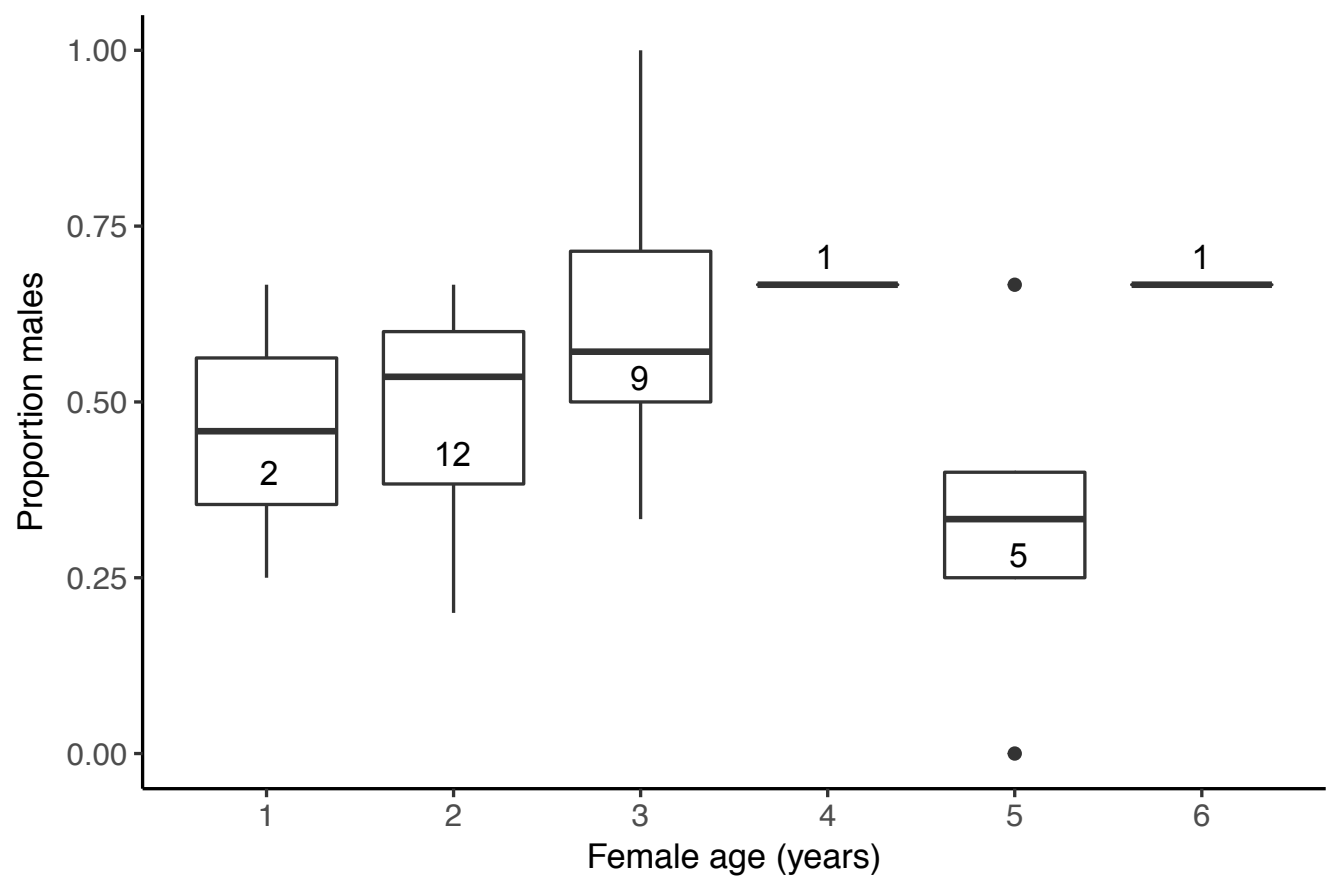

Figure 2.4. Older females had a slightly lower proportion of male fledglings (figure shows only nests with $>2$ fledglings). A similar though less distinct pattern was found with males. 
Average male chick mass increased with male parent age (LMM: $t=3.750$, $\mathrm{P}<0.001$; Figure 2.5) and decreased slightly with lay date (LMM: $\mathrm{t}=-1.485, \mathrm{P}=0.15$; Figure 2.5) (Table 2.3). The marginal $\mathrm{R}^{2}$ for the model was 0.38 (variance explained by the fixed factors) and the conditional $\mathrm{R}^{2}$ (variance explained by the entire model) was the same, indicating pair identity accounted for a negligible amount of the variation. I found that the top two models had similar Akaike weights, and therefore I calculated the importance of the individual predictor variables by summing the Akaike weights of the models containing each predictor variable (male age and hatch date) and the predictor variable with the largest weight, male age, was considered to be the most important (male age $=0.87$, lay date $=0.54)($ Burnham and Anderson 2003).

Table 2.3. Results of analysis (LMM) examining factors influencing average mass of male kakariki nestlings. $\mathrm{K}=$ the number of estimated parameters in the model, $\mathrm{AICc}=$ second-order Akaike information criterion, $\triangle \mathrm{AIC}=[\mathrm{AICC}-\min (\mathrm{AICC})], \mathrm{AICcWt}=$ weight of the model.

\begin{tabular}{lllll} 
Model & $\mathbf{K}$ & AICc & AAICc & AICcWt \\
\hline Male age+Lay Date & 5 & 219.4 & 0 & 0.45 \\
Male age & 4 & 219.53 & 0.13 & 0.42 \\
Female age+Lay Date & 5 & 222.53 & 3.13 & 0.09 \\
Female age & 4 & 225.33 & 5.94 & 0.02 \\
Lay Date & 4 & 228.47 & 9.08 & 0 \\
Null & 3 & 229.58 & 10.19 & 0 \\
\hline
\end{tabular}

There were three known cases of incest in the ZEALANDIA kakariki, all between pairs of siblings (two pairs in which both birds were from the same clutch, one where the birds were from different clutches). However, as the relatedness of the original translocated birds was not known, there may have been more incidences. While one pair failed to produce chicks despite repeated nesting attempts, the others successfully fledged a total of 18 chicks over six nests (one nest for one pair, five nests for the other). There were no apparent differences in the measurements (weight, bill length/width) of the chicks from these pairs. 


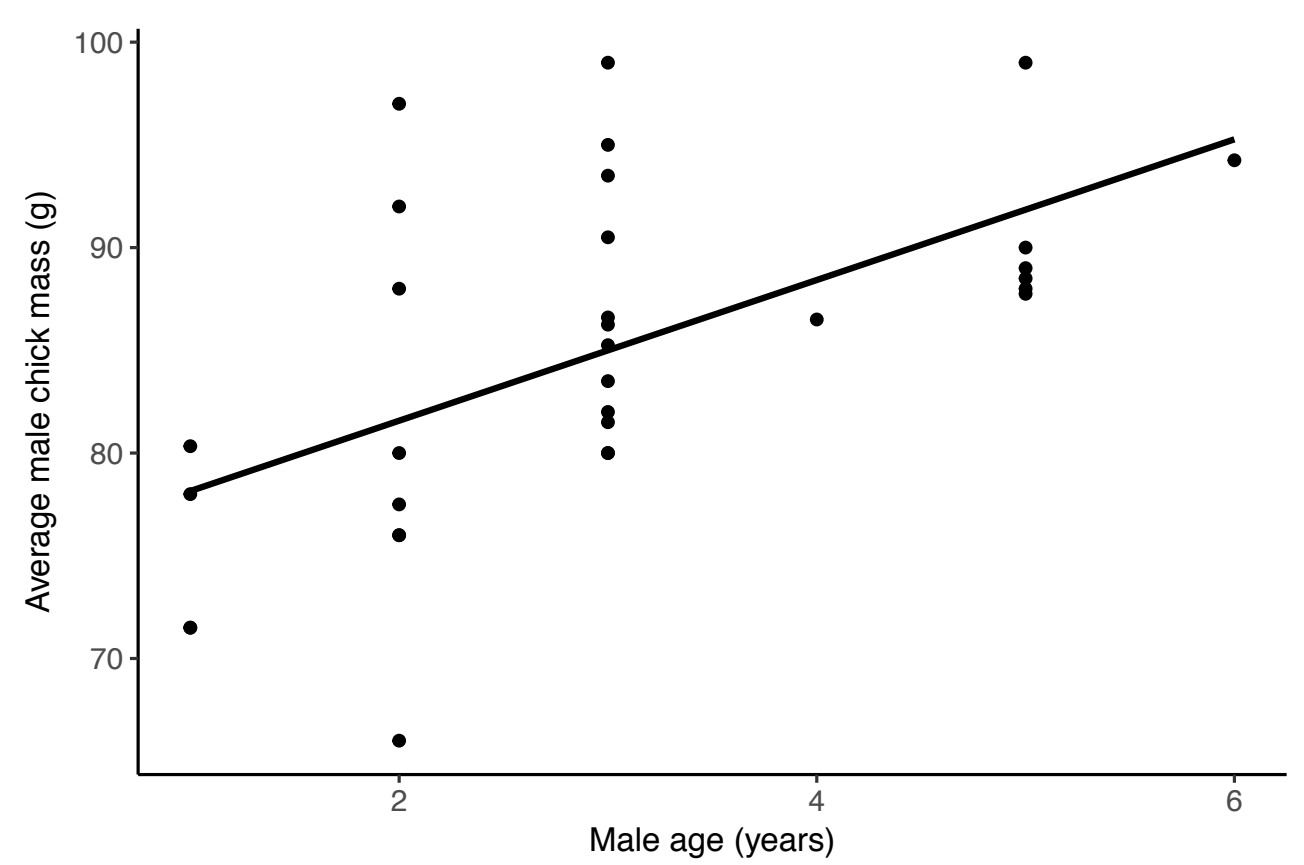

Figure 2.5. The average mass of male kakariki chicks increased with the age of their male parent $\left(\mathrm{R}^{2}=0.33\right)$.

Kakariki were primarily monogamous, with only 49 instances of divorce recorded out of 171 transitions from one clutch to the next (28.6\%). Males that changed partners tended to nest at a farther site from their previous one than those that remained monogamous (Table 2.4). Between-season breeding dispersal was greater than that within a season, regardless of pair fidelity (Table 2.4). Within the divorced records, there were 19 different females that changed partners, and of these, nine were serial divorcees (changed partners multiple times). There were 15 different males that changed partners, two of which were serial divorcees. Divorced males tended to move farther than divorced females (Table 2.4). The majority of birds were 2-3 years old when they changed partners, but there were a few 5-6 year olds as well. Numbers of divorced males and females are unequal because there were not always records of one of the partners nesting again after the divorce. 
Table 2.4. Breeding dispersal distances (movement between clutches) differed within and between years, as well as between birds that remained with their partners between clutches (monogamous) versus those that changed partners between clutches (divorced). Monogamous records track the distance a pair moved, while divorced records track the distance individual birds moved from one clutch to the other when changing partners.

\begin{tabular}{l|ll}
\hline & $\begin{array}{l}\text { Monogamous }(\mathbf{n}=\mathbf{1 2 2}) \\
\text { Average distance }(m)\end{array}$ & $\begin{array}{l}\text { Divorced }(\mathbf{n}=\mathbf{4 9}) \\
\text { Average distance }(m)\end{array}$ \\
\hline Total & $75.0 \pm 9.89$ & $100.7 \pm 11.9$ \\
Within season & $64.2 \pm 11.9$ & $70.1 \pm 12.6$ \\
Between season & $95.9 \pm 17.4$ & $115.5 \pm 26.2$ \\
Males $(n=19)$ & N/A & $161.2 \pm 40.9$ \\
Females $(n=30)$ & N/A & $62.3 \pm 10.7$ \\
\hline
\end{tabular}

After changing partners, $28.5 \%$ of divorced birds fledged fewer chicks in the following nest, while $24.5 \%$ fledged the same number and $44.9 \%$ fledged a greater number. Prior to divorce, $26.5 \%$ of the nests failed (produced no fledglings), $14.3 \%$ resulted in one fledgling and $59.2 \%$ fledged two or more chicks. I could not confirm if the death of a partner was the cause behind any of the divorces; however, in $38.8 \%$ of the cases the bird's partner was still alive after divorce.

\section{Discussion}

\section{Reproductive Success}

Both the number of kakariki nests and the total number of chicks fledged increased markedly after the original translocation, but began to level off by $2013 / 14$. The total number fledged as well as the number of breeding pairs remained relatively constant (fluctuating between 159-172 and 28-42 respectively) in the last three years, indicating that the kakariki population within ZEALANDIA could be reaching its carrying capacity in terms of how many breeding pairs it can support, even though the population itself is still growing. However, it should be noted that the numbers only indicate the number of kakariki nesting in boxes: while a few natural nests were discovered, there were likely to be more throughout the sanctuary, and therefore the numbers may not accurately reflect total kakariki population dynamics within ZEALANDIA. 
As kakariki are generalist feeders (Greene 1998) and have been observed feeding on a wide variety of plants both within the sanctuary and outside - not to mention ZEALANDIA has feeders set up that are regularly supplied with food - they may not currently be limited by food. They may, however, be limited by nest sites. Competition for nest sites has been shown to limit the breeding densities of many bird species, thereby limiting the total population as reproduction is restricted (reviewed by Newton 1994). Brawn and Balda (1988), for example, found that breeding densities of cavity-nesting birds significantly increased in plots where nestboxes were provided relative to controls. Competition for limited nest sites was even thought to be a key factor in the decline of the Puerto Rican parrot (Amazona vittata) (Wiley 1985).

ZEALANDIA's kakariki population in 2015/16 was estimated at 100 birds, and in that season there were 126 nestboxes and 50 mamaku nests set up around the sanctuary for the birds (Gray 2016). However, mamaku nests were rarely used, and many of the nestboxes were set up in small groups, such that if one was being used the others in the immediate vicinity would not be. ZEALANDIA staff have observed that kakariki will chase away conspecifics that venture too close to their nest, and birds rarely nest at sites less than $\sim 25 \mathrm{~m}$ apart (Richard Gray pers. comm.). On New Zealand's Little Barrier Island, Greene (2003) observed numerous competitive interactions at or in nest sites particularly at the start of the breeding season, and suggested that a scarcity of suitable nest cavities likely limited the size of the kakariki population there. Furthermore, previous studies have found low incidences of kakariki cavity reuse (Ortiz-Catedral and Brunton 2009). While the percentage of cavity reuse (26\%) was not high, I likely substantially underestimated it, as I only counted consecutive incidences of reuse. Therefore, overall cavity reuse was probably much more common at ZEALANDIA, which could indicate high competition for nest sites.

Birds unable to find nest sites in the sanctuary will likely venture over the fence line, where given the urban environment, it may be more difficult to find suitable cavities (Marzluff and Ewing 2001; Blewett and Marzluff 2005). Blewett and Marzluff (2005) recorded lower densities of cavity-nesting birds in suburban areas compared to wildlands, and suggested this may have been due to the relative lack of available cavities. Kakariki have been found to use a diversity of different nesting sites (Ortiz-Catedral and Brunton 2009). In Wellington, kakariki have already been observed breeding outside the valley, in a stump as well as inside a house roof 
(Richard Gray pers. comm.), so the birds may be able to find creative sites within the suburban environment. However, as cavity nesters, kakariki are particularly vulnerable to mammalian predation (O'Donnell 1996), which could prove fatal when breeding outside predator-free ZEALANDIA.

Nesting success (proportion of nests that fledged at least one chick) increased with parent age until five years for females and six for males. Because female kakariki do the majority of the breeding work (e.g. laying and incubating the eggs, feeding the chicks) (Pratt et al. 1987; Greene 2003), it follows that nesting success could increase with greater female experience gained with age. Maternal age has been associated with greater breeding success in other animals: for example, Sydeman et al. (1991) found that older western gulls (Larus occidentalis) tended to fledge more offspring each year, likely due to their greater nesting and foraging experience. Male kakariki help select the nest site and provision the female every two hours throughout the period when she is on the nest, and greater experience in finding food sources and good nest sites could increase breeding success (Pratt et al. 1987). Greene (2003) observed several instances of kakariki breeding failure with young nestlings that occurred likely due to the male's inability to provide sufficient food for the female and chicks.

The number and proportion of kakariki chicks fledged did not change substantially with female and male age, although for males both decreased after age five. The lack of a discernable pattern between number and proportion fledged and parent age, particularly in the GLMM, could be due in part to the small number of older birds in the dataset: as kakariki were translocated to ZEALANDIA only in $2010 / 11$, the population has not had time to accrue a large number of older birds. Additionally, there was a large amount of variation in reproductive success among birds at all ages; therefore the sample size may have been too small to determine a trend.

A small sample size could also have been the cause behind the lack of any pattern in fledging sex ratio, particularly as I only used data from the 2015/16 season in that analysis. Previous avian studies have observed male biased sex ratios based on parental age or condition (e.g. Blank and Nolan 1983; Kölliker et al. 1999; Whittingham et al. 2002). However, parent age and/or nestling weight may also not be good measures of parent condition, or alternatively, kakariki may not vary their sex ratios. For example, Ortiz-Catedral et al. (2013) found no bias in primary sex ratio or 
sex ratio at hatching or fledging in kakariki. Older females (age five) tended to fledge a slightly lower proportion of male chicks in nests with $>2$ fledglings. While the sample size was small and the trend may have been a coincidence, it warrants further study as female body condition has often been associated with the increased production of males (e.g. Whittingham et al. 2002). As female nest failure also began to increase at that age, it could be that females are reaching senescence and/or are in worse condition, resulting in the increased production of daughters rather than sons.

After a particular age, the breeding ability of both sexes will likely decline over time as they near senescence, a pattern observed in many bird species (e.g. Weimerskirch 1992; Møller and Lope 1999; Bouwhuis et al. 2012). Nesting success in kakariki did decrease at five years for females and six for males, possibly indicating that birds at those ages were past their prime breeding years. Furthermore, the number and proportion fledged dropped for six year-old males, and a similar pattern may be found for females once there are a greater number of older birds in the sanctuary (there was only one six-year old female in the dataset). However, these results should be re-examined once the population in ZEALANDIA has aged sufficiently to observe a larger number of birds in later age cohorts.

Male age did appear to influence the mass and therefore potentially the quality of their male offspring. Older males often appear to be dominant at feeders in ZEALANDIA, and spend a lot of time there particularly during the breeding season (Richard Gray pers. comm.). Therefore, it is possible that older males provision their partners at greater rates, or with higher quality food, and therefore are able to produce heavier male chicks. As such, this could increase the post-fledging success of their chicks, which may have a competitive size advantage relative to other juvenile males. Relationships between size and fitness or dominance have been observed in a variety of birds: Magrath (1991), for example, found that survival in juvenile blackbirds (Turdus merula) increased with weight, and Garnett (1981) noted that larger great tit (Parus major) fledglings tended to dominate smaller fledglings.

While most studies have found that avian reproductive success decreases throughout the season (e.g. Korpimäki and Lagerström 1988; Norris 1993; Spear and Nur 1994; Naef-daenzer et al. 2001), kakariki nesting success did not appear to change substantially. This is similar to the results of Ortiz-Catedral and Brunton (2009), who also found no influence of lay date on kakariki nesting outcomes. As kakariki at ZEALANDIA have an especially long breeding season, sometimes starting 
as early as July and going through to April, with pairs often producing multiple clutches, it follows that the greatest breeding success could likely be in the middle of summer, when food is plentiful and temperatures are warm. Nests laid in December were slightly more successful than other months. However, this effect was probably skewed by the fact that a greater number of nests were started in that month.

Furthermore, while the average lay date did not change with male or female age, older pairs tended to lay one or two nests right in the middle of the season (summer), rather than producing a nest at the start in late winter/early spring. The higher success in mid-season clutches could therefore have been due to simply a greater number of nests, or perhaps more birds, particularly older more experienced ones, chose to breed then because it was a good time to nest.

By the time kakariki were five years old, they could easily have produced upwards of thirty offspring, according to my estimate of lifetime reproductive success. This estimate, while approximate, could be used in population viability analyses when monitoring kakariki populations or contemplating new translocations. However, in most bird species a large percentage of fledglings die before they can breed, and even among breeders productivity varies substantially (Newton 1989). The estimate I calculated may therefore be skewed towards the breeders, particularly the successful ones. In many avian populations, more than $50 \%$ of the fledglings are produced by a small percentage of breeders (Newton 1989). Hence, population viability analyses or other uses of this 'lifetime reproductive success' estimate should not consider all founders of a population capable of producing at this rate, and be cautious over its applicability to other sites.

While the kakariki population at ZEALANDIA is certainly increasing, inbreeding could be a problem in the future. There were only three recorded instances of incest at the sanctuary, but these resulted in eighteen chicks, which may negatively impact the genetic viability of the population when they enter it as breeders. In addition, as the relatedness of the translocated birds is unknown, inbreeding could be more common than currently observed.

Finally, it should be noted that the ages of the original translocated birds were not known; while many of them were likely juveniles (had hatched in the season prior to translocation), some may not have been, and while this will not likely affect the overall patterns of reproductive success, it may affect the age ranges slightly in terms of when reproductive success begins to decline. 


\section{Breeding Ecology Observations}

On average, kakariki breeding dispersal was $<100 \mathrm{~m}$, indicating the birds were relatively settled in a particular area once they began breeding. It is important to note, however, that there may be a greater density of potential nesting sites (e.g. nestboxes) in ZEALANDIA than there are in a typical forest or especially in a suburban area like that surrounding the sanctuary. Therefore, breeding dispersal in ZEALANDIA may be artificially low.

Breeding dispersal among divorced birds was farther than that of monogamous pairs, as birds changing mates might also have to change breeding locations. Distances were also greater among divorced males than females, possibly indicating that females are more philopatric with regards to their breeding territories. While Greene (2003) suggested that divorces could be due to nest failure, at ZEALANDIA only $26.5 \%$ of divorces occurred after nest failure, and nearly $60 \%$ occurred after producing a nest that fledged two or more chicks. Neither were many of the divorces caused by the death of a partner, as nearly $40 \%$ of divorces occurred while the other partner was still alive (other cases were unknown). In addition, many females changed partners multiple times.

Divorce in birds is thought to be an individual reproductive strategy to improve fitness, and various hypotheses have been proposed to explain specifically why individuals divorce, including finding a higher quality mate or territory, or greater reproductive success (reviewed by Choudhury 1995). Furthermore, many divorce models predict that divorce rate should be higher in younger individuals, as they have a greater amount of time for improvement and will therefore benefit more from the divorce (reviewed by Choudhury 1995). That the vast majority of divorced kakariki were young $(\leq 3)$, many females divorced multiple times, and nearly half of all birds had greater reproductive success after divorcing suggests that divorce in kakariki could be an alternate reproductive strategy to maximize fitness by getting a better mate and/or producing more offspring. 


\section{Management Recommendations and Future Research}

Understanding the basic breeding ecology and the factors influencing kakariki reproductive success is important not only in managing their populations in their current locations, but also for increasing the success of future translocations. Kakariki breeding success may decline with age, and given that older (5/6 year-old) birds appeared to have lower reproductive success, it may not be cost-effective to use them in translocations. My study demonstrates why it is more prudent to use younger birds, which have a greater chance of producing many offspring ( $>30$ by age 5$)$, as well as passing their genes onto the population before they reach reproductive senescence or die.

Further research should be conducted to examine kakariki nesting in urban areas, to determine their preferred nest sites and their nesting success outside the sanctuary. In addition, while there were few known cases of incest among kakariki, the potential for inbreeding and its impact on population success among these birds should be investigated. 
Chapter 2 


\section{Chapter 3}

\section{Post-fledging dispersal of red-crowned parakeets (Cyanoramphus novaezelandiae) from a fenced mainland sanctuary}

\section{Introduction}

Dispersal is a fundamental ecological process, influencing individual survival and reproduction as well as the spatial structure, dynamics, and persistence of populations (Benton and Bowler 2012). Through its impacts on gene flow and species distributions, it also serves an evolutionary function, with implications for speciation (Bohonak 1999; Benton and Bowler 2012; Lenormand 2002; Garant et al. 2007). Individuals are thought to disperse for a variety of reasons, from inbreeding avoidance to locating areas with better quality habitat, reduced competition, and/or improved mating opportunities (Forero et al. 2002; Moksnes 2004; Doerr and Doerr 2005; reviewed by Liu et al. 2008; Rémy et al. 2011; Matthysen 2012; Nevoux et al. 2013). But while there are many potential benefits of dispersal, dispersers often face a lower probability of survival, due to an increased risk from predators, unsuitable habitat, and the energetic costs associated with dispersing (Yoder et al. 2004; Johnson et al. 2009; reviewed by Bonte et al. 2012).

Knowledge of dispersal is key to understanding a species' life history; however, dispersal is difficult to study, and the mechanisms behind it are complex because it is often influenced by multiple factors simultaneously. For example, many species exhibit sex-biased dispersal, where one sex is more likely to disperse greater distances (e.g. Greenwood 1980; Greenwood and Harvey 1982; Clarke and Heathcote 1990; Forero et al. 2002; Dingemanse et al. 2003; Serrano et al. 2003; Withey and Marzluff 2005; Støen et al. 2006; Eldegard et al. 2014). Birds generally exhibit female-biased dispersal while the opposite pattern has been found in mammals, possibly due to a difference in avian versus mammalian mating systems, and/or inbreeding avoidance (Greenwood and Harvey 1982, 1980; Pusey 1987; Clarke and Heathcote 1990; Cockburn et al. 2003; Dingemanse et al. 2003; Bradley et al. 2011). Another commonly-studied effect on dispersal is body condition: in some species, 
smaller subdominant individuals are unable to compete with their more dominant counterparts and subsequently are forced to disperse (Gese et al., 1996; Zedrosser et al. 2007; Pasinelli and Walters 2002; McCauley 2010), while in others, smaller individuals delay dispersal to stay in the safety of their natal territory (Nilsson and Smith 1985; Ellsworth and Belthoff 1999; Barbraud et al. 2003). There can even be more subtle factors at work. For example, increased dispersal has been associated with personality traits like boldness, aggressiveness, or sociability (Fraser et al. 2001; Dingemanse et al. 2003; Cote and Clobert 2007; Duckworth and Badyaev 2007; reviewed by Cote et al. 2010). Several studies have also observed a decreased likelihood of offspring dispersal with parental age, possibly due to the parents' impending senescence (Ronce et al. 1998; Zedrosser et al. 2007).

While important from an ecological perspective, dispersal is also crucial for species conservation and management, particularly in this era of rapid global change. For example, habitat fragmentation and urbanization have already been found to have a considerable effect on species' movements. Habitat fragmentation tends to increase dispersal distance (individuals must travel farther to reach suitable habitat) while decreasing the likelihood of dispersal, presumably due to the energetic costs and risk of mortality that accompany dispersal (Diffendorfer et al. 1995; Matthysen et al. 1995; Baguette et al. 2003; Willson 2004; Martín et al. 2008). In an urban setting, species must also navigate novel conditions including the presence of buildings, cars, invasive predators, and supplementary food and water (Marzluff 2001; reviewed by Marzluff and Ewing 2001; Lepczyk et al. 2003; Robb et al. 2008; van Heezik et al. 2010; Ausprey and Rodewald 2013; Machtans et al. 2013). Despite the global increase in the number and size of cities (Marzluff 2001), dispersal of organisms in urban areas has been rarely studied.

Dispersal is also of particular importance to another conservation issue: species translocation. Translocations, the deliberate, human-mediated movement and release of wildlife from one location to another, are frequently employed in conservation management, particularly for endangered birds (Griffith et al. 1989; Kleiman 1989; Mumme and Below 1999; Pierre 1999; Tweed et al. 2003; OrtizCatedral and Brunton 2010; IUCN/SSC 2013; Miskelly and Powlesland 2013). Dispersal from the target conservation area can affect the ability of a translocation to augment a population or establish a new one (Clarke and Schedvin 1997; Armstrong 
et al. 2013; Tweed et al. 2003; Stamps and Swaisgood 2007; Van Houtan et al. 2010; Bradley et al. 2011). For example, it has been cited as a common cause of failure in reptile translocations (Germano and Bishop 2009). This effect is particularly evident when animals are released into a protected site (van Heezik et al. 2009; Rickett 2010; Müller et al. 2014): in one case, a third of critically endangered black stilts (Himantopus novaezelandiae) dispersed away from the populations they were meant to supplement, many of these going into unmanaged areas where the birds could not be monitored or protected from invasive predators (van Heezik et al. 2009).

New Zealand, which has one of the highest national proportions of threatened avian species, has pioneered translocation methods and practices (Clout 2001; Bell and Merton 2002; Bell et al. 2005; Armstrong et al. 2007; Leech et al. 2007; reviewed by Miskelly and Powlesland 2013). Since at least the 1890s, conservationists have used translocations as a tool to prevent the extinction of native birds, which have been decimated by introduced mammalian predators such as rats and stoats (reviewed by Miskelly and Powlesland 2013). Historically, translocations within New Zealand have been to offshore, predator-free islands (reviewed by Miskelly and Powlesland 2013). However, with the development of predator-resistant fencing, the majority of translocations over the last decade have been to "mainland islands" or sanctuaries, which are predator-free but are surrounded by areas in which predators are still present (Saunders and Norton 2001; reviewed by Miskelly and Powlesland 2013). Many of these translocated populations are dispersing beyond the safety of the mainland islands, but little is known about their activities and survival outside of these sanctuaries. Here dispersal has the potential to result in source/sink dynamics between the sanctuaries and surrounding areas, as birds dispersing outside of mainland sanctuaries will likely have a much higher risk of mortality. An understanding of dispersal and factors affecting it is therefore critical when translocating species to mainland sanctuaries, in order to fulfill the goals of the translocation, and facilitate species conservation. I investigated dispersal patterns and factors influencing the movements of red-crowned parakeets (Cyanoramphus novaezelandiae), or kakariki, recently translocated to a predator-free sanctuary in Wellington City, New Zealand. I aimed to answer two questions:

1. Are kakariki surviving outside the sanctuary?

2. Where do kakariki go, and why? 


\section{Field Site and Methods}

Research took place at ZEALANDIA ${ }^{\text {TM }}$ Eco-sanctuary, a 225 ha mainland island located within suburban Wellington and $2 \mathrm{~km}$ west of Wellington City (CampbellHunt 2002). The valley is surrounded by a predator-exclusion fence that excludes all mammalian pests, except the house mouse (Mus musculus), which can slip through warping in the fence (Campbell-Hunt 2002; Nelson et al. 2016). However, sanctuary staff regularly monitor mice populations and perform ongoing pest control within ZEALANDIA to keep mouse numbers low (Nelson et al. 2016). Red-crowned parakeets (Cyanoramphus novaezelandiae), or kakariki, were translocated from Kapiti Island to ZEALANDIA: fifty-five in July 2010 (38 males, 17 females), and a total of 52 from two separate installments in May and July 2011 (18 males, 17 females, 17 unknown) (Gray 2011; Gray 2012). While once numerous throughout New Zealand, the species was decimated due to habitat destruction, hunting, and predation by invasive mammals (Pratt et al. 1987; Higgins 1999) As a result, kakariki are now primarily confined to offshore islands (Pratt et al. 1987; O’Donnell 1996; Higgins 1999). Kakariki have been monitored by ZEALANDIA staff since their reintroduction, with staff recording the location of nests, the identity of each pair breeding in a particular nest using leg bands, and the number of eggs, approximate hatch date and fledge date of the nestlings. Nestlings are banded approximately a week prior to fledging when they are four weeks old (Gray 2016).

Currently, we have limited knowledge of kakariki movement. Adult kakariki appear to move little before or after breeding, and pairs tend to nest in roughly the same area season after season (Higgins 1999; Chapter 2; Richard Gray pers. comm.). Some long-distance ( $>40-60 \mathrm{~km}$ ) movements between islands have been observed, indicating that relatively long dispersal distances, even over expanses of sea, are possible (Higgins 1999; Ortiz-Catedral 2010). The post-fledging period of this species, as with many birds, has been little studied (Baker 1993; Higgins 1999). Researchers have observed that recent fledglings usually remain within $100 \mathrm{~m}$ of their nest, fed by their parents, for the first two weeks (Pratt et al. 1987; Higgins 1999). Thereafter, fledglings forage over a larger area during the day, while returning to their natal area at night to roost (Pratt et al. 1987; Higgins 1999). Juveniles become independent at 4-5 weeks, after which little is known about their dispersal patterns or the factors that may influence them (Pratt et al. 1987; Higgins 1999). 
During January-September 2016, I led a study tracking the movements of juvenile kakariki. Birds were captured using catch cages and clap traps set up around ZEALANDIA, ideally near locations of nestboxes (Figure 3.1). Both were regularly supplied with food (millet) to attract kakariki and habituate them to feeding in the traps. As kakariki fledglings usually follow their parents for several weeks after fledging (Pratt et al. 1987; Higgins 1999), juveniles were typically led to feeders by their parents, who were already accustomed to feeding in the traps. Both traps were operated using a string attached to the cage doors, or net in the case of the clap trap; therefore, I was able to finely select the birds that I caught. Upon observing a juvenile in the vicinity of the trap, I noted the band combination, and using a list of all the 2015/16 birds banded in ZEALANDIA, was able to determine if it was banded as a nestling (as opposed to as a juvenile or adult), and thus if there was information on the hatch date, parents, nest location, and siblings. I could then determine whether or not to catch it should it enter the trap. Only banded juveniles that had fledged the nest within approximately the past 3-6 weeks were targeted so that birds were tracked from a similar age ( $\sim 2$ months old), and tail feathers were developed enough to carry a transmitter (occurs approximately three weeks after fledging). Two birds caught to replace those that had died were slightly older, 3 and 4 months old. 


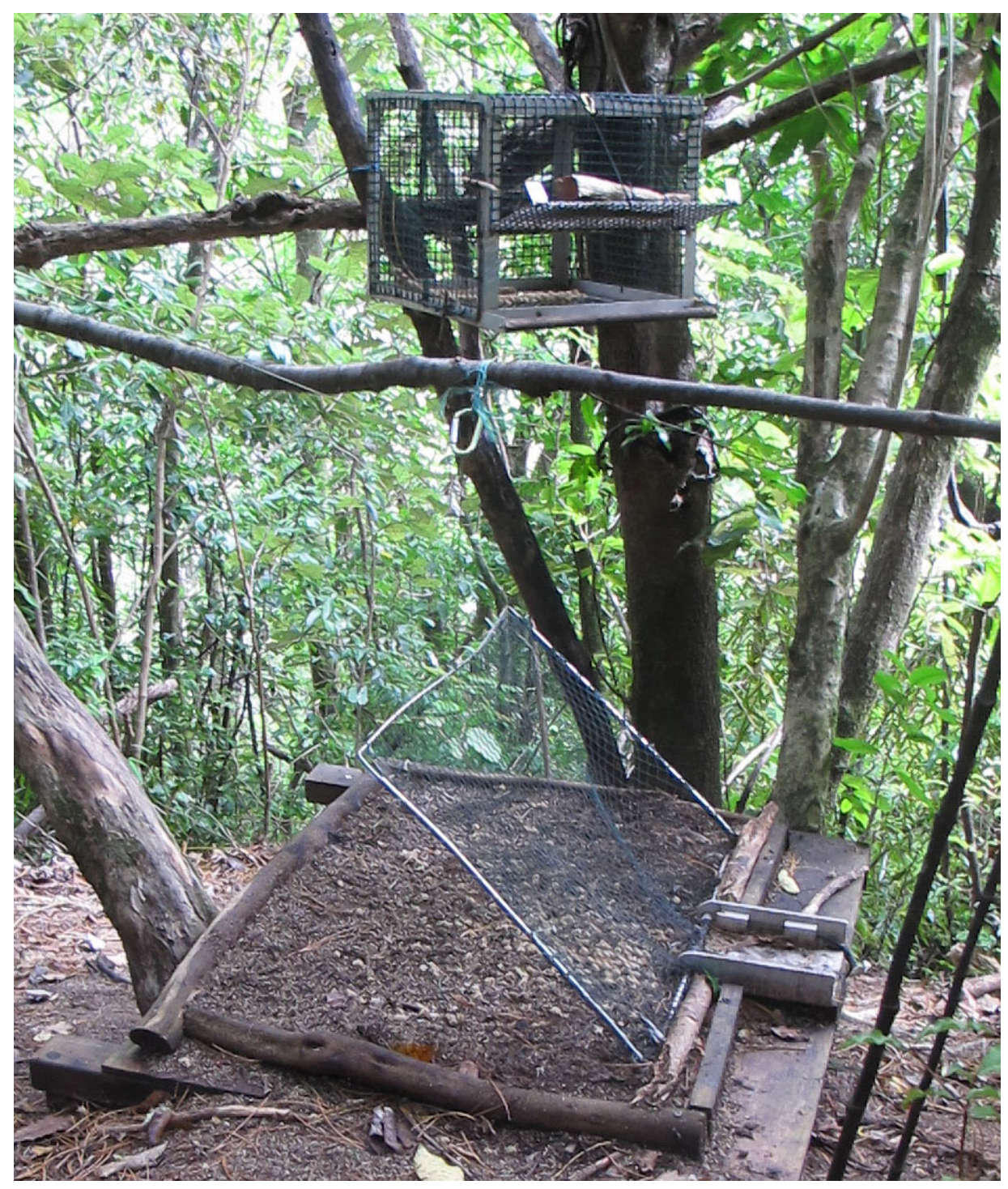

Figure 3.1. A catch cage (top) and clap trap (bottom) used to capture kakariki (Photo by Richard Gray).

Upon capture, each bird was sexed by examining its size and bill dimensions, weighed, and had its tarsus measured. All birds were fitted with a tail-mounted radio transmitter (model BD-2, 1.9g, Holohil Systems, Ontario, Canada), designed to drop off the bird at molting (Figure 3.2). The hatch date, identity of the parents, and details about the clutch were later noted using data collected by ZEALANDIA staff. 


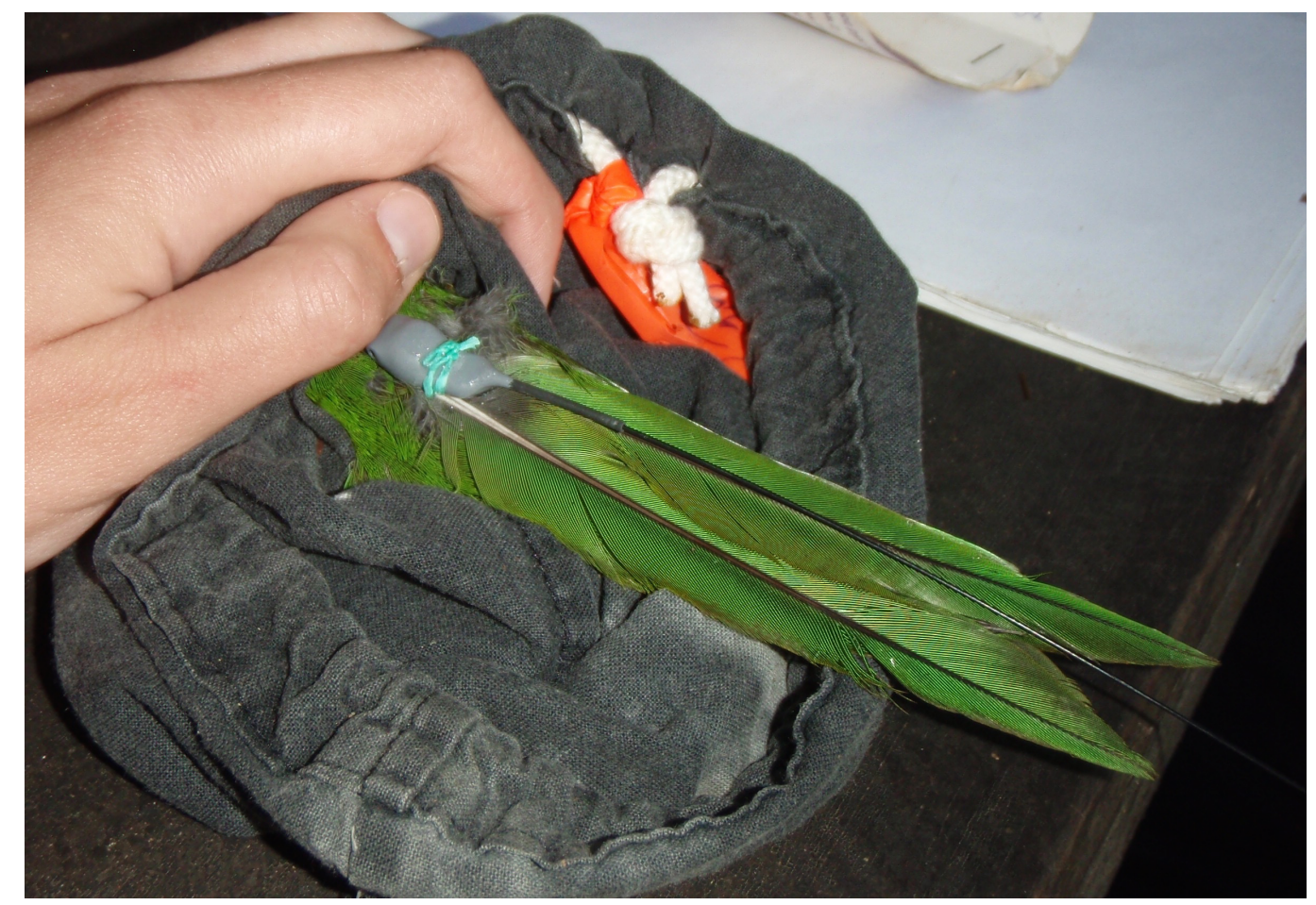

Figure 3.2. A radio transmitter mounted on the tail of a juvenile kakariki (Photo by Ellen Irwin).

The birds were then tracked using an R-1000 receiver and yagi antenna for six months, or until the transmitter battery was exhausted. Overall I recorded the location of each bird once a day, five days per week (a total of five points per week). To do this, I tracked for 6-7 days each week, but I did not obtain the location of all birds every day that I went tracking. I searched for birds initially from high points in ZEALANDIA and $\sim 3 \mathrm{~km}$ around the sanctuary. From a high point, I could pick up a bird's signal from 2-3 km away. If a bird could not be located, I then expanded my search area to include the rest of Wellington City ( 7-9 km around ZEALANDIA), again scanning from high points to expand my search area even further. To account for morning and afternoon variation and to get a fuller picture of their movements, I alternated between finding birds from 08:00-12:00 (birds generally became active around 08/08:30) and 12-16:30. To determine where the birds were roosting I also scanned for them approximately once a week after sunset. Locations were noted either by sighting the bird, gaining an off-aerial signal, or else triangulation using at least three points from a nearby ridgeline. Off-aerial signals (signals detected without the use of the yagi antenna) indicated the bird was within $\sim 5-7 \mathrm{~m}$ of the receiver 


\section{Chapter 3}

(estimated after experimenting with the transmitters). I recorded all points using a hand-held GPS unit (60CSx, Garmin, locations estimated within 5-10 m). For triangulations, I aimed to record all points within a span of 15-20 minutes to minimize error due to bird movement, although on a few occasions it took up to an hour. Triangulations were analyzed using Location of A Signal (LOAS) software (Ecological Software Solutions, LLC, Hegymagas, Hungary).

To determine if particular food sources could be drawing the birds outside the sanctuary, I performed bi-monthly phenology surveys of four plants that have been observed to be popular with kakariki in Wellington: mapou (Myrsine australis), totara (Podocarpus totara), muehlenbeckia (Muehlenbeckia australis), and five-finger (Pseudopanax arboreus). The percentage of the plant covered with ripe fruit/flowers available for kakariki to feed on was estimated for at least four plants per species both inside the sanctuary and at areas outside ZEALANDIA that some of the tracked kakariki frequented, to gain an estimate of food availability inside and outside the sanctuary. Individual plants were selected opportunistically while I was tracking. Averages were calculated per plant species per fortnight, separated by location (inside versus outside the sanctuary). Phenology patterns within and outside ZEALANDIA were nearly identical: species averages were generally within $\pm 10 \%$, with the exception of totara (ZEALANDIA totara produced little fruit in 2016). Therefore, because the data were observational and only a rough approximation of food availability, I concluded that there was little difference in these plant species inside versus outside the sanctuary, and I combined all observations per plant species by month to get an idea of overall phenology patterns in Wellington.

This dispersal study was based on a pilot I conducted in 2015 in which I tracked eleven juveniles from ZEALANDIA from April-August using the same methods described here. However, as some of these birds were not banded as nestlings, little information (e.g. parent identity, hatch date, nest site) was known about them and therefore they could not be included in statistical analyses, although certain results could be compared qualitatively. 


\section{Data Analysis}

Analyses were performed in R v. 3.3.2 (R Core Team 2016). To compare movement patterns among birds, I calculated the distance dispersed during the study period for each bird. I considered a bird dispersed when it left its natal area, or the area immediately around its nest, and did not return (i.e. had not just made a brief exploratory movement). I then determined the distance dispersed using the median coordinates of all points after leaving the natal area, and calculated the distance between that and each bird's nest. I used the median rather than the mean to reduce skew towards far exploratory movements that the birds occasionally made. Natal dispersal is the movement of fledglings from their natal area to their first breeding site (Howard 1960; Verhulst et al. 1997). Because I did not continue to track birds into the breeding season, I could not determine whether they bred in the areas that they settled in as juveniles, and thus the movements measured do not necessarily constitute natal dispersal. I therefore use the term post-fledging dispersal to characterize the movements of the tracked juvenile kakariki: post-fledging dispersal is defined as the movements independent juveniles make when departing the natal area (Anders et al. 1998; Vitz and Rodewald 2010).

To compare activity areas (the area where an individual may be during a set time period (Thompson et al. 1999)), I also computed 95\% Minimum Convex Polygons (MCPs) of the birds' movements after leaving their natal area using $\mathrm{R}$ packages sp, rgdal, and adehabitatHR (Pebesma and Bivand 2005; Calenge 2006; Bivand et al. 2013; Bivand et al. 2015). I did not compute home range, as not all birds had the 30 locations necessary to estimate home range, and even some of those that did still did not appear settled in a particular area (Seaman et al. 1999), as was eventually expected based on of the 2015 study and what is known about adult kakariki movement (Higgins 1999; Chapter 2). As most of the juveniles' activities consisted of foraging, I used activity area as a measure of how much the birds moved around to forage.

To investigate whether inbreeding avoidance could be driving dispersal, I calculated the proportion of the brood that was the opposite sex of the tracked bird (e.g. if the bird was male, what proportion of his nest was female) excluding nests where the tracked bird was the only fledgling. Sex ratio could not be calculated as some nests were made up of chicks of only one sex. I also converted each hatch date 
to a "Julian" hatch-date, based off of the earliest-hatched juvenile used in the study so that I could compare the effect of hatch date and/or seasonality on dispersal without the difficulty of using calendar dates in analyses. The body condition of each bird was calculated from the residuals of a regression of log-transformed mass on logtransformed tarsus length $\left(\mathrm{R}^{2}=0.49\right)$, which has been used in previous avian studies (Potti 1999; Barbraud et al. 2003; Vitz and Rodewald 2010).

I used linear mixed models (LMMs) to explore factors influencing juvenile movements and dispersal. As the tracked individuals included birds that were siblings, from either the same clutch or from a different clutch but the same parents, I used clutch ID nested within pair ID as a random factor. I performed separate LMMs with log-transformed response variables of distance dispersed and activity area. For the model using MCPs, I also included the number of points used to make the MCP as a fixed effect, as birds were tracked for varying lengths of time. One bird whose sex was unknown was included in analyses but its sex and subsequently the proportion of the opposite sex of its brood [hereafter referred to as proportion opposite sex] were not listed.

For the dispersal distance LMM, sex, Julian hatch-date, body condition, brood size (number of fledglings), proportion opposite sex, male parent age, and female parent age were included as fixed effects, although only in certain combinations due to small sample size. All terms except brood size and proportion opposite sex were included in the LMM for activity area. Brood size was used as a measure of kin competition and proportion opposite sex as a measure of inbreeding avoidance, both of which would be unlikely to influence activity area. Furthermore, I excluded three birds, one of whom was captured at four months old, and by then was settled in an area and therefore had an unusually small activity area (i.e. I had missed his exploratory period), and two others that had either picked off their transmitters or died soon after leaving the sanctuary, and therefore had fewer records for analysis.

As male and female parent ages were highly correlated $\left(r_{s}=0.72, P=0.004\right)$, they were never included together in the same model. In addition, because male and female age did not appear to have a linear relationship with distance dispersed, they each were transformed using a quadratic term. Assumptions of normality and homogeneity of variance were assessed where appropriate. Models were compared with a forward stepwise procedure using second-order Akaike Information Criterion (AICc) value for small sample sizes (Burnham and Anderson 2003). Models were 
fitted with the lmer function in the lme 4 package in R, and AICC values and model weights were obtained using the R package AICcmodavg (Bates et al. 2015; Mazerolle 2016). Maps were created in QGIS (Quantum GIS Development Team 2016), and the raster layer of Wellington was sourced from the LINZ Data Service (licensed by the Greater Wellington Regional Council for reuse under the Creative Commons Attribution 3.0 New Zealand license). For some maps, spot records of individual birds were connected by lines to indicate the order of points, but do not necessarily reflect all the movements of each individual.

\section{Results}

Twenty-two kakariki in total were tracked (fourteen males, seven females, and one bird of unknown sex (likely male)), ten beginning in January 2016 when chicks were first fledging, and twelve in April/May 2016 at the end of the breeding season. Two of the twelve birds from the second group were fitted with previously deployed transmitters from birds that either died or removed their transmitters. Birds departed their natal area on average at 80 days old (males: $83.75 \pm 6.79$ days, females: $74.63 \pm$ 5.13 days), sometimes making brief exploratory movements away and back in the week(s) leading up to it.

Of the eleven birds that appeared to permanently leave the sanctuary (did not return to ZEALANDIA during the study period), three were killed, with a cat (Felis catus), ship rat (Rattus rattus), and avian predator (morepork (Ninox novaeseelandiae), falcon (Falco novaeseelandiae) or Australasian harrier (Circus approximans)) being the possible culprits. Deaths were assumed if I found the body and/or a pile of feathers, and the suspected predators were determined based on the location and state of the body and/or feathers. Two additional birds may have also been preyed upon, as the transmitter signals were immobile, but due to the inaccessibility of those locations (e.g. up a tree), these were unable to be retrieved. Therefore, between $27-45 \%$ of the birds that dispersed outside the sanctuary were killed within the study period of just a few months, similar to 2015, in which two of six $(33 \%)$ of birds that left the sanctuary were killed (one killed by a cat, one an unknown predator). No birds in either year that remained within ZEALANDIA died during the study period. 
Eleven out of fourteen males left the sanctuary, and of these nine appeared to do so permanently, while two traveled outside to forage during the day and returned in the late afternoon/early evening (Figure 3.5). Males dispersed an average of $1.34 \pm$ $0.32 \mathrm{~km}$ (range 0.15-3.95 km), while females dispersed $0.63 \pm 0.16 \mathrm{~km}$ (range 0.18$1.33 \mathrm{~km}$ ). This pattern was also seen in 2015, with males generally dispersing farther than females: six of eight males permanently left the sanctuary, while none of the three females did. Two females in 2016 did leave the sanctuary, but the first traveled back and forth between ZEALANDIA and a patch of large totara trees for a week while the trees were fruiting, and afterwards remained within the valley less than a kilometer from her nest for the next nearly five months. The other female did eventually move $\sim 1.5 \mathrm{~km}$ from her nest outside the valley. As she moved unusually late, during the end of winter and the start of the breeding season, she may have been led there by a male showing her potential nest sites.

While kakariki outside the sanctuary primarily foraged in reserves and other forested areas with lots of native trees, in reaching reserves they had to fly over suburban areas, and several of them were also observed foraging in backyards and/or near neighborhoods (Figure 3.3). Additionally, the areas frequented by juvenile kakariki in 2016 were similar to those in the 2015 pilot study, and in both years other kakariki were seen and heard in those areas aside from the bird with the transmitter. Birds were seen feeding on a wide variety of plants, all native plants with the exception of a few species of rhododendron (Appendix 4). 


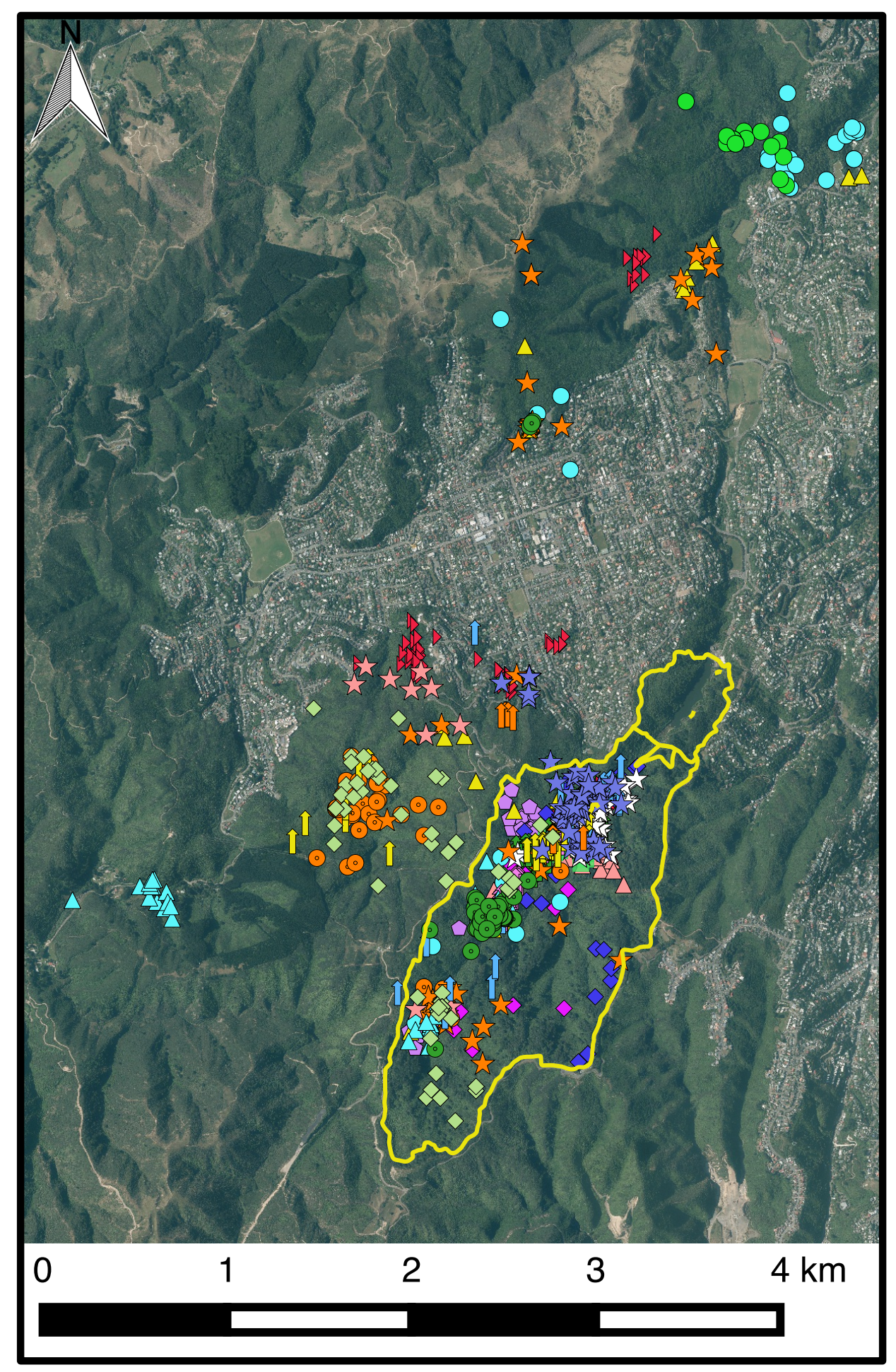

Figure 3.3. Spot records of juvenile kakariki in 2016, with ZEALANDIA fence line outlined in yellow, and each bird represented by a different symbol. 


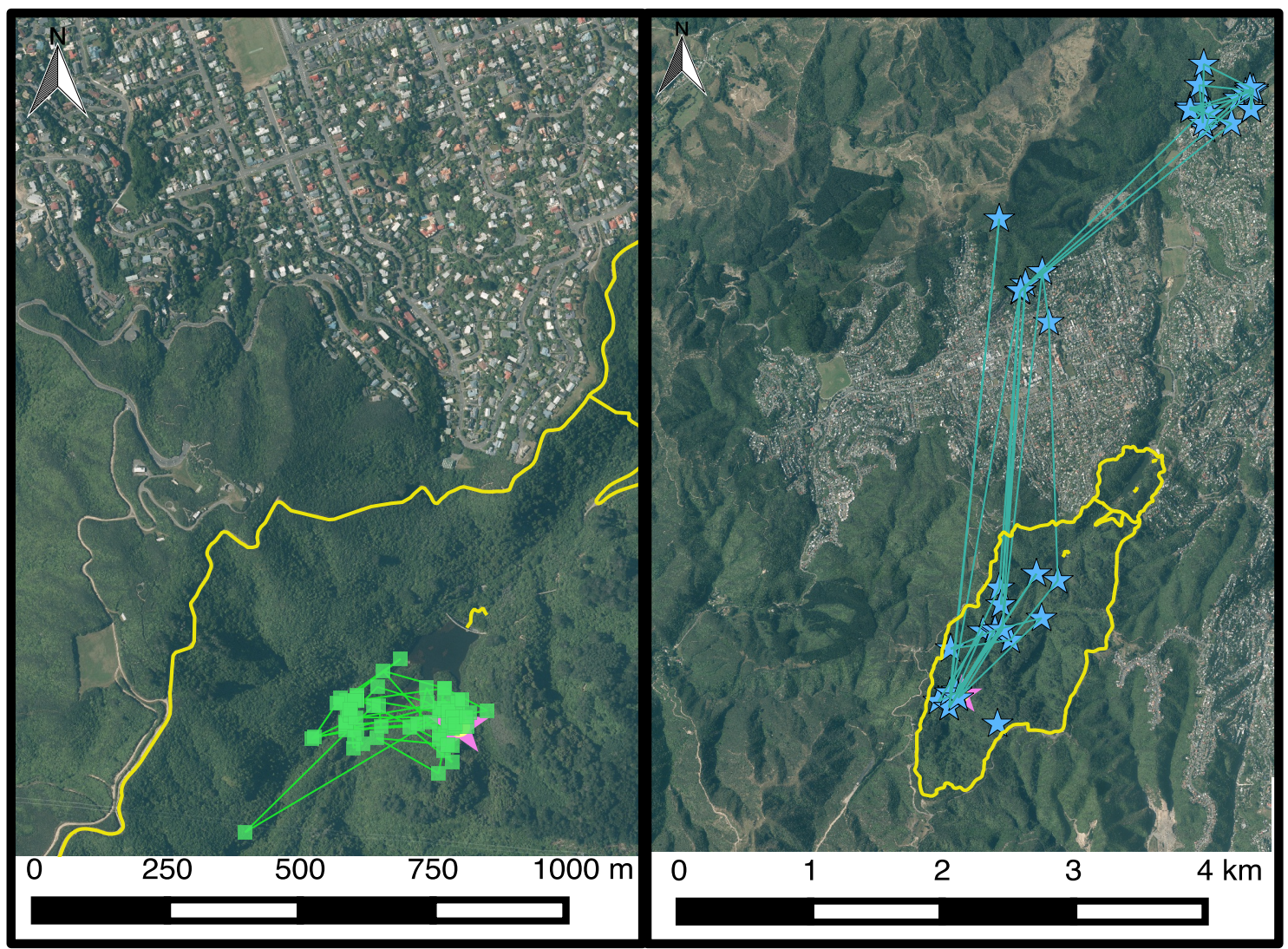

Figure 3.4. Example movements of male birds that remained close to their natal area (left) and those that dispersed farther away (right). ZEALANDIA fence line outlined in yellow, nest points indicated by pink star. 


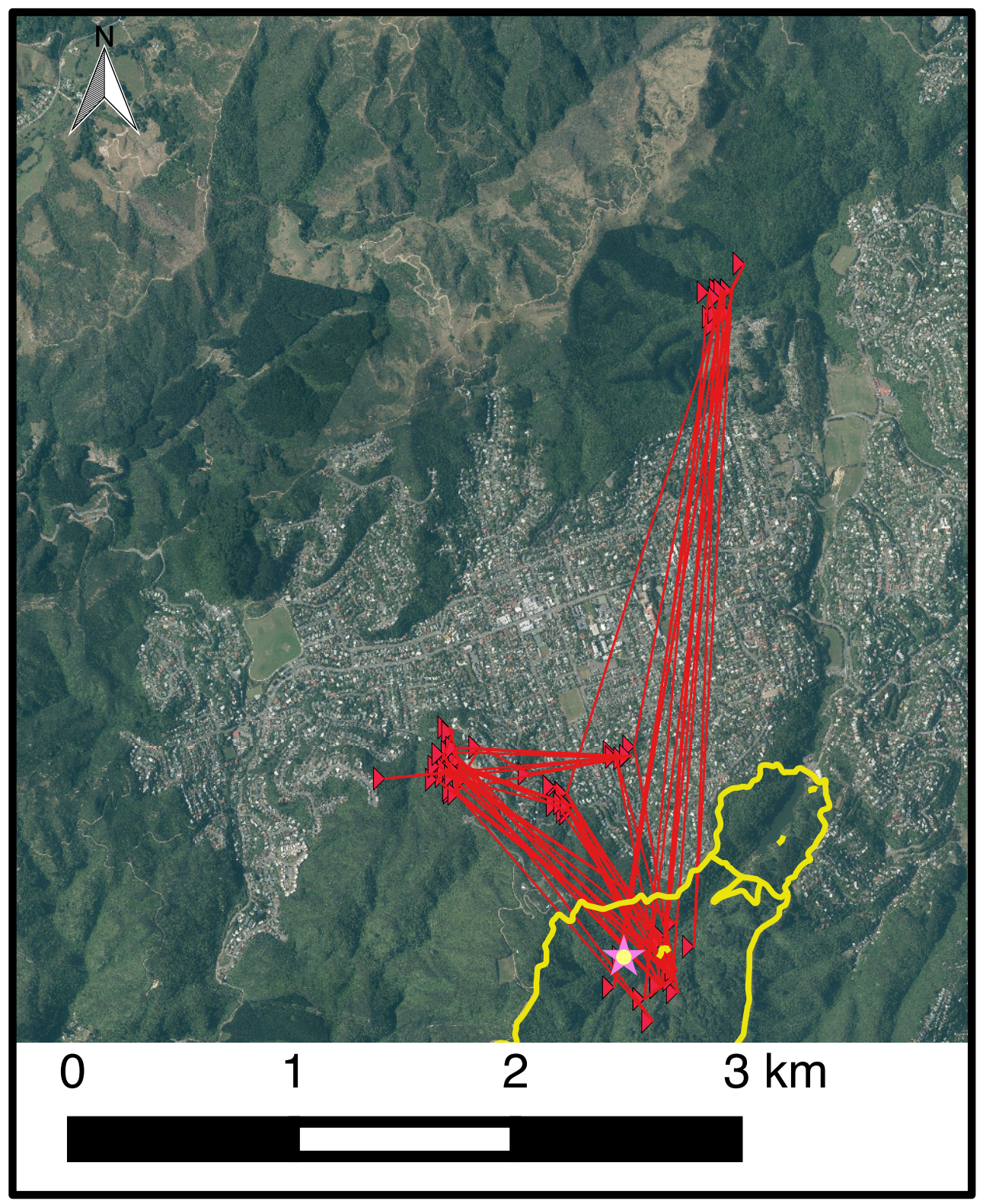

Figure 3.5. Some birds ( $n=2$, both male) never appeared to settle in a particular area, traveling outside the sanctuary each day to forage and returning at night.

ZEALANDIA fence line outlined in yellow, nest point indicated by pink star.

Males tended to disperse farther than females (Figure 3.6; Table 3.1; LMM: $\mathrm{t}=72.14, \mathrm{P}<0.001$ ), and distance dispersed decreased with body condition (Figure 3.7; Table 3.1; LMM: $\mathrm{t}=-13.82, \mathrm{P}<0.001$ ), especially for males (Figure 3.7; LMM: $\mathrm{t}=-$ $5.90, \mathrm{P}=0.002$ ). In addition, birds from a brood of a greater proportion of the opposite sex tended to disperse farther (Figure 3.8; Table 3.1; LMM: $\mathrm{t}=21.21, \mathrm{P}<0.001$ ). The marginal $\mathrm{R}^{2}$ for the dispersal distance LMM was 0.47 (variance explained by the fixed factors) and the conditional $\mathrm{R}^{2}$ (variance explained by the entire model) was 
0.99. In addition, while the term did not appear in the final model, I found that male dispersal distance increased and subsequently dropped off with male parent age (Figure 3.9).

Table 3.1. Results of analysis (LMM) examining factors influencing kakariki postfledging dispersal distance. $\mathrm{K}=$ the number of estimated parameters in the model, $\mathrm{AICc}=$ second-order Akaike information criterion, $\triangle \mathrm{AIC}==[\mathrm{AICC}-\min (\mathrm{AICC})]$, $\mathrm{AICcWt}=$ weight of the model.

\begin{tabular}{lrrrr}
\hline Model & K & AICc & AAICc & AICcWt \\
\hline $\begin{array}{l}\text { Sex*Body condition+Proportion opposite } \\
\text { sex }\end{array}$ & 8 & 44.0 & 0 & 0.97 \\
$\begin{array}{l}\text { Sex*Body condition+Proportion opposite } \\
\text { sex+Hatch date }\end{array}$ & 9 & 51.32 & 7.32 & 0.02 \\
$\begin{array}{l}\text { Sex*Body condition+Proportion opposite } \\
\text { sex+Male parent age }\end{array}$ & 10 & 54.01 & 10.01 & 0.01 \\
Proportion opposite sex & 5 & 62.64 & 18.65 & 0 \\
\hline
\end{tabular}

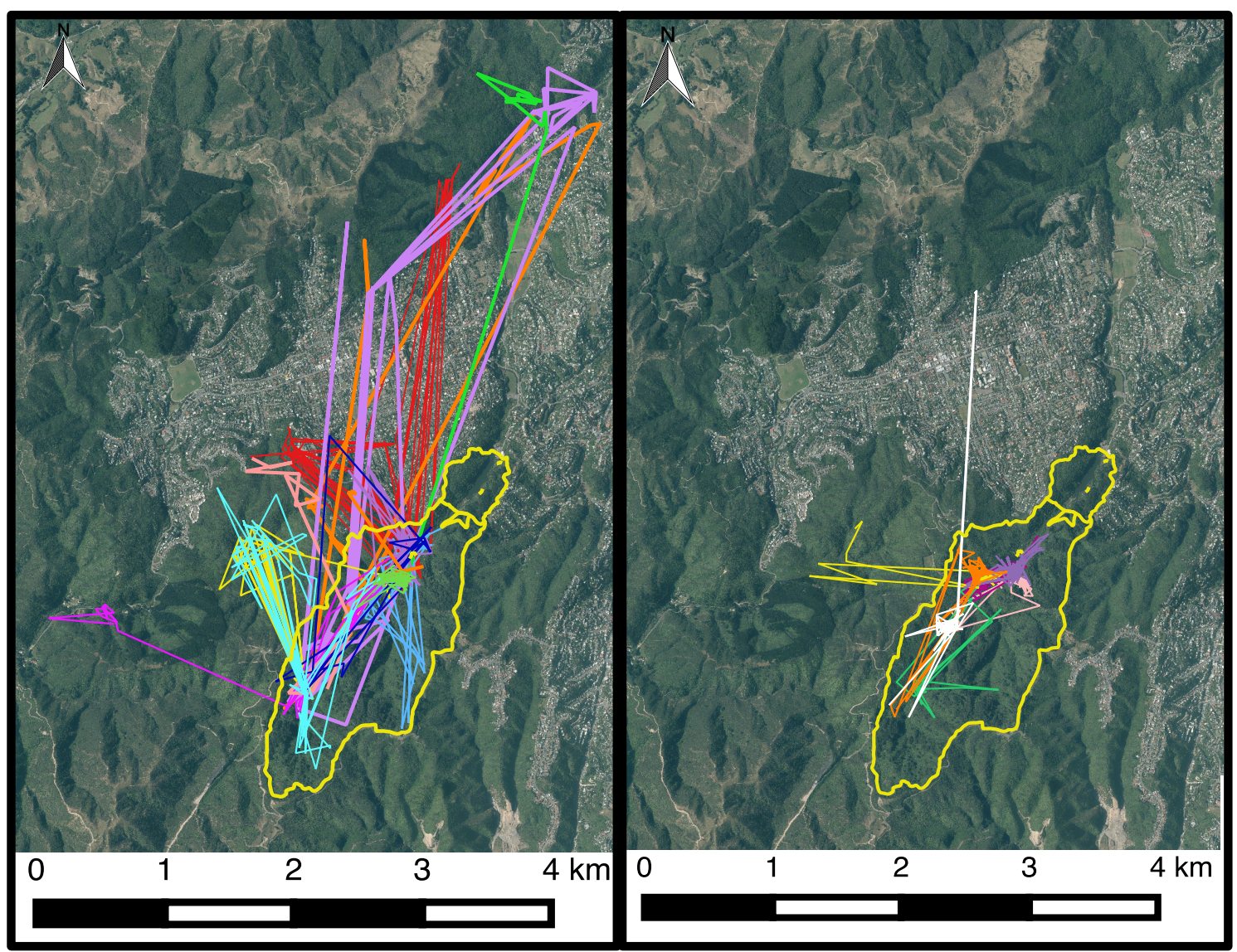

Figure 3.6. Male juvenile kakariki (left) tended to move farther distances than females (right). ZEALANDIA fence line outlined in yellow, each bird represented by a different colored line. 


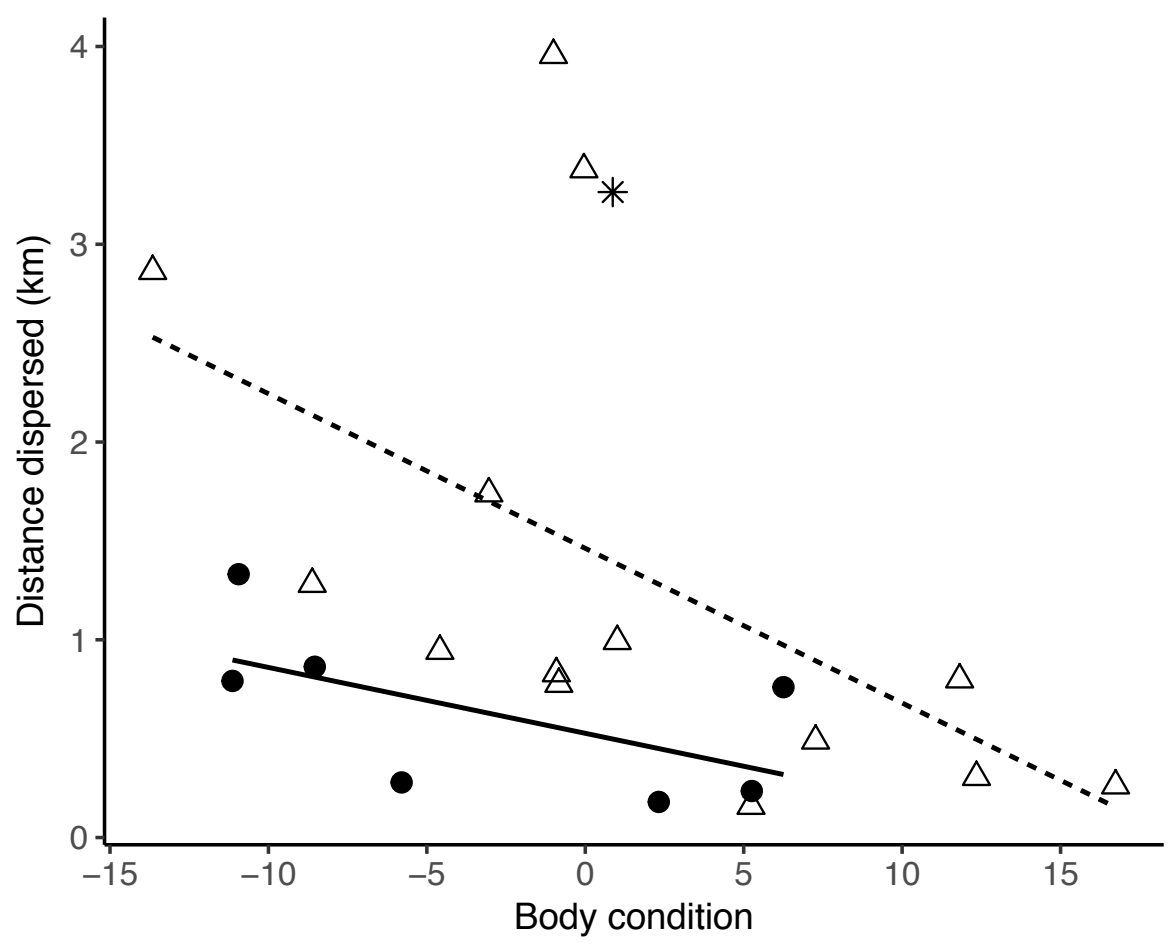

Figure 3.7. Distance dispersed decreased with body condition, particularly for male birds $\left(\mathrm{R}^{2}\right.$ (male) $=0.47$, dotted line; $\mathrm{R}^{2}$ (female) $=0.34$, solid line). Triangles denote male birds, circles females, star indicates bird of unknown sex.

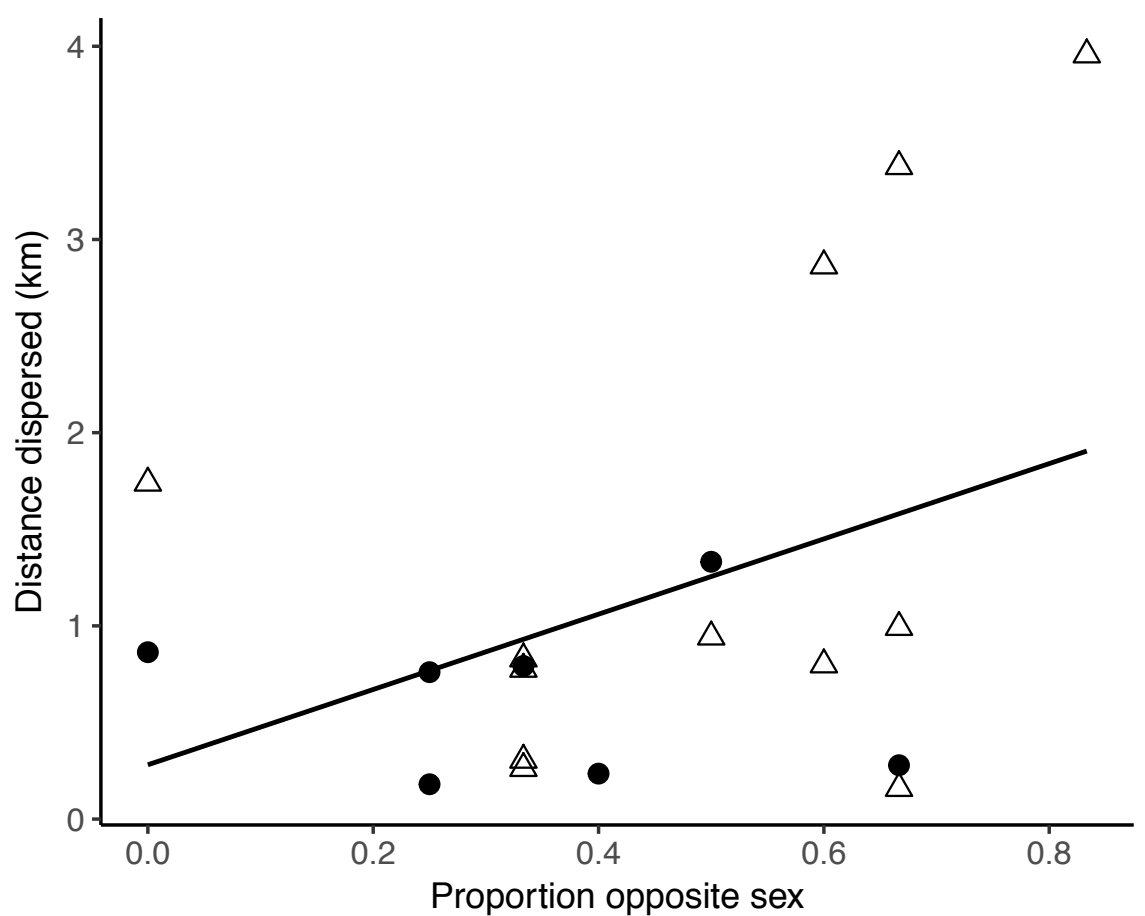

Figure 3.8. Distance dispersed increased with the proportion of the opposite sex in the tracked bird's brood $\left(\mathrm{R}^{2}=0.16\right)$. However, the trend was driven by male birds $\left(\mathrm{R}^{2}\right.$ $($ male $)=0.19)$ rather than both sexes $\left(\mathrm{R}^{2}\right.$ female $\left.)=0.02\right)$. The lack of an interaction between sex and proportion opposite sex was likely due to small sample size and convergence issues in the model when too many terms were included. Triangles denote male birds, circles females. 
Chapter 3

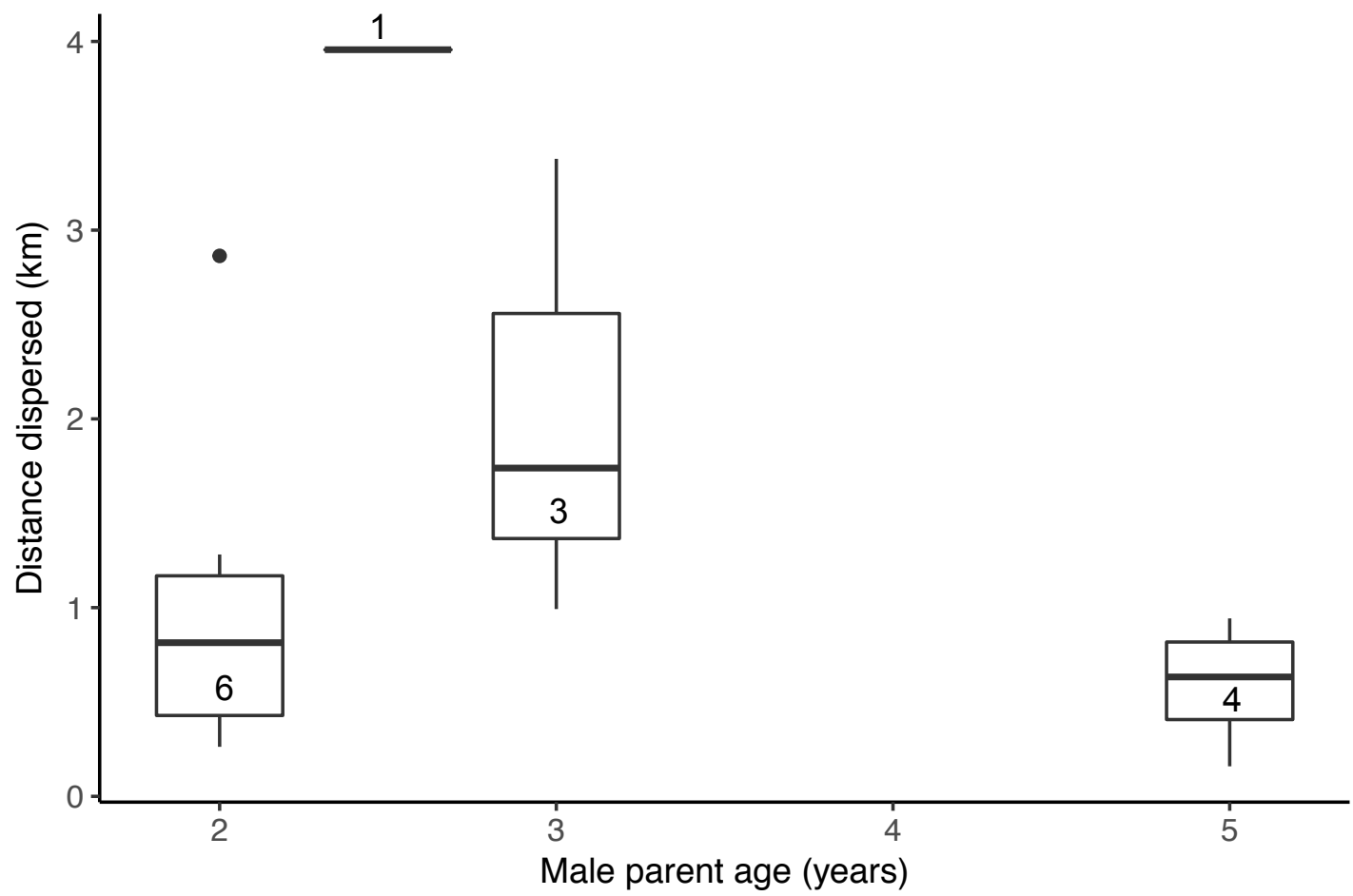

Figure 3.9. Dispersal distance of juvenile males increased and then dropped off with male parent age. Numbers inside boxes indicate sample size.

Kakariki activity area decreased with hatch date (Figure 3.10; LMM: $\mathrm{t}=-2.39$, $\mathrm{P}=0.03$ ); however, this model was only slightly better than the null model (Table 3.2). The marginal $\mathrm{R}^{2}$ for the model was 0.25 as was the conditional $\mathrm{R}^{2}$ was 0.25 , indicating the random effects explained little or none of the model variance. 
Table 3.2. Results of analysis (LMM) on factors influencing kakariki activity area. $\mathrm{K}=$ the number of estimated parameters in the model, $\mathrm{AICc}=$ second-order Akaike information criterion, $\triangle \mathrm{AIC}=[\mathrm{AICC}-\min (\mathrm{AICC})], \mathrm{AICcWt}=$ weight of the model.

\begin{tabular}{lllrr}
\hline Model & K & AICc & $\Delta$ AICc & AICcWt \\
\hline Hatch date & 6 & 81.61 & 0 & 0.41 \\
Null (1+Number Points) & 5 & 82.23 & 0.62 & 0.30 \\
Sex & 7 & 84.44 & 2.83 & 0.1 \\
Hatch date+Sex & 8 & 85.63 & 4.02 & 0.06 \\
Male parent age & 7 & 86.27 & 4.66 & 0.04 \\
Body condition & 6 & 86.37 & 4.76 & 0.04 \\
Hatch date+Body condition & 7 & 86.78 & 5.17 & 0.03 \\
Sex*Hatch date & 9 & 89.71 & 8.10 & 0.01 \\
Hatch date+Male parent age & 8 & 89.74 & 8.13 & 0.01 \\
Female parent age & 7 & 90.09 & 8.48 & 0.01 \\
Hatch date+Female parent age & 8 & 92.46 & 10.85 & 0 \\
\hline
\end{tabular}

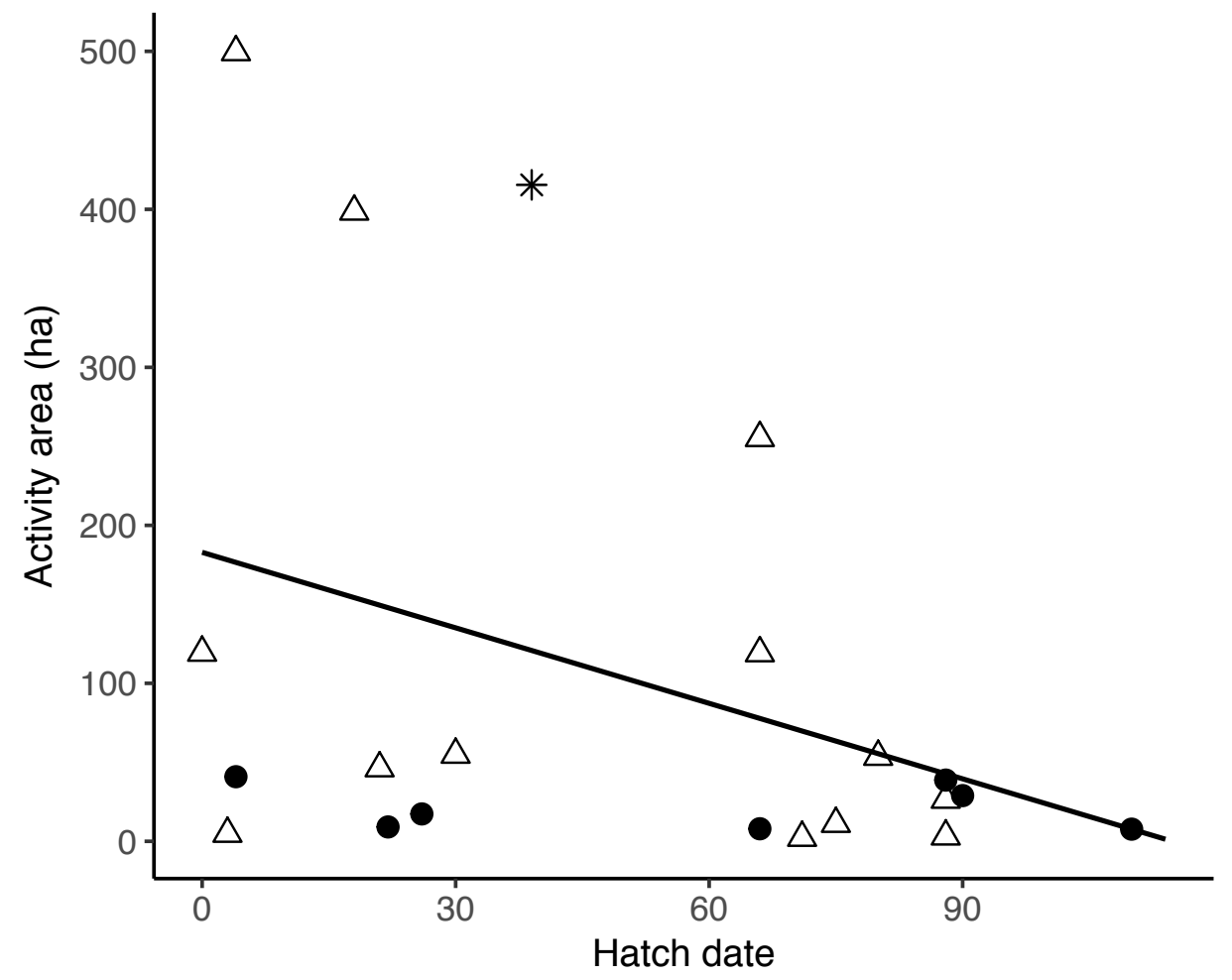

Figure 3.10. Activity area decreased with hatch date for juvenile kakariki $\left(\mathrm{R}^{2}=0.14\right)$, with the pattern primarily driven by males $\left(\mathrm{R}^{2}(\right.$ male $)=0.20, \mathrm{R}^{2}$ (female $\left.)=0.02\right)$. The lack of an interaction between sex and hatch date was likely due to small sample size and convergence issues in the model. Triangles denote male birds, circles females, star indicates bird of unknown sex. 
Chapter 3

In 2016, most key kakariki food sources were available from approximately February-May, peaking around March/April (Figure 3.11). Mapou fruit, however, only became available in August/September (Figure 3.11). In early April, four kakariki appeared to target totara trees outside the sanctuary (Figure 3.12), as the totara in ZEALANDIA produced little fruit in 2016.

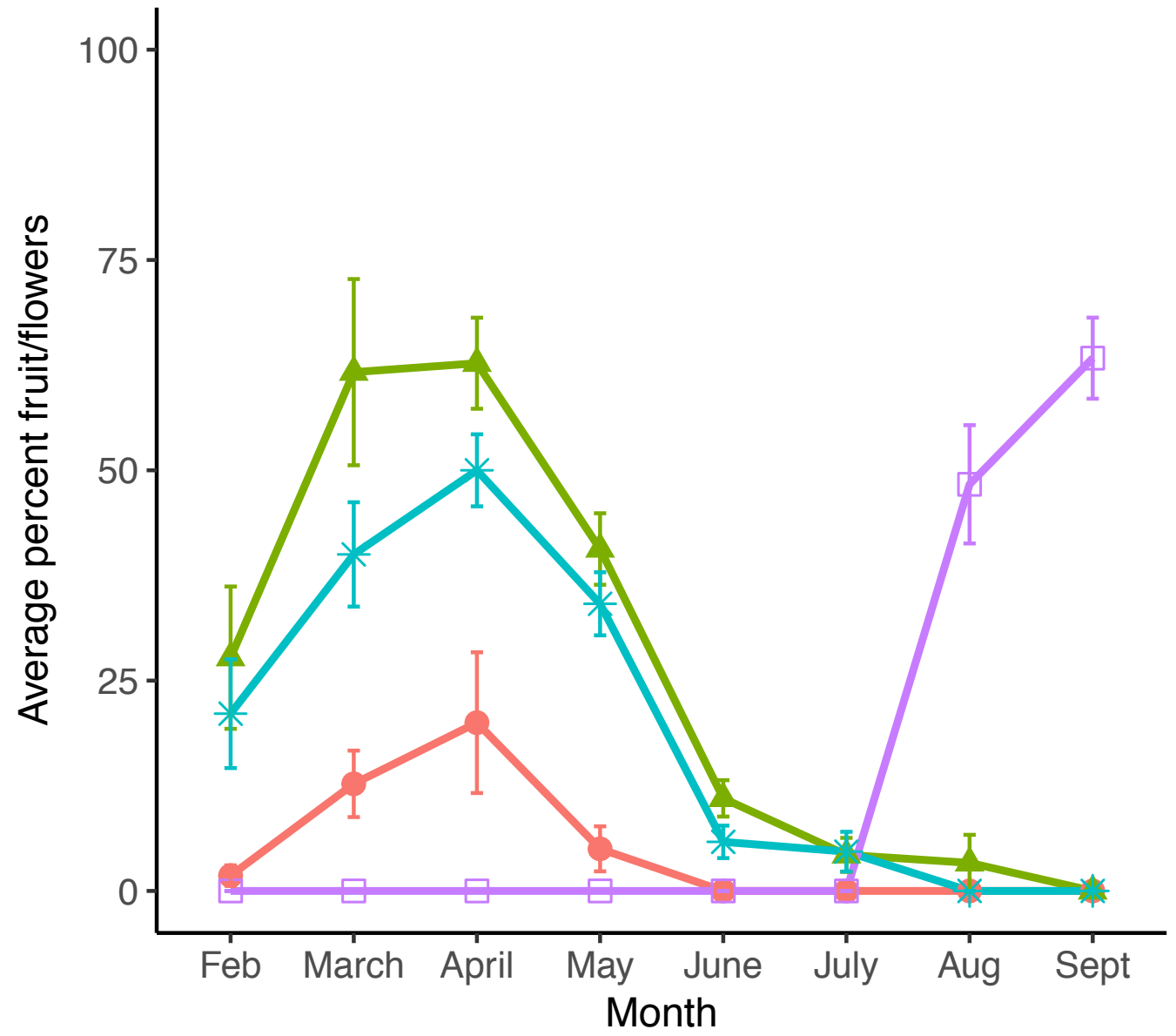

Figure 3.11. Key kakariki food sources like Muehlenbeckia (green triangles), fivefinger (blue stars), and totara (red circles) were available in late summer through autumn, with the exception of mapou (purple squares), which was available in late winter and spring. Five-finger also produced flowers in winter which kakariki were observed feeding on; however, only five-finger fruit was recorded. Error bars represent $\pm 1 \mathrm{SE}$. 


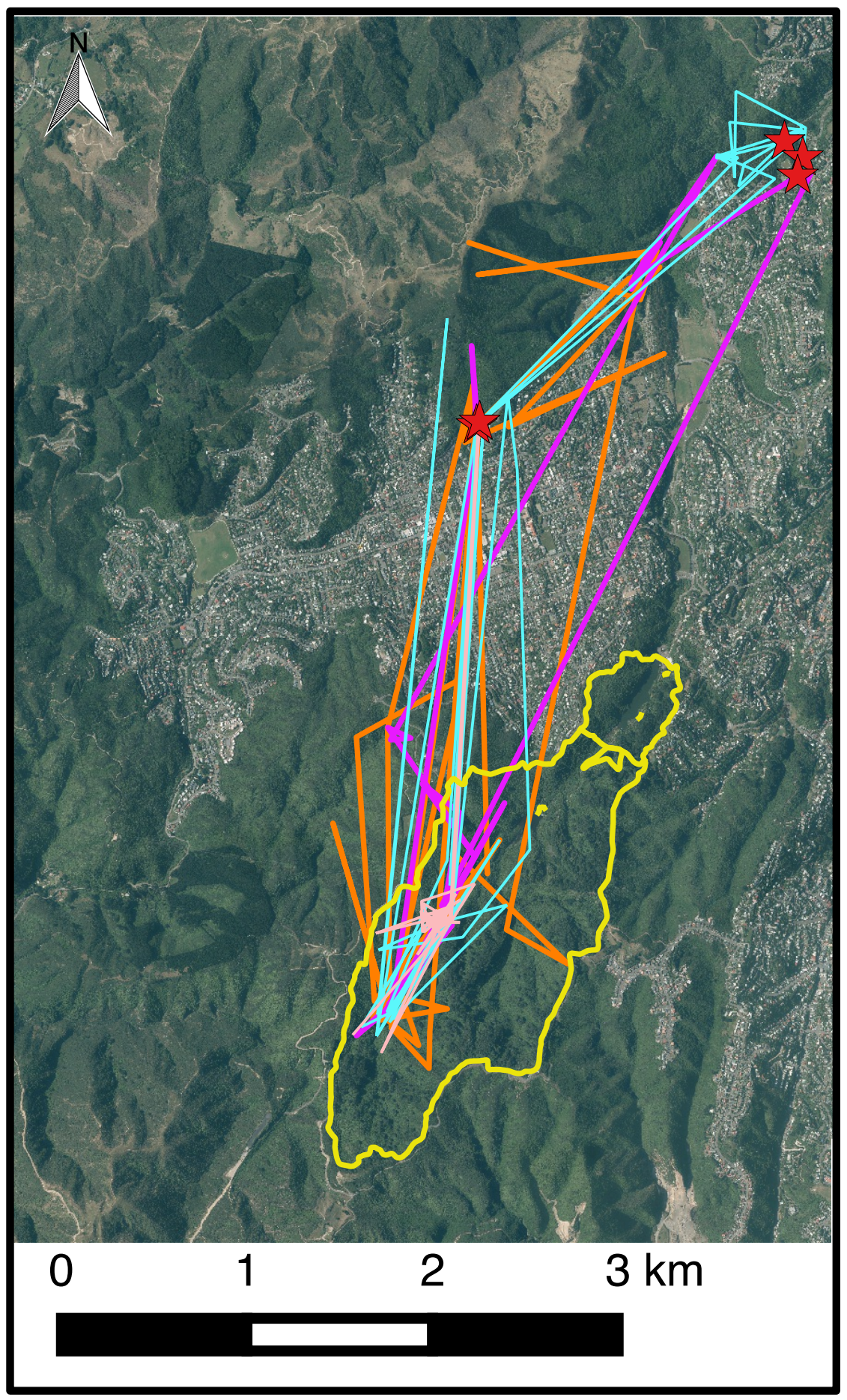

Figure 3.12. Four kakariki targeted totara trees in early April while the trees were producing fruit. ZEALANDIA fence line outlined in yellow, each bird represented by a different colored line.

The sanctuary had 29 reports of dead kakariki both inside $(n=5)$ and outside (24) the sanctuary (Appendix 3). Of those whose sex was known (27 of 29), 77.8\% were male and $22.2 \%$ were female. Overall, juvenile males comprised the greatest 


\section{Chapter 3}

number of records (59\%) (Figure 3.10), and most (64\%) of records for juveniles overall occurred between February and April. Over half (5/9) of the adult records were of birds transferred from Kapiti that were killed within a few weeks or months after translocation.

Of birds outside the sanctuary whose cause of death was known, nearly $70 \%$ $(n=10)$ were killed by predators, mostly by cats $(n=5)$, and one record each for a mustelid, rat, and avian predator, as well as two unknown predator kills. The next most common cause of death was crashing into a window $(19 \% ; n=3)$ followed by being hit by a car $(12 \% ; n=2)$. Data were compiled by Richard Gray from 2010-2016.

\section{Discussion}

Male juvenile kakariki tended to disperse farther from their natal area than females. Dispersal distance increased with the proportion of siblings that were the opposite sex, and decreased with body condition for males in particular. Kakariki hatched earlier in the season also tended to have larger activity areas. Finally, between 27$45 \%$ of kakariki that permanently dispersed outside the sanctuary were killed by predators, similar to the $33 \%$ of those killed outside the sanctuary in 2015 . No birds in the 2015 or 2016 dispersal studies that remained within the sanctuary died during the study period. Predation was also the leading cause of reported kakariki deaths outside the sanctuary according to ZEALANDIA records. The majority of birds that were confirmed dead from both sets of data were juvenile males.

\section{Are kakariki surviving outside the sanctuary?}

Although some of the birds that left the sanctuary did not die during the study period, losing a third or more of the juveniles that did in just a few months does not bode well for long-term kakariki population re-establishment in Wellington. Predation was the greatest issue for kakariki over the fence line according to both the telemetry studies and ZEALANDIA's records. Juvenile birds typically have high mortality rates, with predation often responsible for many of the deaths (Nilsson and Smith 1985; Naefdaenzer et al. 2001; Martín et al. 2008; Faccio et al. 2013; Sim et al. 2013). However, kakariki are unused to the introduced mammalian predators, and are particularly 
vulnerable due to their habits of feeding on the ground and nesting in cavities (Pratt et al. 1987; O’Donnell 1996; Higgins 1999).

Cats were the most commonly reported predator of kakariki, which makes sense given many of the areas surrounding ZEALANDIA are neighborhoods full of domestic cats: New Zealand has the highest recorded rate of cat ownership in the developed world (Mackay 2011). However, just because cats were the most reported predator does not mean they in fact kill the most kakariki. People may just be more likely to find birds killed by cats because cat kills are often close to houses or on people's lawns. At least two birds were reportedly killed by a rat and a mustelid, and mustelids often cache their prey, making bodies difficult to find (Cuthbert 2003). These predators may therefore still represent a large threat to kakariki population establishment outside ZEALANDIA, particularly to females when they are incubating or brooding young nestlings, as they cannot escape from their nest cavity.

As kakariki are prolific breeders and juveniles that remain within the sanctuary appear to enjoy high survival rates, it is unlikely that the ZEALANDIA population itself will crash. In fact, the high loss of male juveniles is likely to have less effect on population success than losses of females or experienced older males. However, the level of predation outside the sanctuary may be unsustainable for population establishment in Wellington.

\section{Where are kakariki going, and why?}

Half of the tracked birds dispersed (left and did not return) outside of ZEALANDIA. Outside the sanctuary, kakariki primarily targeted reserves and other forested areas, although I occasionally observed them foraging in backyards or in neighborhoods with a lot of native bush. As noted above, dispersal also appeared to be male-biased: of the eleven birds that dispersed outside the sanctuary, nine were male, one was unknown but likely male, and only one was female, and overall males tended to disperse farther distances from their natal area. Data on kakariki breeding dispersal (the movement between breeding sites) also supports this pattern: in pairs that divorce, males tend to travel farther than females to their next nest site, possibly indicating that females are overall more philopatric (Chapter 2). That males tended to disperse farther distances if they had a greater proportion of female siblings suggests that inbreeding avoidance could drive kakariki dispersal, i.e. males may travel farther 
distances to avoid breeding with their sisters. While there was no interaction with sex and proportion opposite sex in the final model, this was likely due to the small sample size and convergence issues when too many fixed effects were added, as males clearly drove that trend.

Body condition was also a factor, as birds - males in particular - in better body condition dispersed shorter distances from their natal site. At feeders around ZEALANDIA, larger males are often more dominant and are able to chase away other birds to get the best food for themselves. In addition, both the number of nests and number of breeding pairs in the sanctuary has remained relatively constant over the last three years (Chapter 2), and the recruitment of juveniles in 2014/15 into the ZEALANDIA population was only $3 \%$, as opposed to $38 \%$ in $2012 / 13$ and $26 \%$ in 2013/14 (Gray 2016). These observations suggest that the kakariki population may be at or nearing its carrying capacity within the sanctuary. The constrained resources (whether food or nest sites) may have led to increased competition within the sanctuary, whereby only the larger and/or healthier juveniles were able to successfully compete with adult and juvenile kakariki in ZEALANDIA.

Finally, while not in the final model, I found that dispersal distance for juvenile males increased then dropped off with male parent age when males were around five years old (a similar though less distinct pattern was found for female parent age). Older, experienced male parents could be producing better quality offspring, able to compete to remain closer to their natal area. Older males do tend to produce larger male offspring, possibly due to greater experience and ability to provision their mate and chicks (Chapter 2). However, I found no relationship between juvenile body condition or nestling weight and male parent age among the tracked birds. Males could be passing on other qualities or offspring could be copying their fathers' dominant behavior. Alternatively, offspring dispersal may be related to impending parental senescence (Ronce et al. 1998; Zedrosser et al. 2007). If kakariki males are reaching senescence around age five or six - a possibility given the increased nest failure around that time (Chapter 2) - their male offspring may be more likely to stay closer to their parents' territory as they may have a chance to take it over after their parents die or stop breeding (Ronce et al. 1998). 


\section{Effects of seasonality and phenology}

Kakariki had three different movement patterns. Many birds remained relatively close to their natal area, sometimes only a few hundred meters away, for the whole of the study period. These were primarily the females and males in good body condition. Other birds, mostly males in poorer body condition, moved much farther $(>1.5 \mathrm{~km})$ from their natal area. Two birds moved in and out of the sanctuary, typically going out during the day to forage and then returning at night. Both of these birds were in good body condition, so while settled in the sanctuary for some of the time, they may have been attracted by favored food sources outside ZEALANDIA (e.g. kahikatea). Kakariki were also creatures of routine: they were regularly found in the same small area for several weeks or months until they had possibly depleted or tired of the food sources there, and then moved on to a different spot.

Some birds clearly moved around more than others while foraging: the linear mixed model indicated that hatch date might have influenced kakariki activity area, as birds (primarily males) tended to use a greater area if hatched earlier in the season. However, this model was only slightly better than the null, possibly because I included the number of points used to make the MCP as a fixed factor while excluding three birds from the analysis; my sample size was therefore diminished while the number of fixed factors was increased. The negligible variance of the random factors was also suspect, as were the convergence issues-likely due to the small sample size - in many of the tested models, though not the final one. Nevertheless, while the model may be problematic, male activity area did decrease somewhat with hatch date, something also observed in 2015.

This pattern was likely driven both by the greater amount and variety of food sources available earlier in the season, and that many of those favored food sources were located farther away. Kakariki are generalist feeders, and were observed feeding on a wide array of plants, mostly natives, with the exception of two species of rhododendron. However, kakariki did have their favorite food sources. As in 2015, kakariki appeared to target totara while the trees were fruiting in March/April. While ZEALANDIA has several large totara trees, little fruit was seen on them in 2016; much more was observed on a few patches of large totara outside the sanctuary. During a span of a few weeks four of the birds, including one female, traveled daily from the sanctuary to a reserve approximately two kilometers away that contained a stand of large totara. As the birds appeared to travel very precisely to that area and 


\section{Chapter 3}

back to the sanctuary, there was likely some information exchange between juvenile and adult kakariki- unsurprising given their tendency to feed in flocks. One juvenile, possibly following adults that knew the area, ventured out there earlier in the season just for one day before the trees were fruiting as though to check on the status of the trees - other kakariki from the sanctuary have been observed doing this (Matu Booth pers. comm.).

Similarly, one of the males tracked in 2015 traveled back and forth daily from the sanctuary to a patch of totara trees for months, whereas birds hatched closer to winter barely moved, foraging within a very small area. The 2015 study was also started much later (in April rather than in January), so I likely missed some of the birds that may have dispersed farther earlier in the season, as the ones that traveled $>3$ $\mathrm{km}$ from the sanctuary in 2016 generally dispersed in February or March. It should also be noted that in 2016 totara in Wellington produced very little fruit compared to previous years (Chris Gee pers. comm.), so the influence of totara on kakariki movements was likely diminished compared to other years.

Further illustrating the potential effect of seasonality, one bird traveled daily between a reserve and the sanctuary (a distance of $\sim 3 \mathrm{~km}$ ) earlier in the season, likely feeding primarily on kahikatea fruit, but during winter it only foraged in areas $\sim 1 \mathrm{~km}$ from the sanctuary. For kakariki in winter, there is no point in traveling far to forage if favored food sources (e.g. totara, kahikatea) are not available, as there is plenty of adequate food close by. During winter I observed kakariki regularly feeding on the ground, likely on seeds, both inside and outside ZEALANDIA.

\section{Context with other species}

Generally birds exhibit female-biased dispersal (Greenwood 1980; Greenwood and Harvey 1982; Clarke and Heathcote 1990; Forero et al. 2002; Dingemanse et al. 2003; Serrano et al. 2003; Withey and Marzluff 2005; Bradley et al. 2011; Eldegard et al. 2014). It is thought that sex-biased dispersal in birds may result from their resourcedefense mating system in which males gain and defend territories: as males are more dependent on the local resources, they will benefit from a familiarity with the area, and therefore it may be more advantageous to remain closer to their natal site (Greenwood 1980; Serrano et al. 2003). However, the kakariki mating system may not be resource-defense based. Kakariki share many similarities with other avian 
exceptions to the female-biased dispersal rule, which are mostly in the family Anatidae and exhibit male-biased natal and breeding dispersal and female philopatry (Greenwood 1980; Greenwood and Harvey 1982). Like many of those species, kakariki pair bonds often form well before the start of the breeding season (Greene 2003), and the mating system does not appear to be one in which males defend resources to attract females (resource-defense). While kakariki may sometimes chase away other birds at feeders, they are gregarious and often feed in large groups, so birds may not defend resources per se, with the exception of the area immediately around the nest site (Pratt et al. 1987). Rather, kakariki may have a female or matedefense mating system, in which males attempt to maximize their access to females.

Therefore, the results of this study do not necessarily contradict Greenwood's (1980) review. It is also important to note that some have disputed his theory: Clarke et al. (1997) identified additional avian species outside Anatidae that exhibited malebiased dispersal, including species from a wide variety of breeding systems, and suggested that these could not all be divided into mate-defense versus resourcedefense mating systems. Furthermore, Mabry et al. (2013) tested Greenwood's theory with a phylogenetic analysis in mammals and birds, and while finding some evidence for a relationship between mating systems and sex-biased dispersal in mammals, found no support of such a relationship in birds.

Others have suggested that sex-biased dispersal is primarily a response to avoid breeding with kin (reviewed by Pusey 1987; Cockburn et al. 2003; Szulkin and Sheldon 2008), which is also a likely driver of kakariki dispersal. Szulkin and Sheldon (2008) suggested that dispersal functioned as a mechanism for inbreeding avoidance in the great tit (Parus major), as individuals that bred with a relative dispersed much shorter distances that those that did not. Cockburn et al. (2003) also found that female dispersal in the superb fairy-wren (Malurus cyaneus) could prevent incest, as females dispersed regularly and never bred on their natal territory. There have been three recorded instances of siblings at ZEALANDIA breeding together. One of these pairs failed to hatch let alone fledge chicks despite repeated nesting attempts, while the other two pairs successfully fledged a number of chicks, including three used in this study (Chapter 2). Although there may have been more instances of incest as the relatedness of the original translocated birds was not known, the low number of sibling pairings out of the many observed may result from the use of malebiased dispersal as a way to avoid inbreeding. 
Inbreeding avoidance, however, is rarely the sole factor behind dispersal (Perrin and Mazalov 1999). As in kakariki, body condition has commonly been found to influence dispersal (Nilsson and Smith 1985; Pasinelli and Walters 2002; Barbraud et al. 2003; Zedrosser et al. 2007; McCauley 2010). While in some species, individuals with better body condition are the ones to disperse farther, likely because they can better cope with the energetic demands of dispersal (Nilsson and Smith 1985; Barbraud et al. 2003), in many others, dispersers tend to be smaller and subdominant (Gese et al. 1996; Pasinelli and Walters 2002; Zedrosser et al. 2007; McCauley 2010). For example, Pasinelli and Walters (2002) observed that in male red-cockaded woodpeckers (Picoides borealis) dispersing male fledglings had significantly lower body mass than their dominant, philopatric siblings.

Finally, the urbanized environment surrounding ZEALANDIA likely influenced kakariki movements. In order to reach fruiting totara, birds were forced to fly several kilometers over suburban areas. Habitat fragmentation, like that due to urbanization, has been found to increase dispersal distance, as individuals must travel greater distances to reach suitable habitat (Diffendorfer et al. 1995; Matthysen et al. 1995; Baguette et al. 2003; Willson 2004; Martín et al. 2008). For example, Thaxton and Hingtgen (1996) compared the dispersal behavior of Florida scrub-jays (Aphelocoma coerulescens) in undeveloped preserves and fragmented suburban habitat, and found that females dispersed much greater distances from suburban areas, likely due to habitat fragmentation and the lack of nearby breeding opportunities. Furthermore, no birds dispersed from preserves to suburban areas, presumably due to the less appealing, degraded habitat there (Thaxton and Hingtgen 1996). In Wellington, fragmentation may have increased both dispersal distance as well as activity area, as birds had to travel farther to reach favored food sources or areas with native bush, which appeared to be their preferred habitat. Dispersers often have a higher risk of mortality, and this risk can be increased in a developed or urbanized landscape (Thaxton and Hingtgen 1996; Johnson et al. 2009; Bonte et al. 2012). This was certainly true for kakariki, as dispersers had to face not only invasive predators, but also windows and cars, which resulted in the deaths of several birds according to ZEALANDIA records.

Birds, however, were willing to fly the distance for food sources like totara. Previous studies have found that kakariki may be very selective for particular food items: on Burgess Island, for instance, Bellingham (1987) observed that fruit and 
certain seeds consisted of $40 \%$ of the birds' diet despite being relatively scarce on the island. While kakariki may just have a strong preference for totara fruit, favored food sources also have been linked to breeding success in other species. For example, one female kakapo (Strigops habroptilus) on Little Barrier Island purposefully nested close to the only known female kahikatea on the island, and used it as her main food source during nesting (Leigh Joyce pers. comm.). Researchers have also observed that kakapo breeding activity, as well as that of other native birds including kakariki, appears to be related to the masting of particular native trees, e.g. certain podocarp tree species like kahikatea and rimu (Powlesland et al. 1992; Greene 2003; Leigh Joyce pers. comm.). Kakariki, hihi and kaka breeding in the sanctuary were all extremely productive in 2013/14 (Gray 2016), a mast year in New Zealand (Environmental Protection Authority 2014). Given that climate change could influence the success of some masting plant species through increased storm events and precipitation (Lundquist et al. 2011; Leigh Joyce pers. comm.), it may also present future problems for many New Zealand birds, including kakariki.

\section{Limitations}

One of the primary limitations of this study was sample size. I had an unbalanced design in terms of sex, with fourteen males, seven females and one unknown. Therefore, female patterns of dispersal may have been missed or masked by the greater number of males. Furthermore, when examining dispersal distance versus proportion opposite sex, my sample size was even smaller as I excluded two birds that had no siblings and one bird whose sex was undetermined. Therefore the pattern should be further investigated with a larger sample size.

Another limitation was that I did not track the birds long enough to determine where they bred (natal dispersal). Some of the juveniles may not have permanently settled in the areas in which they were found during the study period. Furthermore, as several of the juveniles died or removed their transmitters, not all birds were tracked for the same length of time, and those tracked for a shorter period may have eventually settled in a different area, perhaps even returning to the sanctuary to breed. Some of the factors that I found to be potentially influencing post-fledging dispersal therefore may not apply if examining dispersal all the way to the first breeding site. 


\section{Future Research}

Natal dispersal in kakariki is still yet to be studied. It is generally thought that natal dispersal is longer than breeding dispersal (the movement between breeding sites) (Greenwood and Harvey 1982), and this does appear true for post-fledging dispersal in kakariki. Breeding dispersal in kakariki, at least in ZEALANDIA, was usually $<100 \mathrm{~m}$, and many pairs bred at the same site multiple times over the years (Chapter 2 ). The movements measured in this study could represent natal dispersal for some of the birds, as several of the birds tracked in 2015 bred or were thought to have bred in the same area they frequented when tracked. However, these birds were ones that remained within ZEALANDIA during the study period, and while it is likely that at least some of the 2016 birds that remained in ZEALANDIA will also breed there, we have no information on where the birds that left the sanctuary bred. Exploring patterns for kakariki natal dispersal would be helpful for future translocations, in determining where and how far kakariki typically travel to breed. Given the high predation rates outside the sanctuary, it is vital to make safe areas that kakariki commonly breed in. Therefore, with a greater understanding of natal dispersal, conservation initiatives could focus on both securing the areas kakariki are currently breeding in, and undertaking work to attract birds to safer areas.

Future research should also explore the possibility for parental effects in kakariki dispersal. Juvenile male dispersal distance dropped off with male parent age. However, the sample size of tracked birds was small and should be tested with a larger sample size. Further investigation should also be done to determine the mechanism by which parents may influence dispersal. While several studies have suggested that reduced dispersal may be related to the senescence of the parent (Ronce et al. 1998; Zedrosser et al. 2007), others have found that offspring dispersal may be influenced by the genotype of the father (Sinervo et al. 2006), or even maternal effects in response to parasitism (Tschirren et al. 2007).

Finally, while there was no noticeable difference in the body condition or behavior from the tracked birds whose parents were siblings, there nevertheless could be other unseen consequences to the birds' fitness. Inbreeding can influence individual survival, reproduction, and resistance to disease and predation, and can lead to reduced population growth and an increased risk of extinction (reviewed by Keller and Waller 2002). Future studies should therefore examine the repercussions of inbreeding in kakariki. 


\section{Management Recommendations}

At least three of the birds in 2015/16 were killed after approximately a week after leaving the sanctuary. In addition, many of the recorded juvenile deaths occurred in February-April, when many plants are flowering or fruiting and recently fledged juvenile males are just leaving the sanctuary. Conservation initiatives could therefore increase predator control and encourage cat owners to keep their cat indoors more often during those months, particularly in areas and around trees (e.g. totara) frequented by kakariki. In addition, using the information on where the birds went and what food sources they preferred, conservationists could attract kakariki to particular areas (e.g. ones with predator control) by planting more native bush, particularly plants favored by kakariki. Given that most of the recorded kakariki deaths were due to the effects of urbanization (e.g. invasive predators like cats, window crashes, cars), encouraging the birds to go to forested rather than developed areas will likely reduce kakariki mortality outside the sanctuary. Furthermore, corridors of native bush could also act as pathways to allow kakariki to move safely throughout and eventually beyond the Wellington region. 
Chapter 3 


\section{Chapter 4}

\section{General Discussion}

With habitat destruction, climate change, and other human impacts contributing to range contractions in species, translocations stand out as an important tool for conserving and shielding affected species (Griffith et al. 1989; Kleiman 1989; Towns and Daugherty 1994; Mumme and Below 1999; Channell and Lomolino 2000; Tweed et al. 2003; Laliberte and Ripple 2004; Parmesan 2006; IUCN/SSC 2013; Miskelly and Powlesland 2013; Bell 2016). However, an understanding of the life history of many threatened species that could benefit from translocation is often lacking (Caughley 1994; Sarrazin and Barbault 1996). A priori knowledge of a species' breeding biology, for example, can aid translocation efforts to successfully establish a self-sustaining population by informing translocation method and practice (Powlesland and Lloyd 1994; Sarrazin and Barbault 1996; Sutherland 1998; Castro et al. 2003; Sigg et al. 2005). Insight into the dispersal patterns of a species is also critical for translocations, as dispersal away from the release site-particularly when the site is a managed sanctuary or protected area - can result in translocation failure (Clarke and Schedvin 1997; Stamps and Swaisgood 2007; van Heezik et al. 2009; Van Houtan et al. 2010; Bradley et al. 2011; Rickett 2010; Armstrong et al. 2013; Müller et al. 2014). With this in mind, I conducted a study examining the breeding biology and post-fledging dispersal of a population of red-crowned parakeets (Cyanoramphus novaezelandiae), or kakariki, recently translocated to a fenced mainland sanctuary in Wellington, New Zealand.

Using a dataset collected by ZEALANDIA staff on kakariki breeding since the first translocation in 2010, I found evidence that parent age could influence reproductive success. Nesting success, for example, increased with parent age before dropping off at around 5-6 years, and older males tended to fledge fewer chicks. Estimates of lifetime reproductive success indicated upwards of 30 fledglings could be produced by age five. Kakariki breeding dispersal was on average $<100 \mathrm{~m}$, although it was greater for divorced birds, particularly divorced males. The population 
in ZEALANDIA may also be reaching its carrying capacity, limited by nest sites, as the number of breeding pairs was relatively constant the last few years.

I also examined post-fledging dispersal through a radio-telemetry study of juvenile kakariki, and found it ranged from $150 \mathrm{~m}$ to almost $4 \mathrm{~km}$. Post-fledging dispersal was male-biased, possibly driven by inbreeding avoidance, and birds in poorer body condition tended to disperse further. There was also some evidence that parent age could influence dispersal, as juvenile males with older fathers tended to remain closer to home. Seasonality may have also influenced movement, as birds hatched earlier in the season tended to have a larger activity area, potentially due to the phenology of favored food sources located outside the sanctuary. Finally, approximately one-third of birds tracked in 2015 and 2016 that dispersed outside the sanctuary were killed by predators, while no tracked birds that remained within ZEALANDIA died in either year during the study period.

Unlike many other avian species, male kakariki tended to disperse farther distances than females in both post-fledging and breeding dispersal. Both could be influenced by the mating system of kakariki, which seems to be driven by female or mate-defense rather than resource-defense. Kakariki pair bonds form before the start of the breeding season, and males do not appear to secure particular food sources or territories per se - although pairs do tend to nest in the same area year after year (Pratt et al. 1987; Higgins 1999; Richard Gray pers. comm.). Males may therefore be driven to move in an attempt to increase their access to females, that is, male movement could be directed by female dispersion patterns. Inbreeding avoidance may have also played a role, as juvenile males with a higher proportion of female siblings dispersed farther. Inbreeding avoidance has been a likely factor motivating avian dispersal, and has been found to prevent incest (Cockburn et al. 2003; Szulkin and Sheldon 2008). The three known cases of incest among kakariki siblings suggests that kakariki may not be able to recognize their relatives, making dispersal all the more important as a mechanism for preventing inbreeding.

Parental age may have also had multiple influences on kakariki life history. Changes in reproductive success as well as effects on offspring mediated via parental age have been documented in a variety of bird species (e.g. Blank and Nolan 1983; Sydeman et al. 1991; Bouwhuis et al. 2010). If kakariki reproductive success does in fact begin to decline around 5-6 years - possibly indicating they are reaching senescence - then it may make sense for them to have offspring that are more 
philopatric, as their offspring can then take over the territory after the parents have died or stopped breeding. This pattern has been observed in other species (Ronce et al. 1998; Zedrosser et al. 2007). For example, Zedrosser et al. (2007) found that the dispersal probability of female brown bears (Ursus arctos) decreased with maternal age as well as body size.

\section{Conservation Implications and Recommendations}

The largest issue kakariki currently face in Wellington is likely predation. In both 2015 and 2016, approximately one-third of tracked birds that dispersed outside ZEALANDIA were killed by predators, and ZEALANDIA records indicate that the majority of birds found dead outside the sanctuary were as well. Kakariki population dynamics within the sanctuary may not be substantially affected, if most of the birds killed are juvenile males and at least some of the good quality (e.g. better body condition) male juveniles remain within the sanctuary. However, population establishment in Wellington is unlikely to be successful if birds continue to be killed off in large numbers by predators. Furthermore, it may not just be the exploratory young males that are being killed off; they may just be more likely to be found. Females are especially vulnerable to predation when incubating or brooding (O'Donnell 1996), and their bodies may be much less likely to be discovered if they are left in the nest cavity or cached. In addition, dispersal outside the sanctuary may only increase in the upcoming years if kakariki are in fact reaching their carrying capacity, limited by nest sites, within ZEALANDIA.

There were particular reserves and neighborhoods that kakariki frequented outside the sanctuary in both 2015 and 2016. Predator control in these areas could provide the birds some protection. However, cats killed many of the birds both in the transmitter studies and the reported deaths to ZEALANDIA. Promoting responsible pet ownership by encouraging cat owners to have their cat wear an anti-predator bell or collar, or keep their pets inside some or all of the time could reduce the impact of domestic (but not feral) cats on kakariki. An especially vulnerable time for kakariki occurs in summer and autumn (February-April) when breeding is occurring outside the sanctuary and juveniles are dispersing. Furthermore, chicks sometimes spend several days on the ground after fledging, rendering them particularly exposed to 
predators (Greene 2003). Cat owners therefore could still have an impact even if they just kept their pet indoors during those months.

In addition, as kakariki appeared to favor specific types of plants (e.g. totara, mapou), predator control in areas with those plants and/or around the time those plants are fruiting could also reduce predation, particularly as kakariki often feed on the fruit that has fallen to the ground. Encouraging people living around ZEALANDIA that have those plants in their yards to trap pests and reduce cat presence while the trees are fruiting could also help. Initiatives could also focus on attracting kakariki to safer, predator-controlled areas. Planting their favored food sources, as well as providing nest boxes if the area is safe enough that breeding should be encouraged, could entice birds. Nest boxes may be especially important, as previous studies have found that cavity nesting birds may have difficulty breeding in urban or developed areas, where appropriate nest sites may be scarce (reviewed by Newton 1994; Blewett and Marzluff 2005).

Finally, future translocations should release primarily younger (i.e. juvenile) birds over several successive introductions (to ensure several age cohorts make up the founder population). Only two birds from the 2010 and five from the 2011 translocations are known to have survived (have been observed in the sanctuary) until 2016 (Gray 2016), and older (5-6 year-old) birds tended to have lower reproductive success, indicating kakariki may not live much beyond $\sim 6$ years in the wild. Moving younger birds therefore ensures their high reproductive output is exploited at the new site.

\section{Limitations}

The primary limitation of this study was sample size. As kakariki were only translocated to ZEALANDIA in 2010, there was not enough time to accrue many older birds (alternatively, many of the older birds died), and therefore trends examining the influence of parental age on various aspects of reproductive success and dispersal may under-represent patterns. Twenty-two birds was not a large number to examine the influence of multiple factors on dispersal patterns, particularly when separating by sex. The unbalanced sample size of seven females versus fifteen males could have also masked female-specific dispersal patterns. However, given the amount of time it took to catch a single bird (often several days), the cost of the 
individual transmitters, and my limited ability to track twenty-two birds at once, the small sample size was unavoidable.

As I only noted each bird's location once a day/five times a week, I may also have missed important movements that the birds were making. I used triangulation frequently to save time rather than finding the exact location of each bird, usually in difficult to access locations outside the sanctuary. I was therefore often unable to collect specific behavioral data on the tracked birds, e.g. who they were with and what they were eating. The unknown fate of the several birds that lost their transmitters or whose transmitters failed unusually early was also a shortcoming of this study.

The other major limitation of the dispersal study was that I did not track the birds long enough to determine where they bred (natal dispersal). While some of the birds likely did go on to breed in the areas where they settled, not all birds were tracked long enough to have a definite area that they appeared to settle in (e.g. those outside the sanctuary that were killed, or whose transmitters failed or were removed by the bird). If some of the birds outside ZEALANDIA had returned to the sanctuary or nearby to breed, patterns that I found with post-fledging dispersal (e.g. that it could be related to inbreeding avoidance) may not actually apply when taking into account the full natal dispersal distance.

\section{Future Research}

Parental effects on various aspects of their offspring's life history remain a relatively little understood and fascinating topic for future study. They have been shown to influence everything from offspring sex ratio (Blank and Nolan 1983; Whittingham et al. 2002), to dispersal (Massot and Clobert 1995; Sinervo et al. 2006; Tschirren et al. 2007; Zedrosser et al. 2007), to their offspring's own reproductive success (Bouwhuis et al. 2010). Here, I found evidence to suggest that parent age could be potentially influence fledging sex ratio as well as post-fledging dispersal. However, the sample size was small, and further studies should be conducted to determine if this is actually the case, as well as how parents may influence their offspring's life history in other ways. Parental effects may be mediated through venues other than age. For example, Tschirren et al. (2007) found that the transfer of maternal yolk androgens in reaction to parasitism modified offspring's dispersal behavior in the great tit (Parus major), 


\section{Chapter 4}

and Massot and Clobert (1995) found that dispersal in the common lizard (Lacerta vivipara) was influenced by food available to the mother during gestation.

Natal dispersal should also be studied in kakariki, to determine how far the birds typically travel before breeding, where they choose to breed - specifically in more developed or urban areas - and why. This information would be particularly useful for conservation and management purposes, as the state of kakariki breeding dynamics outside the sanctuary is relatively unknown. More information on this topic could help in supporting population establishment throughout Wellington, as initiatives could focus on attracting pairs to breed in predator-controlled areas. Furthermore, this information could aid in future kakariki translocation efforts, by allowing conservationists to select the sites likely to best support successful kakariki breeding.

\section{Conclusion}

With increasing numbers of wildlife being translocated to buffer them from human impacts, more research must be done to study the basic life histories of candidates for translocation, to improve method and practice, and increase the likelihood of translocation success. With this in mind, I studied the reproductive biology and dispersal of a population of kakariki recently translocated to a mainland sanctuary. The results of this study will contribute to knowledge on kakariki life history that may be used to inform future translocations. I have furthered our understanding of the post-fledging period in kakariki, which is little understood in many avian species. 


\section{References}

Alonso-Álvarez, C., \& Velando, A. (2003). Female body condition and brood sex ratio in Yellow-legged Gulls Larus cachinnans. Ibis, 145(2), 220-226.

Anders, A., Faaborg, J., \& Thompson, F. (1998). Postfledging dispersal, habitat use, and home-range size of juvenile Wood Thrushes. The Auk, 115(2), 349-358.

Andreassen, H. P., \& Ims, R. A. (2001). Dispersal in patchy vole populations: Role of patch configuration, density dependence, and demography. Ecology, 82(10), 2911-2926.

Armstrong, D. P., Castro, I., \& Griffiths, R. (2007). Using adaptive management to determine requirements of re-introduced populations: The case of the New Zealand hihi. Journal of Applied Ecology, 44(5), 953-962.

Armstrong, D. P., Davidson, R. S., Dimond, W. J., Perrott, J. K., Castro, I., Ewen, J. G., ... Taylor, J. (2002). Population dynamics of reintroduced forest birds on New Zealand islands. Journal of Biogeography, 29, 609-621.

Armstrong, D. P., Ewen, J. G., Dimond, W. J., Lovegrove, T. G., Bergstrom, A., \& Walter, B. (2000). Breeding biology of North Island robins (Petroica australis longipes) on Tiritiri Matangi Island, Hauraki Gulf, New Zealand. Notornis, 47(2), 106-118.

Armstrong, D. P., McArthur, N., Govella, S., Morgan, K., Johnston, R., Gorman, N., Pike, R., \& Richard, Y. (2013). Using radio-tracking data to predict post-release establishment in reintroductions to habitat fragments. Biological Conservation, $168,152-160$.

Ausprey, I. J., \& Rodewald, A. D. (2013). Post-fledging dispersal timing and natal range size of two songbird species in an urbanizing landscape. The Condor, $115(1), 102-114$.

Baguette, M., Mennechez, G., Petit, S., \& Schtickzelle, N. (2003). Effect of habitat fragmentation on dispersal in the butterfly Proclossiana eunomia. Comptes Rendus Biologies, 326 (03), S200-S209.

Baker, R. R. (1993). The Function of Post-Fledging Exploration: A pilot study of three species of passerines ringed in Britain. Ornis Scandinavica, 24(1), 71-79.

Barbraud, C., Johnson, A. R., \& Bertault, G. (2003). Phenotypic correlates of postfledging dispersal in a population of greater flamingos: The importance of body condition. Journal of Animal Ecology, 72(2), 246-257. 
Bates D., Maechler M., Bolker B., Walker S. (2015). Fitting Linear Mixed-Effects Models Using lme4. Journal of Statistical Software, 67(1), 1-48.

Bell, B.D., \& Merton, D.V. (2002). Critically endangered bird populations and their management. In K. Norris and D. Pain, (Eds), Conserving Bird Biodiversity: General Principles and their Application (pp.105-138). Cambridge, UK: Cambridge University Press.

Bell, M., Bell, B. D., \& Bell, E. A. (2005). Translocation of fluttering shearwater (Puffinus gavia) chicks to create a new colony. Notornis, 52(1), 11-15.

Bell, B.D. (2016). Behavior-based management: conservation translocations. In O. Berger-Tal, \& D. Saltz. (Eds.), Conservation Behavior: Applying Behavioral Ecology to Wildlife Conservation and Management (pp. 212-246). Cambridge, UK: Cambridge University Press.

Bellingham, M. (1987). Red-crowned parakeet on Burgess Island. Notornis, 34, 234236.

Benton, T. G., \& Bowler, D. E. (2012). Linking dispersal to spatial dynamics. In J. Clobert, M. Baguette, T.G. Benton, \& J.M. Bullock (Eds.), Dispersal Ecology and Evolution (pp. 251-265). Oxford, UK: Oxford University Press.

Bivand, R., Pebesma, E., \& Gomez-Rubio V. (2013). Applied spatial data analysis with R, Second edition. Springer, NY. http://www.asdar-book.org/

Bivand, R., Keitt, T., \& Rowlingson, B. (2015). rgdal: Bindings for theGeospatial Data Abstraction Library. R package version 0.9-2. http://CRAN.Rproject.org $/$ package $=$ rgdal.

Blank, J. L., \& Nolan, V. (1983). Offspring sex ratio in red-winged blackbirds is dependent on maternal age. Proceedings of the National Academy of Sciences of the United States of America, 80(19), 6141-5.

Blewett, C. M., \& Marzluff, J. M. (2005). Effects of urban sprawl on snags and the abundance and productivity of cavity-nesting birds. The Condor, 107(3), 678693.

Bohonak, A. J. (1999). Dispersal, gene flow, and population structure. Quarterly Review of Biology. 74(1): 21-45.

Bonte, D., Van Dyck, H., Bullock, J. M., Coulon, A., Delgado, M., Gibbs, M., ... Travis, J. M. J. (2012). Costs of dispersal. Biological Reviews, 87(2), 290-312.

Boon, W. M., Kearvell, J. C., Daugherty, C. H., \& Chambers, G. K. (2000). Molecular systematics of New Zealand Cyanoramphus parakeets: conservation of orange-fronted and Forbes' Parakeets. Bird Conservation International, 10(3), 211-239. 
Boonstra, R. (1989). Life history variation in maturation in fluctuating meadow vole populations (Microtus pennsylvanicus). Oikos, 54(3), 265-274.

Bouwhuis, S., Charmantier, A., Verhulst, S., \& Sheldon, B. C. (2010). Transgenerational effects on ageing in a wild bird population. Journal of Evolutionary Biology, 23(3), 636-642.

Bouwhuis, S., Choquet, R., Sheldon, B. C., \& Verhulst, S. (2012). The forms and fitness cost of senescence: Age-specific recapture, survival, reproduction, and reproductive value in a wild bird population. The American Naturalist, 179(1), E15-E27.

Boyer, D. A., \& Brown, R. D. (1988). A survey of translocations of mammals in the United States 1985. Translocations of Wild Animals, 1-11.

Bradley, D. W., Ninnes, C. E., Valderrama, S. V., \& Waas, J. R. (2011). Does "acoustic anchoring" reduce post-translocation dispersal of North Island robins? Wildlife Research, 38, 69-76.

Brawn, J. D., \& Balda, R. P. (1988). Population biology of cavity nesters in northern Arizona: Do nest sites limit breeding densities? The Condor, 90(1), 61-71.

Burger, C., \& Both, C. (2011). Translocation as a novel approach to study effects of a new breeding habitat on reproductive output in wild birds. PLOS ONE, 6(3), e18143.

Burnham KP, \& Anderson DR. (2003). Model selection and multimodel inference: a practical information-theoretic approach. New York, USA: Springer-Verlag.

Butler D., \& Merton D. (1992). The black robin: saving the world's most endangered bird. Oxford, UK: Oxford University Press.

Calenge, C. (2006). The package adehabitat for the R software: a tool for the analysis of space and habitat use by animals. Ecological Modelling, 197, 516-519.

Campbell-Hunt, D. (2002). Developing a Sanctuary: The Karori Experience. Wellington, New Zealand: Victoria Link Ltd.

Castro, I., Brunton, D. H., Mason, K. M., Ebert, B., \& Griffiths, R. (2003). Life history traits and food supplementation affect productivity in a translocated population of the endangered Hihi (Stitchbird, Notiomystis cincta). Biological Conservation, 114(2), 271-280.

Caughley, G. (1994). Directions in conservation biology. Journal of Animal Ecology, $63,215-244$.

Channell, R., \& Lomolino, M. V. (2000). Trajectories to extinction: spatial dynamics of the contraction of geographic ranges of endangered species. Journal of Biogeography, 27, 169-180. 
Choudhury, S. (1995). Divorce in birds: a review of the hypotheses. Animal Behaviour, 50(2), 413-429.

Clarke, A. L., Sæther, B.-E., \& Røskaft, E. (1997). Sex biases in avian dispersal: a reappraisal. Oikos, 79(3), 429-438.

Clarke, M. F., \& Heathcote, C. F. (1990). Dispersal, survivorship and demography in the co-operatively-breeding bell miner Manorina melanophrys. Emu, 90(1), 1523.

Clarke, M. F., \& Schedvin, N. (1997). An experimental study of the translocation of noisy miners Manorina melanocephala and difficulties associated with dispersal. Biological Conservation, 80(2), 161-167.

Clavero, M., \& García-Berthou, E. (2005). Invasive species are a leading cause of animal extinctions. Trends in Ecology and Evolution, 20(3), 110.

Clout, M. (2001). Where protection is not enough: active conservation in New Zealand. Trends in Ecology and Evolution, 16(8), 415-416.

Clout, M. N., Elliott, G. P., \& Robertson, B. C. (2002). Effects of supplementary feeding on the offspring sex ratio of kakapo: A dilemma for the conservation of a polygynous parrot. Biological Conservation, 107(1), 13-18.

Cockburn, A., Osmond, H. L., Mulder, R. A, Green, D. J., \& Double, M. C. (2003). Divorce, dispersal and incest avoidance in the cooperatively breeding superb fairy-wren Malurus cyaneus. Journal of Animal Ecology, 72, 189-202.

Cooper, C. B., \& Walters, J. R. (2002). Experimental evidence of disrupted dispersal causing decline of an Australian passerine in fragmented habitat. Conservation Biology, 16(2), 471-478.

Cote, J., \& Clobert, J. (2007). Social personalities influence natal dispersal in a lizard. Proceedings of the Royal Society of London B: Biological Sciences, 274(1608), 383-390.

Cote, J., Clobert, J., Brodin, T., Fogarty, S., \& Sih, A. (2010). Personality-dependent dispersal: characterization, ontogeny and consequences for spatially structured populations. Philosophical Transactions of the Royal Society of London. Series B, Biological Sciences, 365(1560), 4065-4076.

Cote, S., Durand, O., Laroche, E., \& Warden, R. (2013). Evaluating the Interactions between Wellington Residents and the Threatened Kaka Parrot. Worcester Polytechnic Institute.

Coulon, A., Fitzpatrick, J. W., Bowman, R., \& Lovette, I. J. (2010). Effects of habitat fragmentation on effective dispersal of Florida scrub-jays. Conservation Biology, 24(4), 1080-1088. 
Cuthbert, R. (2003). Sign left by introduced and native predators feeding on Hutton's shearwaters Puffinus huttoni. New Zealand Journal of Zoology, 30(3), 163-170.

Diffendorfer, J. E., Gaines, M. S., \& Holt, R. D. (1995). Habitat fragmentation and movements of three small mammals (Sigmodon, Microtus, and Peromyscus). Ecology, 76(3), 827-839.

Dingemanse, N. J., Both, C., van Noordwijk, A. J., Rutten, A. L., \& Drent, P. J. (2003). Natal dispersal and personalities in Great Tits. Proceedings of the Royal Society of London B: Biological Sciences, 270(1516), 741-7.

Doerr, E. D., \& Doerr, V. A. J. (2005). Dispersal range analysis: Quantifying individual variation in dispersal behaviour. Oecologia, 142(1), 1-10.

Duckworth, R. A, \& Badyaev, A. V. (2007). Coupling of dispersal and aggression facilitates the rapid range expansion of a passerine bird. Proceedings of the National Academy of Sciences of the United States of America, 104(38), 1501722.

Ebert, D., Haag, C., Kirkpatrick, M., Riek, M., Hottinger, J. W., \& Pajunen, V. I. (2002). A selective advantage to immigrant genes in a Daphnia metapopulation. Science, 295(5554), 485-488.

Ekmann, J., Baglione, V., Egger, S., \& Griesser, M. (2001). Delayed dispersal: living under the reign of nepotistic parents. The Auk, 118(1), 1-10.

Eldegard, K., Vognild, H., \& Sonerud, G. A. (2014). Intersexual difference in early natal dispersal: Abrupt departure by females and gradual emigration by males in Tengmalm's Owl Aegolius funereus. Journal of Ornithology, 155(1), 235-242.

Ellsworth, E., \& Belthoff, J. R. (1999). Effects of social status on the dispersal behaviour of juvenile western screech-owls. Animal Behaviour, 57(4), 883-892.

Environmental Protection Authority. (2014). Annual Report on the Aerial Use of 1080. Wellington, NZ.

Faccio, S. D. S., Amaral, M., Martin, C. J. C., Lloyd, J. D., French, T. W., \& Tur, A. (2013). Movement patterns, natal dispersal, and survival of Peregrine falcons banded in New England. Journal of Raptor Research, 47(3), 246-261.

Fischer, J., \& Lindenmayer, D. B. (2000). An assessment of the published results of animal relocations. Biological Conservation, 96(1), 1-11.

Fonseca, D. M., \& Hart, D. D. (1996). Density-dependent dispersal of black fly neonates is mediated by flow. Oikos, 75(1), 49-58.

Forero, M. G., Donázar, J. A., \& Hiraldo, F. (2002). Causes and fitness consequences of natal dispersal in a population of black kites. Ecology, 83(3), 858-872. 
Fraser, D. F., Gilliam, J. F., Daley, M. J., Le, A. N., \& Skalski, G. T. (2001). Explaining leptokurtic movement distributions: intrapopulation variation in boldness and exploration. The American Naturalist, 158(2), 124-135.

Garant, D., Forde, S. E., \& Hendry, A. P. (2007). The multifarious effects of dispersal and gene flow on contemporary adaptation. Functional Ecology, 21(3), 434-443.

Garnett, M. C. (1981). Body size, its heritability and influence on juvenile survival among great tits, Parus major. Ibis, 123, 31-41.

Germano, J. M., \& Bishop, P. J. (2009). Suitability of amphibians and reptiles for translocation. Conservation Biology, 23(1), 7-15.

Gese, E. M., Ruff, R. L., \& Crabtree, R. L. (1996). Social and nutritional factors influencing the dispersal of resident coyotes. Animal Behaviour, 52(1992), 1025-1043.

Gosselink, T. E., Piccolo, K. A., van Deelen, T. R., Warner, R. E., \& Mankin, P. C. (2010). Natal dispersal and philopatry of red foxes in urban and agricultural areas of Illinois. Journal of Wildlife Management, 74(6), 1204-1217.

Grant, A. D., \& Kearvell, J. (2001). Orange-fronted parakeet (Cyanoramphus malherbi) recovery plan, 1999-2005. Department of Conservation, Biodiversity Recovery Unit. 24p. Wellington, NZ: Department of Conservation.

Gray, R.S. (2011). Red Crowned Parakeet (Cyanoramphus novaezelandiae) Seasonal Report 2010-11. Wellington, NZ: ZEALANDIA.

Gray, R.S. (2012). Red Crowned Parakeet (Cyanoramphus novaezelandiae) Seasonal Report 2011-12. Wellington, NZ: ZEALANDIA.

Gray, R.S. (2013). Red Crowned Parakeet (Cyanoramphus novaezelandiae) Seasonal Report 2012-13. Wellington, NZ: ZEALANDIA.

Gray, R.S. (2014). Red Crowned Parakeet (Cyanoramphus novaezelandiae) Seasonal Report 2013-14. Wellington, NZ: ZEALANDIA.

Gray, R.S. (2015). Red Crowned Parakeet (Cyanoramphus novaezelandiae) Seasonal Report 2014-15. Wellington, NZ: ZEALANDIA.

Gray, R.S. (2016). Red Crowned Parakeet (Cyanoramphus novaezelandiae) Seasonal Report 2015-16. Wellington, NZ: ZEALANDIA.

Greene, T. C. (1998). Foraging ecology of the red-crowned parakeet (Cyanoramphus novaezelandiae novaezelandiae) and yellow-crowned parakeet (C.auriceps auriceps) on Little Barrier Island, Hauraki Gulf, New Zealand. New Zealand Journal of Ecology, 22(2), 161-171. 
Greene, T. C. (2003). Breeding biology of red-crowned parakeets (Cyanoramphus novaezelandiae) on Little Barrier Island, Hauraki Gulf, New Zealand. Notornis, 50, 83-99.

Greenwood, P. J. (1980). Mating systems, philopatry and dispersal in birds and mammals. Animal Behavior, 28(1960), 1140-1162.

Greenwood, P. J., \& Harvey, P. H. (1982). The natal and breeding dispersal of birds. Annual Review of Ecology and Systematics, 13(1982), 1-21.

Griffith, B., Scott, J. M., Carpenter, J. W., \& Reed, C. (1989). Translocation as a species conservation tool: status and strategy. Science, 245(4917), 477-480.

Haig, S. M., Belthoff, J. R., \& Allen, D. H. (1993). Population viability analysis for a small population of red- cockaded woodpeckers and an evaluation of enhancement strategies. Conservation Biology, 7(2), 289-301.

Higgins, P.J. (1999). Handbook of Australian, New Zealand and Antarctic birds. Volume 4. Parrots to Dollarbirds. Melbourne, AU: Oxford University Press.

Howard, W. E. (1960). Innate and environmental dispersal of individual vertebrates. American Midland Naturalist, 63(1), 152-161.

[IUCN/SSC]. International Union for Conservation of Nature/Species Survival Commission. (2013). Guidelines for reintroductions and other conservation translocations. Version 1.0. (P.S. Soorae, editor). Gland, Switzerland: IUCN Species Survival Commission.

Jamieson, I. G. (2011). Founder effects, inbreeding, and loss of genetic diversity in four avian reintroduction programs. Conservation Biology, 25(1), 115-123.

Jamieson, I. G., \& Ryan, C. J. (2000). Increased egg infertility associated with translocating inbred takahe (Porphyrio hochstetteri) to island refuges in New Zealand. Biological Conservation, 94(1), 107-114.

Johnson, C. A., Fryxell, J. M., Thompson, I. D., \& Baker, J. A. (2009). Mortality risk increases with natal dispersal distance in American martens. Proceedings of the Royal Society B: Biological Sciences, 276(1671), 3361-3367.

Jones, W. T. (1988). Density-related changes in survival of philopatric and dispersing kangaroo rats. Ecology, 69(5), 1474-8.

Keller, L. F., \& Waller, D. M. (2002). Inbreeding effects in wild populations. Trends in Ecology and Evolution, 17(5), 230-241.

Kershner, E. L., Walk, J. W., \& Warner, R. E. (2004). Postfledging movements and survival of juvenile Eastern Meadowlarks (Sturnella magna) in Illinois. The Auk, 121(4), 1146-1154. 
Kleiman, D. G. (1989). Reintroduction of captive mammals for conservation. BioScience, 39(3), 152-161.

Kölliker, M., Heeb, P., Werner, I., Mateman, A. C., Lessells, C. M., \& Richner, H. (1999). Offspring sex ratio is related to male body size in the great tit (Parus major). Behavioral Ecology, 10(1), 68-72.

Korpimäki, E., \& Lagerström, M. (1988). Survival and natal dispersal of fledglings of Tengmalm's owl in relation to fluctuating food conditions and hatching date. The Journal of Animal Ecology, 57(2), 433-441.

Laliberte, A. S., \& Ripple, W. J. (2004). Range contractions of North American carnivores and ungulates. Bioscience, 54(2), 123-138.

Leech, T. J., Craig, E., Beaven, B., Mitchell, D. K., \& Seddon, P. J. (2007). Reintroduction of rifleman Acanthisitta chloris to Ulva Island, New Zealand: evaluation of techniques and population persistence. Oryx, 41(3), 369-375.

Lenormand, T. (2002). Gene flow and the limits to natural selection. Trends in Ecology and Evolution, 17(4), 183-189.

Lepczyk, C. A., Mertig, A. G., \& Liu, J. (2003). Landowners and cat predation across rural-to-urban landscapes. Biological Conservation, 115(2), 191-201.

Liu, Y., \& Zhang, Z. W. (2008). Research progress in avian dispersal behavior. Frontiers of Biology in China, 3(4), 375-384.

Lundquist, C. L., Ramsay, D., Bell, R., Swales, A., \& Kerr, S. (2011). Predicted impacts of climate change on New Zealand's biodiversity. Pacific Conservation Biology, 17(3), 179-191.

Lunn, N. J., Boyd, I. L., \& Croxall, J. P. (1994). Reproductive performance of female Antarctic fur seals: The influence of age, breeding experience, environmental variation and individual quality. Journal of Animal Ecology, 63(4), 827-840.

Mabry, K. E., Shelley, E. L., Davis, K. E., Blumstein, D. T., \& van Vuren, D. H. (2013). Social mating system and sex-biased dispersal in mammals and birds: a phylogenetic analysis. PLOS ONE, 8(3), 1-9.

Machtans, C. S., Wedeles, C. H. R., \& Bayne, E. M. (2013). A first estimate for Canada of the number of birds killed by colliding with building windows. Avian Conservation and Ecology, 8(2), 6.

Mackay, J. (2011). Companion Animals in New Zealand. Auckland, New Zealand: New Zealand Companion Animal Council.

Magrath, R. (1991). Nestling weight and juvenile survival in the blackbird, Turdus merula. Journal of Animal Ecology, 60(1), 335-351. 
Martín, C. A., Alonso, J. C., Alonso, J. A., Palacín, C., Magaña, M., \& Martín, B. (2008). Natal dispersal in great bustards: The effect of sex, local population size and spatial isolation. Journal of Animal Ecology, 77(2), 326-334.

Marzluff, J. M. (2001). Worldwide urbanization and its effects on birds. In J. M. Marzluff, R. Bowman, \& R. Donnelly (Eds.), Avian Ecology and Conservation in an Urbanizing World (pp. 19-47). Boston, MA: Springer US.

Marzluff, J. M., \& Ewing, K. (2001). Restoration of fragmented landscapes for the conservation of birds: a general framework and specific recommendations for urbanizing landscapes. Restoration Ecology, 9(3), 280-292.

Massot, M., \& Clobert, J. (1995). Influence of maternal food availability on offsrping dispersal. Behavioral Ecology and Sociobiology, 37(6), 413-418.

Matthysen, E. (2012). Multicausality of dispersal: a review. In J. Clobert, M. Baguette, T.G. Benton, \& J.M. Bullock (Eds.), Dispersal ecology and evolution (pp. 3-18). Oxford, UK: Oxford University Press.

Matthysen, E., Adriaensen, F., \& Dhondt, A. A. (1995). Dispersal distances of nuthatches, Sitta europaea, in a highly fragmented forest habitat. Oikos, 72(3), $375-381$.

Mazerolle, M. J. (2016). AICcmodavg: Model selection and multimodel inference based on (Q)AIC(c). R package version 2.1-0. https://cran.rproject.org/package $=$ AICcmodavg.

McCauley, S. J. (2010). Body size and social dominance influence breeding dispersal in male Pachydiplax longipennis (Odonata). Ecological Entomology, 35(3), 377385 .

McLennan, J. A., Rudge, M. R., \& Potter, M. A. (1987). Range size and denning behaviour of brown kiwi, Apteryx australis mantelli, in Hawke's Bay, New Zealand. New Zealand Journal of Ecology.

Miskelly, C. M., \& Powlesland, R. G. (2013). Conservation translocations of New Zealand birds, 1863-2012. Notornis, 60, 3-28.

Moksnes, P. O. (2004). Interference competition for space in nursery habitats: Density-dependent effects on growth and dispersal in juvenile shore crabs Carcinus maenas. Marine Ecology Progress Series, 281, 181-191.

Møller, A. P., \& De Lope, F. (1999). Senescence in a short-lived migratory bird: Agedependent morphology, migration, reproduction and parasitism. Journal of Animal Ecology, 68(1), 163-171.

Müller, J., Wölfl, M., Wölfl, S., Müller, D. W. H., Hothorn, T., \& Heurich, M. (2014). Protected areas shape the spatial distribution of a European lynx population more than 20 years after reintroduction. Biological Conservation, $177,210-217$. 
Mumme, R. L., \& Below, T. H. (1999). Evaluation of translocation for the threatened Florida scrub-jay. The Journal of Wildlife Management, 63(3), 833-842.

Naef-Daenzer, B., Widmer, F., \& Nuber, M. (2001). Differential post-fledging survival of great and coal tits in relation to their condition and fledging date. Journal of Animal Ecology, 70(5), 730-738.

Nelson, N. J., Romijn, R. L., Dumont, T., Reardon, J. T., Monks, J. M., Hitchmough, R. A., ... \& Briskie, J. V. (2016). Lizard Conservation in Mainland Sanctuaries. In D. Chapple (Ed.), New Zealand Lizards (pp. 321-339). Cham, Switzerland: Springer International Publishing.

Nevoux, M., Arlt, D., Nicoll, M., Jones, C., \& Norris, K. (2013). The short- and longterm fitness consequences of natal dispersal in a wild bird population. Ecology Letters, 16(4), 438-445.

Newton, I. (1989). Synthesis. In I. Newton (Ed.), Lifetime reproduction in birds (pp. 441-469). San Diego, USA: Academic Press.

Newton, I. (1994). The role of nest sites in limiting the numbers of hole-nesting birds: a review. Biological Conservation, 70(3), 265-276.

Nilsson, J. A., \& Smith, H. G. (1985). Early fledgling mortality and the timing of juvenile dispersal in the Marsh Tit Parus Palustris. Ornis Scandinavica, 16(4), 293-298.

Norris, K. (1993). Seasonal variation in the reproductive success of blue tits: an experimental study. Journal of Animal Ecology, 62(2), 287-294.

O'Donnell, C. F. J. (1996). Predators and the decline of New Zealand forest birds: An introduction to the hole-nesting bird and predator programme. New Zealand Journal of Zoology, 23(3), 213-219.

Oro, D., Martínez-Abraín, A., Villuendas, E., Sarzo, B., Mínguez, E., Carda, J., \& Genovart, M. (2011). Lessons from a failed translocation program with a seabird species: determinants of success and conservation value. Biological Conservation, 144(2), 851-858.

Ortiz-Catedral, L. (2010). Homing of a red-crowned parakeet (Cyanoramphus novaezelandiae) from Motuihe Island to Little Barrier Island, New Zealand. Notornis, 57(1), 48-49.

Ortiz-Catedral, L., \& Brunton, D. H. (2008). Clutch parameters and reproductive success of a translocated population of red-crowned parakeet (Cyanoramphus novaezelandiae). Australian Journal of Zoology, 56(6), 389-393.

Ortiz-Catedral, L., \& Brunton, D. H. (2009). Nesting sites and nesting success of reintroduced red-crowned parakeets (Cyanoramphus novaezelandiae) on Tiritiri Matangi Island, New Zealand. New Zealand Journal of Zoology, 36, 1-10. 
Ortiz-Catedral, L., Kearvell, J. C., Hauber, M. E., \& Brunton, D. H. (2009). Breeding biology of the critically endangered Malherbes parakeet on Maud Island, New Zealand, following the release of captive-bred individuals. Australian Journal of Zoology, 57(6), 433-439.

Ortiz-Catedral, L., \& Brunton, D. H. (2010). Success of translocations of red-fronted parakeets Cyanoramphus novaezelandiae novaezelandiae from Little Barrier Island (Hauturu) to Motuihe Island, Auckland, New Zealand. Conservation Evidence, 7, 21-26.

Ortiz-Catedral, L., Hauber, M. E., \& Brunton, D. H. (2013). Growth and survival of nestlings in a population of red-crowned parakeets (Cyanoramphus novaezelandiae) free of introduced mammalian nest predators on Tiritiri Matangi Island, New Zealand. New Zealand Journal of Ecology, 37(3), 370-378.

Parmesan, C. (2006). Ecological and evolutionary responses to recent climate change. Annual of Ecology, Evolution and Systematics, 37(2006), 637-669.

Pasinelli, G., \& Walters, J. R. (2002). Social and environmental factors affect natal dispersal and philopatry of male Red-cockaded woodpeckers. Ecology, 83(8), 2229-2239.

Pebesma, E.J., \& Bivand, R.S. (2005). Classes and methods for spatial data in R. $R$ News, 5(2), https://cran.r-project.org/doc/Rnews/.

Perrin, N., \& Mazalov, V. (1999). Dispersal and inbreeding avoidance. The American Naturalist, 154(3), 282-292.

Phillips, M. K. (1990). Measures of the value and success of a reintroduction project: red wolf reintroduction in Alligator River National Wildlife Refuge. Endangered Species Update, 8, 24-26.

Pierre, J. P. (1999). Reintroduction of the South Island saddleback (Philesturnus carunculatus carunculatus): dispersal, social organisation and survival. Biological Conservation, 89(2), 153-159.

Potti, J. (1999). Maternal effects and the pervasive impact of nestling history on egg size in a passerine bird. Evolution, 53(1), 279-285.

Powlesland, R. G., \& Lloyd, B. D. (1994). Use of supplementary feeding to induce breeding in free-living Kakapo Strigops habroptilus in New Zealand. Biological Conservation, 69, 97-106.

Pratt, D., Bruner, P.L. and D.G. Berrett. (1987). A field guide to the birds of Hawaii and the tropical Pacific. Princeton University Press, Princeton, N.J.

Priddel, D., Carlile, N., \& Wheeler, R. (2006). Establishment of a new breeding colony of Gould's petrel (Pterodroma leucoptera leucoptera) through the creation of artificial nesting habitat and the translocation of nestlings. Biological Conservation, 128(4), 553-563. 
Pusey, A. (1987). Sex-biased dispersal and inbreeding avoidance in birds and mammals. Trends in Ecology and Evolution, 2(10), 295-299.

Quantum GIS Development Team (2016). Quantum GIS Geographic Information System. Open Source Geospatial Foundation Project. http://qgis.osgeo.org.

R Core Team (2016). R: A language and environment for statistical computing. $\mathrm{R}$ Foundation for Statistical Computing, Vienna, Austria. http://www.Rproject.org/.

Rémy, A., Le Galliard, J. F., Gundersen, G., Steen, H., \& Andreassen, H. P. (2011). Effects of individual condition and habitat quality on natal dispersal behaviour in a small rodent. Journal of Animal Ecology, 80(5), 929-937.

Rickett, J. (2010). The dispersal and survivorship of pateke (Anas chlorotis) in relation to experimental release techniques; supplementary feeding and wingclipping. Massey University.

Robb, G. N., McDonald, R. A., Chamberlain, D. E., \& Bearhop, S. (2008). Food for thought: supplementary feeding as a driver of ecological change in avian populations. Frontiers in Ecology and the Environment, 6(9), 476-484.

Ronce, O., Clobert, J., \& Massot, M. (1998). Natal dispersal and senescence. Proceedings of the National Academy of Sciences of the United States of America, 95, 600-605.

Rowe, S. J., \& Bell, B. D. (2007). The influence of geographic variation in song dialect on post-translocation pair formation in North Island kokako (Callaeas cinerea wilsoni). Notornis, 54(1), 28-37.

Ryan, C. J., \& Jamieson, I. G. (1998). Estimating the home range and carrying capacity for takahe (Porphyrio mantelli) on predator-free offshore islands: implications for future management. New Zealand Journal of Ecology, 22(1), $17-24$.

Sarrazin, F., Bagnolini, C., Pinna, J. L., \& Danchinl, E. (1994). Breeding biology during establishment of a reintroduced Griffon Vulture Gyps fulvus population. Ibis, 138(2), 315-325.

Sarrazin, F., \& Barbault, R. (1996). Reintroduction: challenges and lessons for basic ecology. Trends in Ecology and Evolution, 11(11), 474-478.

Saunders, A., \& Norton, D. (2001). Ecological restoration at Mainland Islands in New Zealand. Biological Conservation, 99(1), 109-119.

Seaman, D. E., Millspaugh, J. J., Kernohan, B. J., Brundige, G. C., Raedeke, K. J., \& Gitzen, R. A. (1999). Effects of sample size on kernel home range estimates. The Journal of Wildlife Management, 63(2), 739-747. 
Seddon, P. J., Armstrong, D. P., \& Maloney, R. F. (2007). Developing the science of reintroduction biology. Conservation Biology, 21(2), 303-312.

Serrano, D., Tella, J. L., Donázar, J. A., \& Pomarol, M. (2003). Social and individual features affecting natal dispersal in the colonial Lesser Kestrel. Ecology, 84(11), 3044-3054.

Sigg, D. P., Goldizen, A. W., \& Pople, A. R. (2005). The importance of mating system in translocation programs: reproductive success of released male bridled nailtail wallabies. Biological Conservation, 123(3), 289-300.

Sim, I., Ludwig, S., Grant, M., Loughrey, J., Rebecca, G., \& Reid, J. M. (2013). Postfledging survival, movements, and dispersal of Ring Ouzels (Turdus torquatus). The Auk, 130(1), 69-77.

Sinervo, B., Calsbeek, R., Comendant, T., Both, C., Adamopoulou, C., \& Clobert, J. (2006). Genetic and maternal determinants of effective dispersal: the effect of sire genotype and size at birth in side-blotched lizards. The American Naturalist, 168(1), 88-99.

Small, D. R. (2004). Survival, breeding success and habitat selection of North Island robins Petroica Australis Longipes. Victoria University of Wellington.

Soulsbury, C. D., Baker, P. J., Iossa, G., \& Harris, S. (2008). Fitness costs of dispersal in red foxes (Vulpes vulpes). Behavioral Ecology and Sociobiology, 62(8), 12891298.

Spear, L., \& Nur, N. (1994). Brood size, hatching order and hatching date: effects on four life-history stages from hatching to recruitment in western gulls. Journal of Animal Ecology, 63(2), 283-298.

Stamps, J. A. (1988). Conspecific attraction and aggregation in territorial species. The American Naturalist, 131(3), 329-347.

Stamps, J. A., Krishnan, V. V., \& Reid, M. L. (2005). Search costs and habitat selection by dispersers. Ecology, 86(2), 510-518.

Stamps, J. A., \& Swaisgood, R. R. (2007). Someplace like home: experience, habitat selection and conservation biology. Applied Animal Behaviour Science, 102(3), 392-409.

Støen, O. G., Zedrosser, A., Saebø, S., \& Swenson, J. E. (2006). Inversely densitydependent natal dispersal in brown bears Ursus arctos. Oecologia, 148(2), 356364.

Sutherland, W. (1998). The importance of behavioural studies in conservation biology. Animal Behaviour, 56(4), 801-809. 
Sydeman, W. J., Penniman, J. F., Penniman, T. M., Pyle, P., \& Ainley, D. G. (1991). Breeding performance in the western gull: effects of parental age, timing of breeding and year in relation to food availability. Journal of Animal Ecology, $60(1), 135-149$.

Szulkin, M., \& Sheldon, B. C. (2008). Dispersal as a means of inbreeding avoidance in a wild bird population. Proceedings of the Royal Society B: Biological Sciences, 275, 703-711.

Tarwater, C. E., \& Brawn, J. D. (2010). Family living in a Neotropical bird: Variation in timing of dispersal and higher survival for delayed dispersers. Animal Behaviour, 80(3), 535-542.

Thaxton, J. E., \& Hingtgen, T. M. (1996). Effects of suburbanization and habitat fragmentation on Florida Scrub-Jay dispersal. Florida Field Naturalist, 24(2), $25-37$.

Thompson, G. G., de Boer, M., \& Pianka, E. R. (1999). Activity areas and daily movements of an arboreal monitor lizard, Varanus tristis (Squamara: Varanidae) during the breeding season. Australian Journal of Ecology, 24(2), 117-122.

Towns, D. R., \& Daugherty, C. H. (1994). Patterns of range contractions and extinctions in the New Zealand herpetofauna following human colonisation. New Zealand Journal of Zoology, 21(4), 325-339.

Tschirren, B., Fitze, P. S., \& Richner, H. (2007). Maternal modulation of natal dispersal in a passerine bird: an adaptive strategy to cope with parasitism? The American Naturalist, 169(1), 87-93.

Tweed, E. J., Foster, J. T., Woodworth, B. L., Oesterle, P., Kuehler, C., Lieberman, A. A., ... Telfer, T. (2003). Survival, dispersal, and home-range establishment of reintroduced captive-bred puaiohi, Myadestes palmeri. Biological Conservation, $111,1-9$.

van Heezik, Y., Maloney, R. R. F., \& Seddon, P. J. P. (2009). Movements of translocated captive-bred and released Critically Endangered kaki (black stilts) Himantopus novaezelandiae and the value of long-term post-release monitoring. Oryx, 43(4), 639-647.

van Heezik, Y., Smyth, A., Adams, A., \& Gordon, J. (2010). Do domestic cats impose an unsustainable harvest on urban bird populations? Biological Conservation, 143(1), 121-130.

Van Houtan, K. S., Bass, O. L., Lockwood, J., \& Pimm, S. L. (2010). Importance of estimating dispersal for endangered bird management. Conservation Letters, 3 , 260-266.

Verhulst, S., Perrins, C., \& Riddington, R. (1997). Natal dispersal of great tits in a patchy environment. Ecology, 78(3), 864-872. 
Vitousek, P. M., D’Antonio, C. M., Loope, L. L., Rejmánek, M., \& Westbrooks, R. (1997a). Introduced species: A significant component of human-caused global change. New Zealand Journal of Ecology, 21(1), 1-16.

Vitousek, P. M., Mooney, H. A., Lubchenco, J., \& Melillo, J. M. (1997b). Human domination of Earth's ecosystems. Science, 277(5325), 494-499.

Vitz, A. (2008). Survivorship, habitat use, and movements for two species of mature forest birds. The Ohio State University.

Vitz, A. C., \& Rodewald, A. D. (2010). Movements of fledgling Ovenbirds (Seiurus Aurocapilla) and Worm-Eating Warblers (Helmitheros vermivorum) within and beyond the natal home range. The Auk, 127(2), 364-371.

Weimerskirch, H. (1992). Reproductive effort in long-lived birds: age-specific patterns of condition, reproduction and survival in the wandering albatross. Oikos, 64(3), 464-473.

West, R., Tisdall, C., \& Aviss, M. (1995). Antipodes Island parakeet captive management plan (Cyanoramphus unicolor). Threatened species occasional publication, 6. Wellington, NZ: Department of Conservation.

Whittingham, L., Valkenaar, S., Poirier, N. E., \& Dunn, P. O. (2002). Maternal conditions and nesting sex ratio in House Wrens. The Auk, 119(1), 125-131.

Wiley, J.W. (1985). The Puerto Rican parrot and competition for its nest sites. In P.J. Moors (Ed.), Conservation of island birds (pp. 213-223). ICBP Technical Publication, 3. Cambridge, UK: International Council for Bird Preservation.

Wilkinson, G. S. (1985). The social organization of the common vampire bat. Behavioral Ecology and Sociobiology, 17(2), 123-134.

Willson, M. F. (2004). Loss of habitat connectivity hinders pair formation and juvenile dispersal of Chucao Tapaculos in Chilean rainforest. The Condor, 106(1), 166-171.

Withey, J. C., \& Marzluff, J. M. (2005). Dispersal by juvenile American crows (Corvus brachyrhynchos) influences population dynamics across a gradient of urbanization. The Auk, 122, $205-221$.

Wolf, J. B., \& Wade, M. J. (2009). What are maternal effects (and what are they not)? Philosophical Transactions of the Royal Society of London B, 364(1520), 11071115.

Woodburn, M. I. A. (2001). Comparative breeding success of wild and reared pheasants (Phasianus colchicus) in southern England. Game \& Wildlife Science, 18(3-4), 319-329. 
Yoder, J. M., Marschall, E. A., \& Swanson, D. A. (2004). The cost of dispersal: predation as a function of movement and site familiarity in ruffed grouse. Behavioral Ecology, 15(3), 469-476.

Zedrosser, A., Støen, O. G., Sæbø, S., \& Swenson, J. E. (2007). Should I stay or should I go? Natal dispersal in the brown bear. Animal Behaviour, 74(3), 369376. 


\section{Appendices}

Appendix 1. Information on juvenile kakariki tracked in 2016.

\begin{tabular}{|c|c|c|c|c|c|c|}
\hline Bird & Sex & $\begin{array}{r}\text { Mass } \\
\text { (g) }\end{array}$ & $\begin{array}{r}\text { Tarsus } \\
\text { length } \\
(\mathrm{mm})\end{array}$ & $\begin{array}{r}\text { Hatch } \\
\text { Date }\end{array}$ & $\begin{array}{r}\text { Activity } \\
\text { Area (ha) }\end{array}$ & $\begin{array}{r}\text { Distance } \\
\text { dispersed } \\
(\mathrm{km})\end{array}$ \\
\hline dGB-R & Male & 58 & 21 & $2-F e b-16$ & 119.10 & 2.86 \\
\hline dGpP-R & Male & 75 & 21.8 & 7-Feb-16 & - & 0.83 \\
\hline dGR-R & Male & 84 & 21.1 & 2-Feb-16 & 255.31 & 0.80 \\
\hline dGW-R & Female & 62 & 18.2 & 2-Feb-16 & 7.96 & 0.24 \\
\hline OpP-R & Male & 64 & 21.2 & 28-Dec-15 & 54.87 & 1.28 \\
\hline pBB-R & Male & 78 & 22.2 & 2-Dec-15 & 499.53 & 3.38 \\
\hline pBdG-R & Female & 52 & 19.4 & 2-Dec-15 & 40.91 & 0.79 \\
\hline pBG-R & Male & 72 & 19.7 & 28-Nov-15 & 119.43 & 0.49 \\
\hline pBLG-R & Male & 60 & 19 & 1-Dec-15 & - & 3.96 \\
\hline R-BB & Male & 75 & 22.2 & $11-F e b-16$ & 11.13 & 1.74 \\
\hline $\mathrm{R}-\mathrm{BdG}$ & Female & 63 & 18.2 & 17-Mar-16 & 7.71 & 0.76 \\
\hline R-BpB & Male & 82 & 23.1 & 16-Feb-16 & 53.54 & 0.78 \\
\hline R-OdG & Male & 66 & 20.8 & 21-Mar-16 & - & 0.94 \\
\hline R-pBLG & Female & 49 & 18.8 & 26-Feb-16 & 28.94 & 1.33 \\
\hline R-pBpB & Male & 84 & 21 & 24-Feb-16 & 26.39 & 0.31 \\
\hline R-pBR & Male & 82 & 19.8 & 24-Feb-16 & 3.13 & 0.26 \\
\hline R-pBY & Female & 60 & 19.9 & 24-Feb-16 & 38.76 & 0.28 \\
\hline WG-R & Female & 53 & 19.1 & 20-Dec-15 & 9.10 & 0.86 \\
\hline WpB-R & Male & 87 & 22.9 & 19-Dec-15 & 46.30 & 0.16 \\
\hline YB-R & Male & 70 & 20.5 & 16-Dec-15 & 398.60 & 0.99 \\
\hline YpP-R & Female & 58 & 18 & 24-Dec-15 & 17.34 & 0.18 \\
\hline OO-R & Male? & 64 & 19.4 & 6-Jan-16 & 415.47 & 3.26 \\
\hline
\end{tabular}


Appendix 2. Full model selection table for LMMs on factor influencing distance dispersed on all birds. $\mathrm{K}=$ the number of estimated parameters in the model, $\mathrm{AICc}=$ second-order Akaike information criterion, $\triangle \mathrm{AIC}=[\mathrm{AICC}-\min (\mathrm{AICC})], \mathrm{AICcWt}=$ weight of the model.

\begin{tabular}{lrrrr}
\hline Model & \multicolumn{1}{c}{ K } & \multicolumn{1}{c}{ AICc } & \multicolumn{1}{c}{$\boldsymbol{\Delta \text { AICc }}$} & AICcWt \\
\hline Sex*Body condition+Proportion opposite sex & 8 & 44 & 0 & 0.97 \\
Sex*Body condition+Proportion opposite & & & & \\
sex+Hatch date & 9 & 51.32 & 7.32 & 0.02 \\
Sex*Body condition+Proportion opposite & & & & \\
sex+Male parent age & 10 & 54.01 & 10.01 & 0.01 \\
Proportion opposite sex & 5 & 62.64 & 18.65 & 0 \\
Sex+Proportion opposite sex & 6 & 63.62 & 19.62 & 0 \\
Body condition+Proportion opposite sex & 6 & 63.64 & 19.64 & 0 \\
Sex*Body condition & 8 & 64.59 & 20.60 & 0 \\
Proportion opposite sex+Number of nestlings & 6 & 65.82 & 21.83 & 0 \\
Male parent age & 6 & 66.29 & 22.29 & 0 \\
Proportion opposite sex+Male parent age & 7 & 66.78 & 22.79 & 0 \\
Body condition & 5 & 66.95 & 22.96 & 0 \\
Proportion opposite sex+Hatch date & 6 & 67.01 & 23.01 & 0 \\
Sex*Nestling weight+Proportion opposite sex & 8 & 67.24 & 23.24 & 0 \\
Null & 4 & 67.30 & 23.30 & 0 \\
Sex & 6 & 68.29 & 24.29 & 0 \\
Sex*Proportion opposite sex & 7 & 68.76 & 24.76 & 0 \\
Proportion opposite sex+Female parent age & 7 & 69.01 & 25.02 & 0 \\
Sex*Male parent age & 8 & 69.32 & 25.33 & 0 \\
Female parent age & 6 & 69.90 & 25.90 & 0 \\
Sex*Nestling weight & 8 & 70.43 & 26.43 & 0 \\
Hatch date & 5 & 70.67 & 26.67 & 0 \\
Number of siblings & 5 & 70.69 & 26.69 & 0 \\
Sex*Number of siblings & 8 & 76.40 & 32.4 & 0 \\
Sex*Hatch date & 8 & 77.10 & 33.10 & 0 \\
Sex*Female parent age & 10 & 83.05 & 39.06 & 0 \\
\hline & & & & \\
\hline
\end{tabular}


Appendix 3. Recorded deaths of banded kakariki in Wellington.

\begin{tabular}{|c|c|c|c|c|c|}
\hline Sex & $\begin{array}{c}\text { Juvenile/ } \\
\text { Adult }\end{array}$ & Origin & Date of Death & $\begin{array}{l}\text { Likely Cause } \\
\text { of Death (if } \\
\text { known) }\end{array}$ & $\begin{array}{c}\text { Location of } \\
\text { death } \\
\text { (inside/outside } \\
\text { sanctuary) } \\
\end{array}$ \\
\hline $\mathrm{M}$ & Adult & Kapiti & July 2010 & Cat kill & Outside \\
\hline $\mathrm{F}$ & Adult & Kapiti & Sept 2010 & & Outside \\
\hline M & Adult & Kapiti & Oct 2010 & Car-run over & Outside \\
\hline M & Adult & Kapiti & Oct 2010 & Window & Outside \\
\hline $\mathrm{F}$ & Adult & Kapiti & Sept 2011 & $\begin{array}{l}\text { Mustelid kill } \\
\text { Crop } \\
\text { impaction- }\end{array}$ & Outside \\
\hline M & Juvenile & ZEALANDIA & June 2012 & overeating & Inside \\
\hline M & Adult & ZEALANDIA & Oct 2012 & Window & Outside \\
\hline $\mathrm{F}$ & Adult & ZEALANDIA & Feb 2013 & & Inside \\
\hline M & Juvenile & ZEALANDIA & Dec 2013 & & Outside \\
\hline M & Juvenile & ZEALANDIA & Feb 2014 & $\begin{array}{l}\text { Cat kill } \\
\text { Unknown }\end{array}$ & Outside \\
\hline$?$ & Juvenile & ZEALANDIA & March 2014 & predator kill & Outside \\
\hline M & Juvenile & ZEALANDIA & Sept 2014 & & Outside \\
\hline $\mathrm{F}$ & Juvenile & ZEALANDIA & Nov 2014 & & Inside \\
\hline$?$ & Juvenile & ZEALANDIA & Nov 2014 & & Outside \\
\hline M & Juvenile & ZEALANDIA & Jan 2015 & & Outside \\
\hline $\mathrm{M}$ & Adult & ZEALANDIA & Feb 2015 & & Outside \\
\hline $\mathrm{M}$ & Juvenile & ZEALANDIA & Feb 2015 & & Outside \\
\hline M & Juvenile & ZEALANDIA & Feb 2015 & & Inside \\
\hline M & Juvenile & ZEALANDIA & April 2015 & $\begin{array}{l}\text { Unknown } \\
\text { predator kill }\end{array}$ & Outside \\
\hline $\mathrm{M}$ & Juvenile & ZEALANDIA & April 2015 & Cat kill & Outside \\
\hline $\mathrm{F}$ & Adult & ZEALANDIA & Aug 2015 & & Outside \\
\hline $\mathrm{M}$ & Juvenile & ZEALANDIA & Jan 2016 & Cat kill & Outside \\
\hline $\mathrm{M} ?$ & Juvenile & ZEALANDIA & March 2016 & & Inside \\
\hline $\mathrm{F}$ & Juvenile & ZEALANDIA & April 2016 & Window & Outside \\
\hline $\mathrm{M}$ & Juvenile & ZEALANDIA & April 2016 & & Outside \\
\hline $\mathrm{M} ?$ & Juvenile & ZEALANDIA & April 2016 & Car-run over & Outside \\
\hline $\mathrm{M}$ & Juvenile & ZEALANDIA & May 2016 & $\begin{array}{l}\text { Cat kill } \\
\text { Avian }\end{array}$ & Outside \\
\hline $\mathrm{M} ?$ & Juvenile & ZEALANDIA & May 2016 & predator kill & Outside \\
\hline $\mathrm{M}$ & Juvenile & ZEALANDIA & June 2016 & Rat kill? & Outside \\
\hline
\end{tabular}


Appendix 4. List of plants kakariki were observed feeding on in Wellington. Particularly favored plants are noted with an asterisk.

\begin{tabular}{lll}
\hline Latin Name & Common Name & Part of Plant \\
\hline $\begin{array}{l}\text { Podocarpus totara } \\
\text { Pseudopanax arboreus }\end{array}$ & Totara* & Five-Finger* \\
$\begin{array}{l}\text { Myrsine australis } \\
\text { Muehlenbeckia }\end{array}$ & $\begin{array}{l}\text { Mapou* } \\
\text { Pohuehue/Large-leaved } \\
\text { australis }\end{array}$ & Muehlenbeckia* \\
$\begin{array}{l}\text { Dacrycarpus } \\
\text { dacrydioides }\end{array}$ & Kahikatea & Fruit \\
$\begin{array}{l}\text { Coprosma robusta } \\
\text { Pittosporum }\end{array}$ & Karamu & Flowers/Seeds \\
eugenioides & Lemonwood & Fruit \\
Vitex lucens & Puriri & Fruit \\
Rhododendron spp. & Rhododendron & Fruit \\
\hline
\end{tabular}

